UNIVERSIDADE DE SÃO PAULO

INSTITUTO DE GEOCIÊNCIAS

\title{
AVALIAÇÃO DA EFICIÊNCIA DE BARREIRA REATIVA COM FERRO ZERO-VALENTE NA REMEDIAÇÃO DE ÁGUA SUBTERRÂNEA CONTAMINADA POR COMPOSTOS ORGÂNICOS CLORADOS
}

FLÁVIO AUGUSTO FERLINI SALLES

Orientador: Prof. Dr. Uriel Duarte

TESE DE DOUTORAMENTO

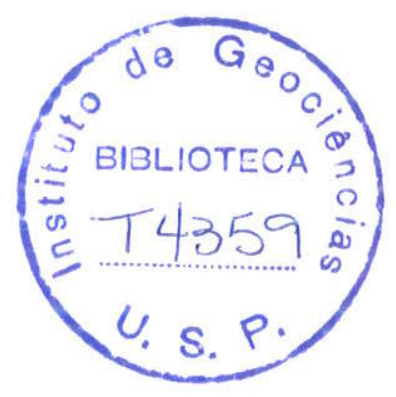

COMISSÃO JULGADORA

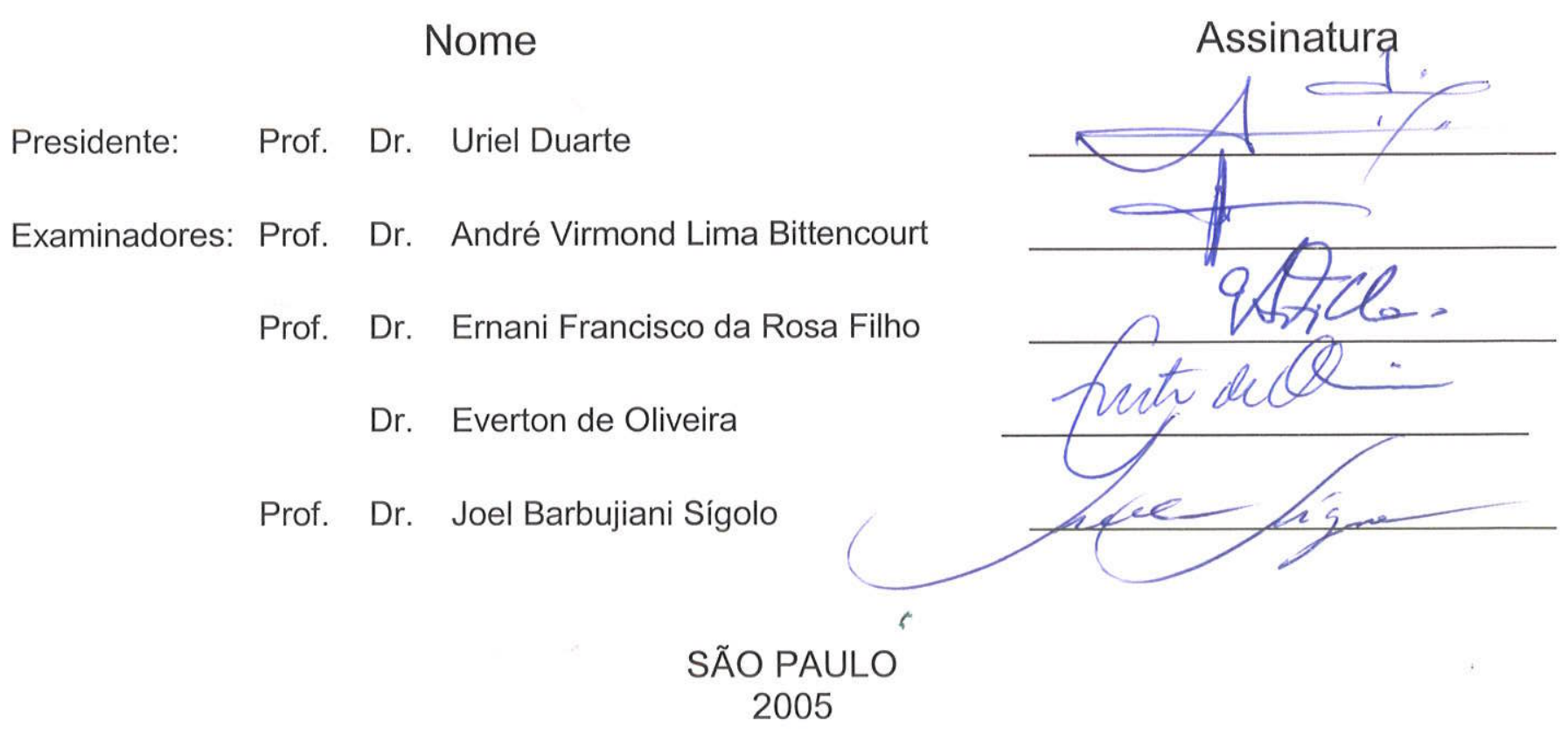




\section{UNIVERSIDADE DE SÃO PAULO \\ INSTITUTO DE GEOCIÊNCIAS}

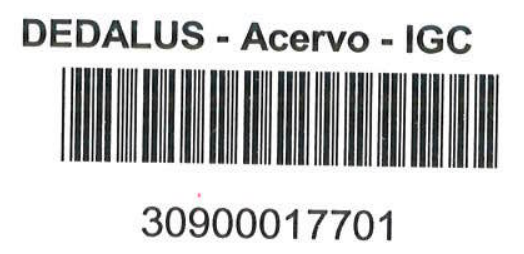

AVALIAÇÃO DA EFICIÊNCIA DE BARREIRA REATIVA COM FERRO ZERO-VALENTE NA REMEDIAÇÃO DE ÁGUA SUBTERRÂNEA CONTAMINADA POR COMPOSTOS ORGÂNICOS CLORADOS

Flávio Augusto Ferlini Salles

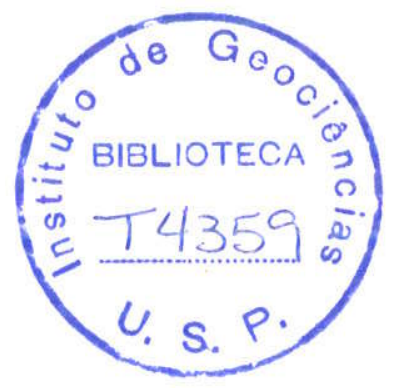

Orientador: Prof.Dr. Uriel Duarte

TESE DE DOUTORAMENTO

Programa de Pós-Graduação em Recursos Minerais e Hidrogeologia

SÃO PAULO

2005 
"Não há meio-termo possível.

E preciso que tudo isso seja belo."

Vinicius de Moraes 


\section{Indice}

1 Resumo 1

2 Abstract 2

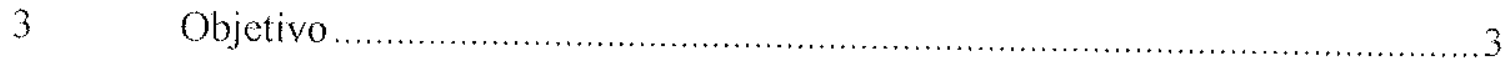

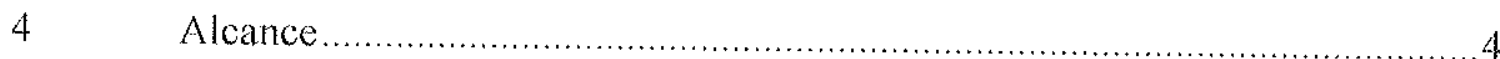

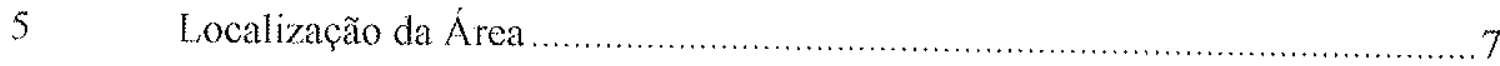

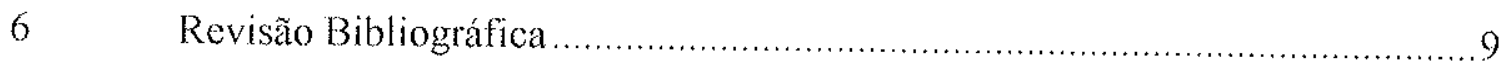

6.1 Degradação de Solventes Clorados ......................................................

6.2 Aplicação de ferro para degradação de solventes clorados ...................... 12

7 Implantação do Sistema de Remediação In Situ ....................................... 17

7.1 Aspectos Geológicos da Área Estudada ............................................ 17

7.2 Definição do Local de Instalação do Sistema de Remediação In Situ .........21

7.2.1 Dimensionamento da Zona Reativa .........................................23

7.2.2 Definição do Material Reativo .............................................24

7.3 Instalação da Barreira Reativa......................................................27

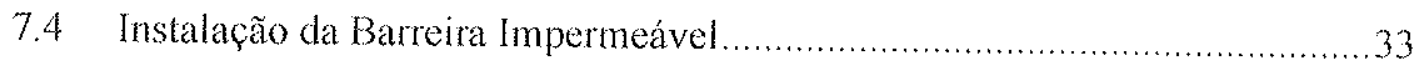

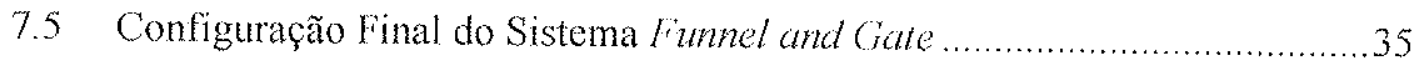

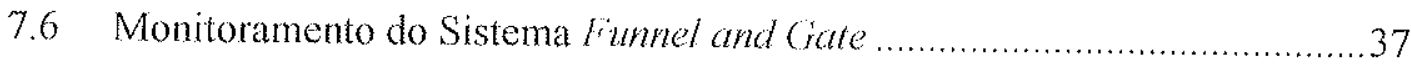

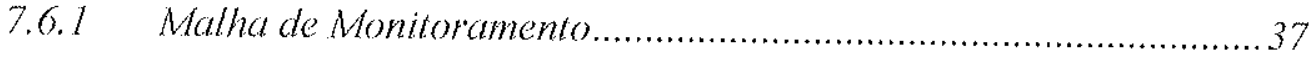

7.6.2 Parametros de Monitoramento ................................................40

8 Resultados Obtidos e Discussão ...................................................... 42

8.1 Monitoramento das Concentrações de Etenos ...................................42

8.2 Monitoramento das concentrações de Etanos ............................................56

8.3 Monitoramento da Seqüência de Degradação do Tetracloreto de Carbono..70

8.4 Monitoramento de Parâmetros Inorgânicos ..........................................83

9 Eficiência do Sistema de Remediação na Remoção de Contaminantes .........89

10 Conclusões Sobre o Sistema de Remediação In Situ ................................. 92

11 Recomendações Sobre o Sistema de Remediação In Situ ...........................95

12 Referências Bibliográficas ..........................................................97 


\section{Índice de Tabelas}

Tabela 1. Relação das áreas contaminadas no Estado de São Paulo (modificada de CETESB, 2005)

Tabela 2. Tempo, em minutos, para redução da concentração em 50 \%. Modificado de Gillham \& O’Hannesin (1992)

Tabela 3. Especificações Granulométricas da Granalha Angular 26

Tabela 4. Relação entre Tipo de Solo e Índice de Resistência à Penetração (IRP) ........34

Tabela 5. Relação dos compostos orgânicos voláteis (VOC) selecionados para avaliação do sistema de remediação

Tabela 6. Resultados analíticos da sequência dos Etenos Concentrações em $\mu \mathrm{g} / \mathrm{L}$ PM SR01 M; PM SR01 B; PM SR02 J

Tabela 7. Resultados analíticos da sequência dos Etenos Concentrações em $\mu \mathrm{g} / \mathrm{L}$

PM SR01 M; PM SR01 B; PM SR02 J

Tabela 8. Resultados analíticos da sequência dos Etenos Concentrações em $\mu \mathrm{g} / \mathbf{L}$ PM SR01 M; PM SR01 B; PM SR02 J

Tabela 9. Resultados analíticos da sequência dos Etenos Concentrações em $\mu \mathrm{g} / \mathrm{L}$ PM SR01 M; PM SR01 B; PM SR02 J

Tabela 10.Resultados analíticos da sequência dos Etenos Concentrações em $\mu \mathrm{g} / \mathrm{L}$ PM SR01 M; PM SR01 B; PM SR02 J

Tabela 11.Resultados analíticos da sequência dos Etenos Concentrações em $\mu \mathrm{g} / \mathrm{L}$ PM SR01 M; PM SR01 B; PM SR02 J

Tabela 12.Resultados analíticos da sequência dos Etenos Concentrações em $\mu \mathrm{g} / \mathrm{L}$ PM SR01 M; PM SR01 B; PM SR02 J.

Tabela 13.Resultados analíticos da sequência dos Etenos Concentrações em $\mu \mathrm{g} / \mathrm{L}$ PM SR01 M; PM SR01 B; PM SR02 J

Tabela 14.Resultados analíticos da sequência dos Etenos Concentrações em $\boldsymbol{\mu g} / \mathbf{L}$ PM SR01 M; PM SR01 B; PM SR02 J

Tabela 15.Resultados analíticos da sequência dos Etenos Concentrações em $\mu \mathrm{g} / \mathrm{L}$ PM SR01 M; PM SR01 B; PM SR02 J 
Tabela 16. Resultados analíticos da sequência dos Etenos Concentrações em $\mu \mathrm{g} / \mathrm{L}$ PM SR01 M; PM SR01 B; PM SR02 J

Tabela 17.Resultados analíticos da sequência dos Etenos Concentrações em $\mu \mathrm{g} / \mathrm{L}$ PM SR01 M; PM SR01 B; PM SR02 J .54

Tabela 18.Resultados analíticos da sequência dos Etanos Concentrações em $\mu \mathrm{g} / \mathrm{L}$ PM SR01 M; PM SR01 B; PM SR02 J 57

Tabela 19.Resultados analíticos da sequência dos Etanos Concentrações em $\mu \mathrm{g} / \mathrm{L}$ PM SR01 M; PM SR01 B; PM SR02 J 58

Tabela 20.Resultados analíticos da sequência dos Etanos Concentrações em $\boldsymbol{\mu g} / \mathbf{L}$ PM SR01 M; PM SR01 B; PM SR02 J

Tabela 21.Resultados analíticos da sequência dos Etanos Concentrações em $\mu \mathrm{g} / \mathrm{L}$ PM SR01 M; PM SR01 B; PM SR02 J

Tabela 22. Resultados analíticos da sequência dos Etanos Concentrações em $\boldsymbol{\mu g} / \mathbf{L}$ PM SR01 M; PM SR01 B; PM SR02 J

Tabela 23. Resultados analíticos da sequência dos Etanos Concentrações em $\boldsymbol{\mu g} / \mathbf{L}$ PM SR01 M; PM SR01 B; PM SR02 J

Tabela 24. Resultados analíticos da sequência dos Etanos Concentrações em $\mu \mathrm{g} / \mathrm{L}$ PM SR01 M; PM SR01 B; PM SR02 J

Tabela 25.Resultados analíticos da sequência dos Etanos Concentrações em $\boldsymbol{\mu g} / \mathbf{L}$ PM SR01 M; PM SR01 B; PM SR02 J

Tabela 26.Resultados analíticos da sequência dos Etanos Concentrações em $\boldsymbol{\mu g} / \mathbf{L}$ PM SR01 M; PM SR01 B; PM SR02 J

Tabela 27.Resultados analíticos da sequência dos Etanos Concentrações em $\boldsymbol{\mu g} / \mathbf{L}$ PM SR01 M; PM SR01 B; PM SR02 J.

Tabela 28. Resultados analíticos da sequência dos Etanos Concentrações em $\mu \mathrm{g} / \mathrm{L}$

PM SR01 M; PM SR01 B; PM SR02 J

Tabela 29.Resultados analíticos da sequência dos Etanos Concentrações em $\boldsymbol{\mu g} / \mathbf{L}$

PM SR01 M; PM SR01 B; PM SR02 J 
Tabela 30.Resultados analíticos da sequência de Degradação do Tetracloreto de Carbono Concentrações em g/L PM SR01 M; PM SR01 B; PM SR02 J.....71

Tabela 31.Resultados analíticos da sequência de Degradação do Tetracloreto de Carbono Concentrações em $\mu \mathrm{g} / \mathrm{L}$ PM SR01 M; PM SR01 B; PM SR02 J..... 72

Tabela 32.Resultados analíticos da sequência de Degradação do Tetracloreto de Carbono Concentrações em $\mu$ g/L PM SR01 M; PM SR01 B; PM SR02 J..... 73

Tabela 33.Resultados analíticos da sequência de Degradação do Tetracloreto de Carbono Concentrações em $\mu$ g/L PM SR01 M; PM SR01 B; PM SR02 J.....74

Tabela 34.Resultados analíticos da sequência de Degradação do Tetracloreto de Carbono Concentrações em $\boldsymbol{\mu g}$ /L PM SR01 M; PM SR01 B; PM SR02 J.....75

Tabela 35.Resultados analíticos da sequência de Degradação do Tetracloreto de Carbono Concentrações em $\mu \mathrm{g} / \mathrm{L}$ PM SR01 M; PM SR01 B; PM SR02 J.....76

Tabela 36.Resultados analíticos da sequência de Degradação do Tetracloreto de Carbono Concentrações em g/L PM SR01 M; PM SR01 B; PM SR02 J..... 77

Tabela 37.Resultados analíticos da sequência de Degradação do Tetracloreto de Carbono Concentrações em $\mu \mathrm{g} / \mathrm{L}$ PM SR01 M; PM SR01 B; PM SR02 J.....78

Tabela 38. Resultados analíticos da sequência de Degradação do Tetracloreto de Carbono Concentrações em $\boldsymbol{\mu g} / \mathbf{L}$ PM SR01 M; PM SR01 B; PM SR02 J.....79

Tabela 39. Resultados analíticos da sequência de Degradação do Tetracloreto de Carbono Concentrações em $\boldsymbol{\mu g} / \mathrm{L}$ PM SR01 M; PM SR01 B; PM SR02 J.....80

Tabela 40.Resultados analíticos da sequência de Degradação do Tetracloreto de Carbono Concentrações em $\mu \mathrm{g} / \mathrm{L}$ PM SR01 M; PM SR01 B; PM SR02 J.....81

Tabela 41.Resultados analíticos da sequência de Degradação do Tetracloreto de Carbono Concentrações em $\mu$ g/L PM SR01 M; PM SR01 B; PM SR02 J.....8 82

Tabela 42. Sequência de resultados analíticos para parâmetros inorgânicos .84

Tabela 43. Concentrações totais de organoclorados nos poços monitorados. 89 


\section{Índice de Figuras}

Figura 1. Ocorrências de contaminantes na relação de áreas contaminadas da CETESB (2005)

Figura 2. Técnicas de remediação aplicadas no Estado de São Paulo. Modificado de CETESB (2005) 5

Figura 3. Localização da área estudada 8

Figura 4. Energia necessária para dehalogeneização na seqüência Hexacloroetano -..Etano. Modificado de Pankow \& Cherry (1996)

Figura 5. Energia necessária para dehalogeneização na seqüência Tetracloreto de Carbono - Metano. Modificado de Pankow \& Cherry (1996)....

Figura 6. Energia necessária para dehalogeneização na seqüência

Tetracloroeteno - Eteno. Modificado de Pankow \& Cherry (1996)

Figura 7. Energia Livre para dehalogeneização seqü̉encial. Modificado de Pankow \& Cherry (1996)

Figura 8. Degradação de organoclorado $(\mathrm{RCl})$ pela transferência direta de elétrons do ferro zero-valente $\left(\mathrm{Fe}^{0}\right)$. Modificado de Pereira e Freire (2005).

Figura 9. Dehalogeneização de organoclorado ( $\mathrm{RCl}$ ) na presença de ferro bivalente $\left(\mathrm{Fe}^{2+}\right)$. Modificado de Pereira e Freire (2005).

Figura 10.Dehalogeneização de organoclorado (RCl) na presença de hidrogênio $\left(\mathrm{H}_{2}\right) .15$

Figura 11.Reação de dehalogeneização de pentacloroetano para tetracloroeteno na presença de esmectita. (Modificada de Stucki et al., 2002)

Figura 12.Mapa geológico da região estudada (modificado de Vieira el al., 1990).

Destaque em laranja da geologia da área estudada. 18

Figura 13. Bloco de rocha encontrado a jusante da industria, na trincheira escavada para instalação das barreiras reativas

Figura 14. Detalhe de amostra coletada na área de instalação das barreiras 19

Figura 15.Localização dos poços de monitoramento multiníveis na área de estudo......21 
Figura 16.Pluma principal de contaminação por solventes clorados na direção preferencial de fluxo norte-sul

Figura 17.Distribuição aproximada do sistema instalado 23

Figura 18.Escavadeira utilizada na instalação do sistema de remediação. 27

Figura 19.Escavação para Barreira Reativa 28

Figura 20.Posicionamento vertical da placa leste após cravação 29

Figura 21. Detalhe da placa da barreira impermeável oeste, cravada sob a superfície do solo 29

Figura 22. Inserção de placa em madeira para redução da largura da Barreira Reativa ..30

Figura 23. Matriz reativa de areia e granalha..................................................... 30

Figura 24.Preenchimento da trincheira por mistura reativa ................................. 31

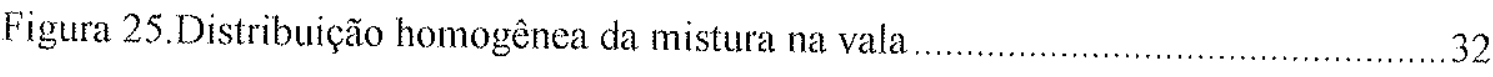

Figura 26.Localização em planta da Barreira Reativa e da seção estratigráfica A-B....35

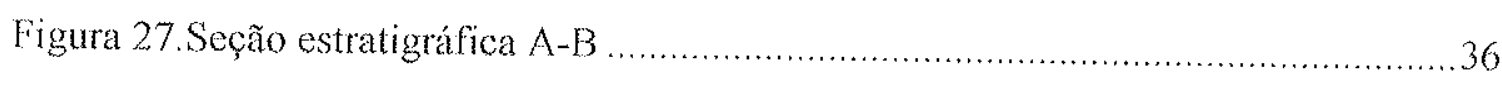

Figura 28. Seção local com os poços de monitoramento do sistema de remediação ........39 


\section{Agradecimentos}

À minha Mãe.

Ao meu Pai.

À minha Vó Lola, símbolo de força.

Aos senhores Alexandre Olio, Valdir Olio e Djalma Olio (in memorian), pela confiança depositada e pelo apoio ao longo de todo o projeto;

Ao Professor Dr. Uriel Duarte pelo apoio em todas as horas.

À Hidroplan, ao Everton de Oliveira e ao Celso Kolesnikovas que possibilitaram a realização do trabalho.

Aos meus amigos.

À Bella, à Capitu e ao Kiko, donos da casa.

À toda a minha família, sempre querida.

À Regiane, companheira, mãe, mulher.

$A o(A ̀)$ filho(a) que nós queremos ter. 


\section{RESUMO}

Foi instalada uma barreira reativa (sistema funnel and gate) com a finalidade de pesquisar a degradação abiótica de solventes clorados presentes em água subterrânea a jusante de indústria química localizada no município de São Paulo.

O sistema instalado em escala piloto foi monitorado ao longo de 29 meses para acompanhamento das concentrações dos contaminantes de interesse (organoclorados) identificados anterior e posteriormente à passagem pelo sistema de remediação.

Os resultados dos últimos 12 eventos de monitoramento comprovaram a eficiência esperada do sistema para degradação dos solventes clorados com dupla ligação (etenos) e ainda apresentaram resultados positivos na degradação de etanos.

As concentrações medidas em três poços de monitoramento, instalados a montante, jusante e dentro da barreira reativa forneceram evidências do processo de degradação a partir das quais puderam ser observadas a total dehalogeneização dos etenos.

A barreira reativa instalada com profundidade de $5,15 \mathrm{~m}$, comprimento de $3,00 \mathrm{~m}$ e largura de 1,20 $\mathrm{m}$ foi preenchida por mistura de granalha de aço e areia na proporção em massa de $81,93 \%$ de areia para $18,07 \%$ de granalha, quantidade de ferro pouco superior ao valor sugerido na literatura e que culminou na eficiência esperada do sistema mesmo após 2 anos e 5 meses de funcionamento contínuo sem alterações estruturais. 
A permeable reactive barrier (funnel and gate system) was installed to evaluate abiotic degradation of chlorinated solvents in groundwater downgrandient of a chemical industry on São Paulo.

The remediation system was installed on a pilot scale and was monitored during 29 months to measure the concentrations of chlorinated solvents in groundwater before and after the reactive barrier.

The results of the latest 12 monitoring events confirmed the system's efficiency for ethene's degradation and showed an unexpected but positive result for ethane's degradation.

The concentrations were measured on three monitoring wells installed upgradient, inside and downgradient the reactive barrier and showed evidences of dehalogenation processes of ethenes.

The reactive barrier has 5,15 $\mathrm{m}$ depth, 3,00 $\mathrm{m}$ long and 1,20 $\mathrm{m}$ large, was filled by a mixture of steel grains and sand at proportion of $81,93 \%$ weight of sand and $18,07 \%$ weight of steel, a little more than steel (iron) suggested on the bibliography.

Two years and 5 months after the system installation, without any structural changes, the efficiency on the chlorinated degradation processes was maintained. 
Este trabalho tem como objetivo avaliar os resultados de caso prático de aplicação de barreira reativa para remediação de solventes clorados através da utilização de ferro zero-valente, subsidiar futuras remediações através do sistema de barreiras permeáveis e impermeáveis (funnel and gate) e fomentar discussões e pesquisas sobre as formas de sua utilização e melhorias técnicas.

Foram avaliadas publicações nacionais que tratam do assunto, no entanto, não foi identificada a implantação de Barreira Reativa no Brasil, mesmo que em escala piloto, para a finalidade aqui apresentada.

O estudo de caso brasileiro visa ainda identificar fatores de influência no processo de remediação gerados pelas condições naturais aqui encontradas, como a situações geológicas e hidrogeológicas. 
A Companhia de Tecnologia de Saneamento Ambiental (CETESB) divulgou em maio de 2005 uma lista de áreas contaminadas catalogadas no Estado de São Paulo (Tabela 1).

Tabela 1. Relação das áreas contaminadas no Estado de São Paulo (modificada de CETESB, 2005)

\begin{tabular}{|c|c|c|c|c|c|c|}
\hline Região/Atividade & Comercial & Industrial & Residuos & $\begin{array}{c}\text { Postos de } \\
\text { Combustiveis }\end{array}$ & $\begin{array}{c}\text { Acidentes } \\
\text { desconhecidos }\end{array}$ & Total \\
\hline São Paulo & 28 & 42 & 20 & 398 & 2 & 490 \\
\hline RMSP - outros & 11 & 70 & 11 & 222 & 4 & 318 \\
\hline Interior & 44 & 84 & 21 & 332 & 9 & 490 \\
\hline Litoral & 10 & 31 & 10 & 63 & 1 \\
\hline Vale do Paraíba & 1 & 19 & 0 & 71 & 0 & 91 \\
\hline Total & 94 & 246 & 62 & 1.086 & 16 \\
\hline
\end{tabular}

Das 1.504 áreas listadas pela CETESB (Figura 1), 147 apresentam "Solventes Halogenados" ou "Solventes Aromáticos Halogenados" como contaminantes de interesse, com é o caso da indústria estudada neste trabalho). Dos 147 casos citados, 45 ocorrências relatam a presença de solventes aromáticos halogenados (categoria na qual se enquadram os contaminantes avaliados neste trabalho). 
Figura 1. Ocorrências de contaminantes na relação de áreas contaminadas da CETESB (2005)

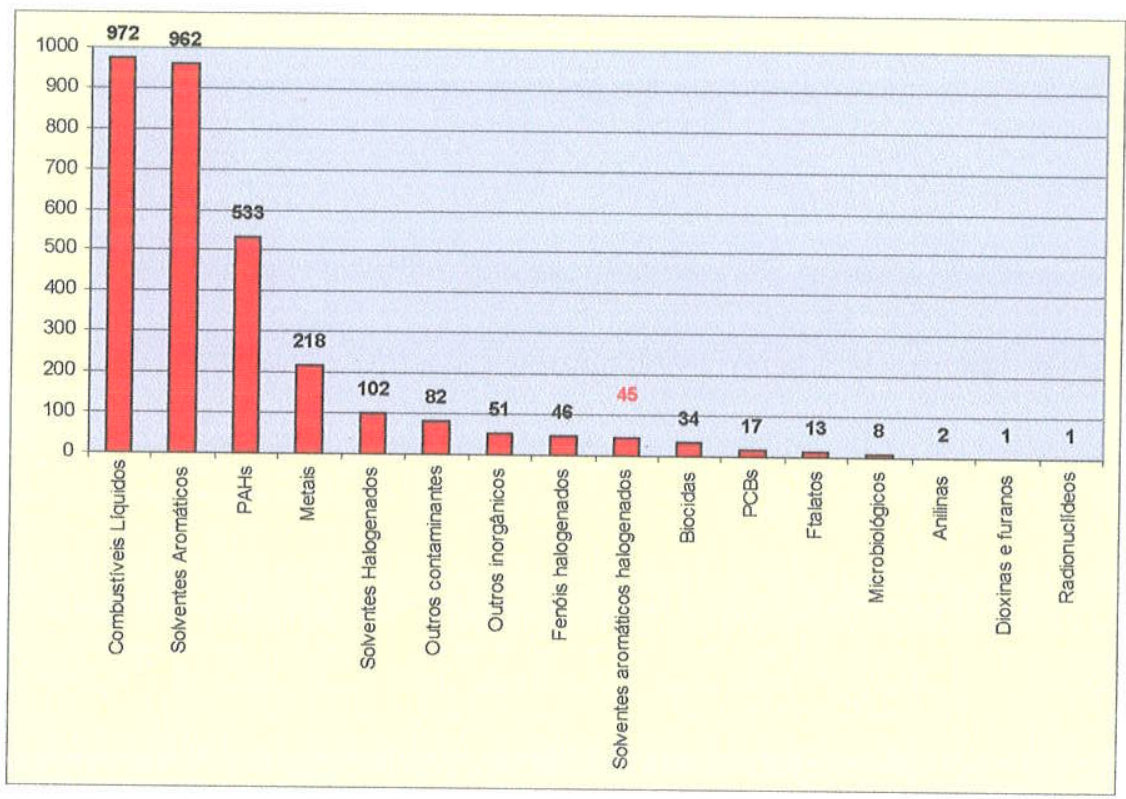

Na relação de áreas contaminadas apresentada pela CETESB (2005), em apenas 2 casos é identificada a aplicação de barreiras reativas como processo de "remediação adotado", como ilustra a Figura 2, e ainda assim apenas uma das barreiras é aplicada para áreas contaminadas por compostos clorados (objeto deste estudo).

Figura 2. Técnicas de remediação aplicadas no Estado de São Paulo. Modificado de CETESB (2005)

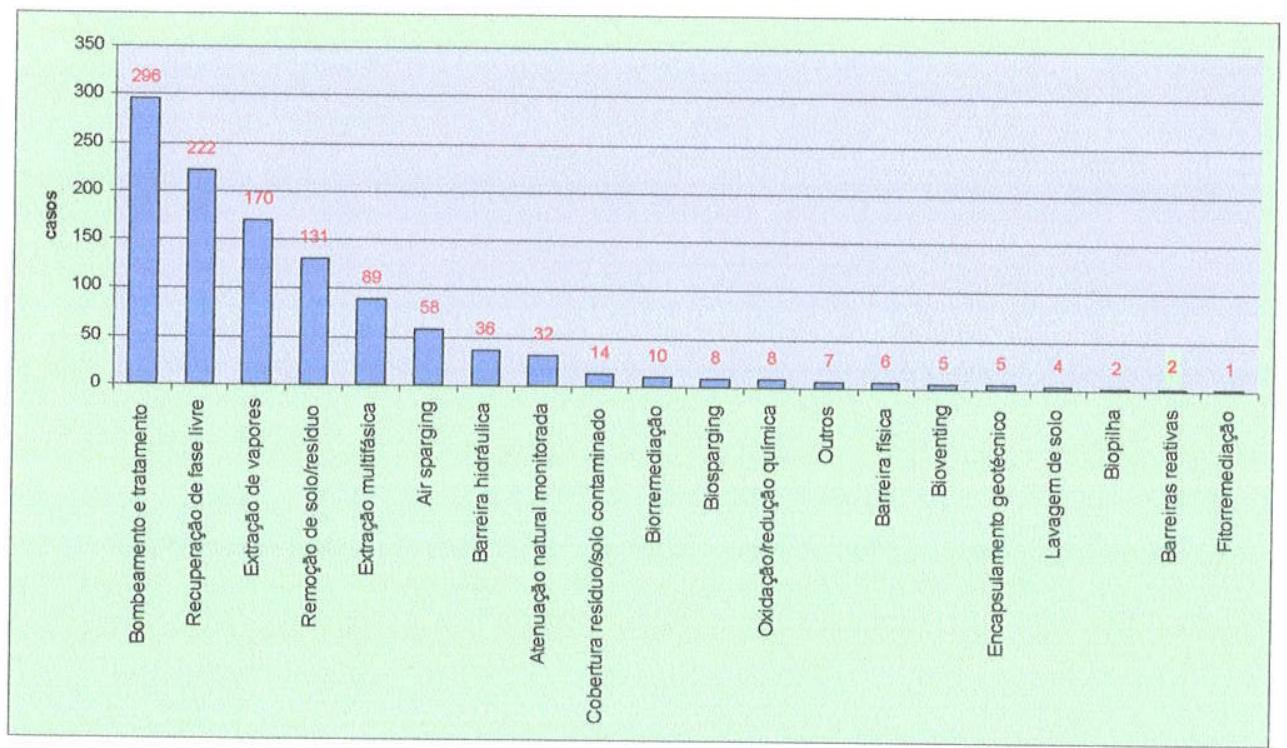


Não se pode concluir que em todas as áreas contaminadas por solventes clorados (halogenados aromáticos ou não) poderia ser aplicada a técnica de remediação por degradação abiótica ou por barreiras reativas, uma vez que a lista não apresenta informações sobre a extensão da contaminação em água subterrânea, sobre a profundidade da contaminação, sobre as condições geológicas e hidrogeológicas locais, ou seja, cada caso deve ser estudado individualmente para avaliação da viabilidade de implantação do método de remediação.

Excluindo-se do total de áreas contaminadas apresentadas na Tabela 1 os casos relacionados a contaminação por postos de combustiveis, que também podem apresentar contaminação por solventes halogenados, mas que estão relacionados, na grande maioria dos casos, a contaminações por hidrocarbonetos derivados de petróleo, o valor inicial de 1.504 áreas é reduzido a 418. Neste cenário, em que excluem-se os casos de postos de combustíveis, as áreas contaminadas por solventes aromáticos halogenados representam mais de $20 \%$ do total de áreas, nas quais é potencializada a aplicação de métodos de remediação que envolvam degradação abiótica dos contaminantes.

Salienta-se que a lista de áreas contaminadas da CETESB não é definitiva e deve ser atualizada periodicamente, o que provavelmente deve alterar a porcentagem apresentada anteriormente, mas a avaliação inicial indica que os resultados deste estudo deverão ter aplicação em inúmeras áreas contaminadas já existentes, ainda mais porque a lista da CETESB é restrita ao Estado de São Paulo e casos semelhantes estão disseminados pelo território nacional.

A indústria química estudada neste trabalho é um dos dois casos relacionados pela CETESB (2005) nos quais são aplicadas barreiras reativas como método de remediação de água subterrânea.

Em função da incipiente experiência brasileira na aplicação de ferro zero-valente para degradação de solventes clorados, espera-se que os resultados deste trabalho insiram-se como colaboração para fomentar novas pesquisas e novas tecnologias. 


\section{LOCALIZAÇÃO DA ÁREA}

A área em estudo localiza-se no bairro de Parelheiros, zona sul do município de São Paulo, e é separada da zona de inundação da Represa de Guarapiranga pela Estrada que the dá acesso, estando a cerca de $500 \mathrm{~m}$ de distância do corpo d'água superficial da Represa, com ilustra a Figura 3. 
Figura 3. Localização da área estudada
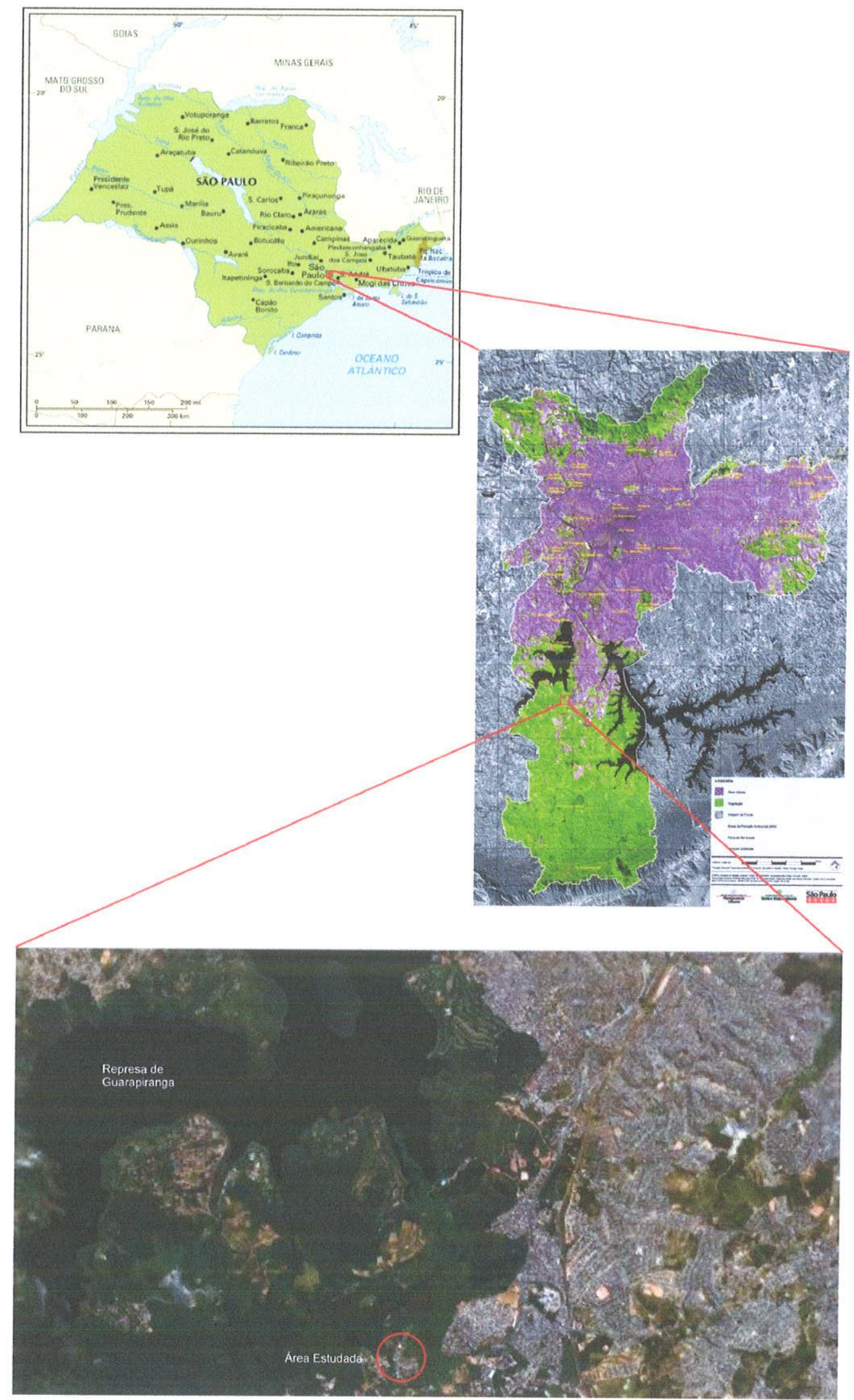


\section{REVISÃO BIBLIOGRÁFICA}

\subsection{Degradação de Solventes Clorados}

A degradação de solventes clorados é dependente da sua composição química e das condições físico-químicas do meio em que se encontram.

Os processos de degradação podem ser bióticos ou abióticos, mas mesmo neste último caso as reações podem ser catalisadas na presença de microorganismos. Em processos naturais de degradação, o decaimento de primeira ordem pode ocorrer simultaneamente em rotas bióticas e abióticas, no entanto, etenos possuem degradação biótica predominante sobre as rotas abióticas (Vogel and McCarty, 1987).

Pankow \& Cherry (1996) apresentam as reações de substituição, dehidrohalogeneização, oxidação e redução como as principais no processo de degradação dos solventes halogenados.

Com base em Vogel et.al. (1987), Pankow \& Cherry (1996) concluem que a reações de dehalogeneização por redução são favorecidas energeticamente na presença de elementos inorgânicos, tais como hidrogênio, que oxida na reação de $\mathrm{H}_{2}$ para $\mathrm{H}^{+}$, e ferro, que passa de $\mathrm{Fe}^{2+}$ para $\mathrm{Fe}(\mathrm{OH})_{3}$.

Para uma etapa simples de dehalogeneização Pankow \& Cherry (1996) calcularam a energia necessária para a transferência de um mol de elétrons, como ilustra a Figura 4.

Os gráficos das Figuras 4, 5 e 6 indicam que para dehalogeneização nas seqüências iniciadas em hexacloroetano (HCA), tetracloreto de carbono (CT) e tetracloroeteno (PCE) há, em geral, decaimento de energia, o que reflete o favorecimento termodinâmico destas reações. 
Figura 4. Energia necessária para dehalogeneização na seqüência HexacloroetanoEtano. Modificado de Pankow \& Cherry (1996)

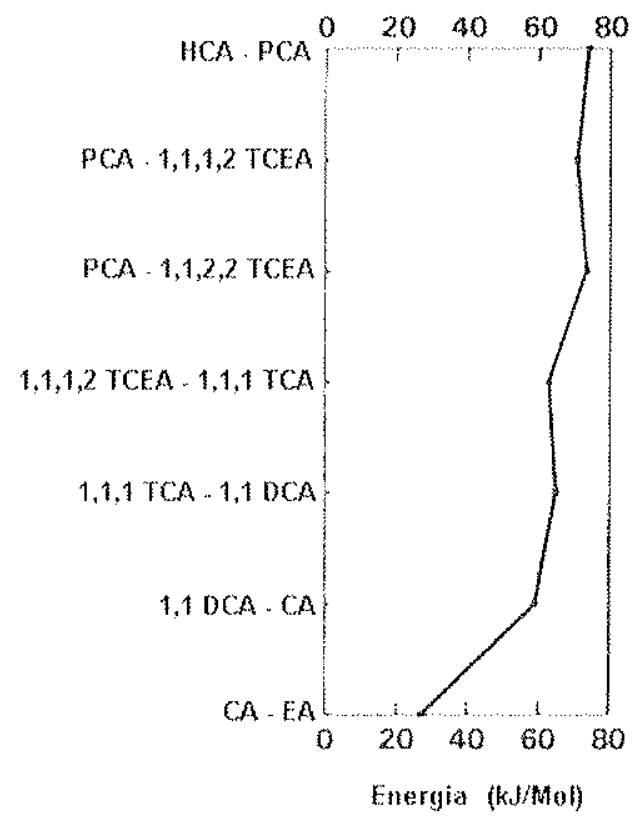

$H C A=$ hexacloroetano; $P C A=$ pentacloroetano; $1,1,1,2$ TCEA $=1,1,1,2$ tetracloroetano;

$1,1,1 \mathrm{TCA}=1,1,1$ tricloroetano; $1,1 \mathrm{DCA}=1,1$ dicloroetano; $\mathrm{CA}=$ cloroetano; $\mathrm{EA}=$ etano

Figura 5. Energia necessária para dehalogeneização na seqüência Tetracloreto de Carbono - Metano. Modificado de Pankow \& Cherry (1996)

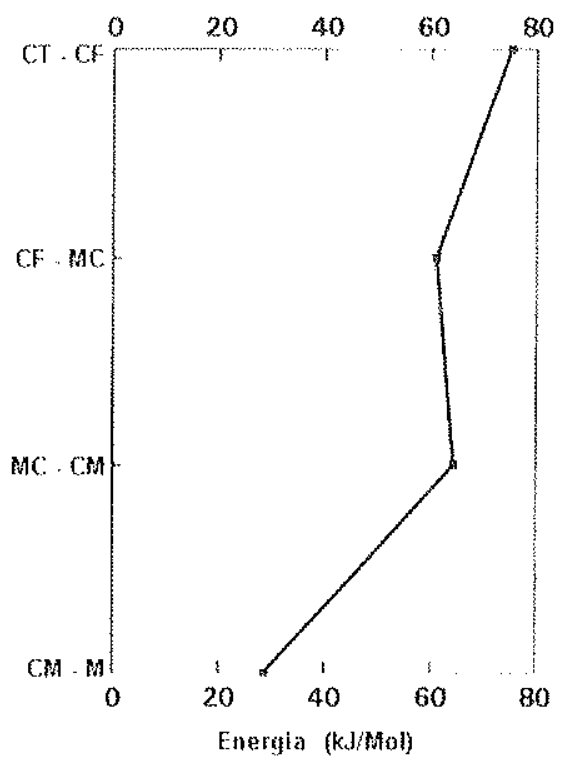

$\mathrm{CT}=$ tetracloreto de carbono; $\mathrm{CF}=$ clorofórmio; $\mathrm{MC}=$ cloreto de metileno;

$\mathrm{CM}=$ clorometano; $\mathrm{M}=$ metano; 
Figura 6. Energia necessária para dehalogeneização na seqüência Tetracloroeteno - Eteno. Modificado de Pankow \& Cherry (1996)

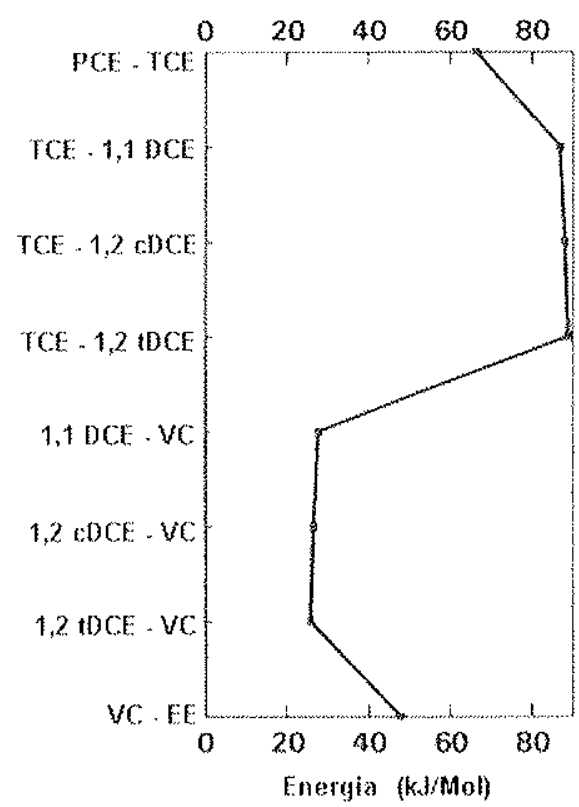

PCE = tetracloroeteno; $\mathrm{TCE}=$ tricloroeteno; $1,1 \mathrm{DCE}=1,1$ dicloroeteno; $1,2 \mathrm{CDCE}=$ cis 1,2 dicloroeteno; 1,2 tDCE $=$ trans 1,2 dicloroeteno; $V C=$ cloreto de vinila; $E E=$ eteno;

Na seqüência iniciada em tetracloroeteno (PCE), no entanto, observa-se que a dehalogeneização de 1,2 trans dicloroeteno (12tDCE) para cloreto de vinila (VC) é termodinamicamente desfavorável, pois há aumento do valor de energia livre. Por esta razão, pode-se afirmar que o 1,2 tDCE, na seqüência de degradação apresentada, é um sub-produto que deve ser mais comumente encontrado que o cloreto de vinila.

A energia livre para dehalogeneização na presença de $\mathrm{Fe}^{0}$ (oxida para $\mathrm{Fe}^{2+}$ ), $\mathrm{Mn}^{0}$ (oxida para $\mathrm{Mn}^{2+}$ ), $\mathrm{S}^{2-}$ (oxida para $\mathrm{S}^{0}$ ) e $\mathrm{CH}_{4}$ (metano, oxida para $\mathrm{HCO}_{3}$ ) foi comparada de acordo com o ilustrado na Figura 7. 
Figura 7. Energia Livre para dehalogeneização seqüencial. Modificado de Pankow \& Cherry (1996)

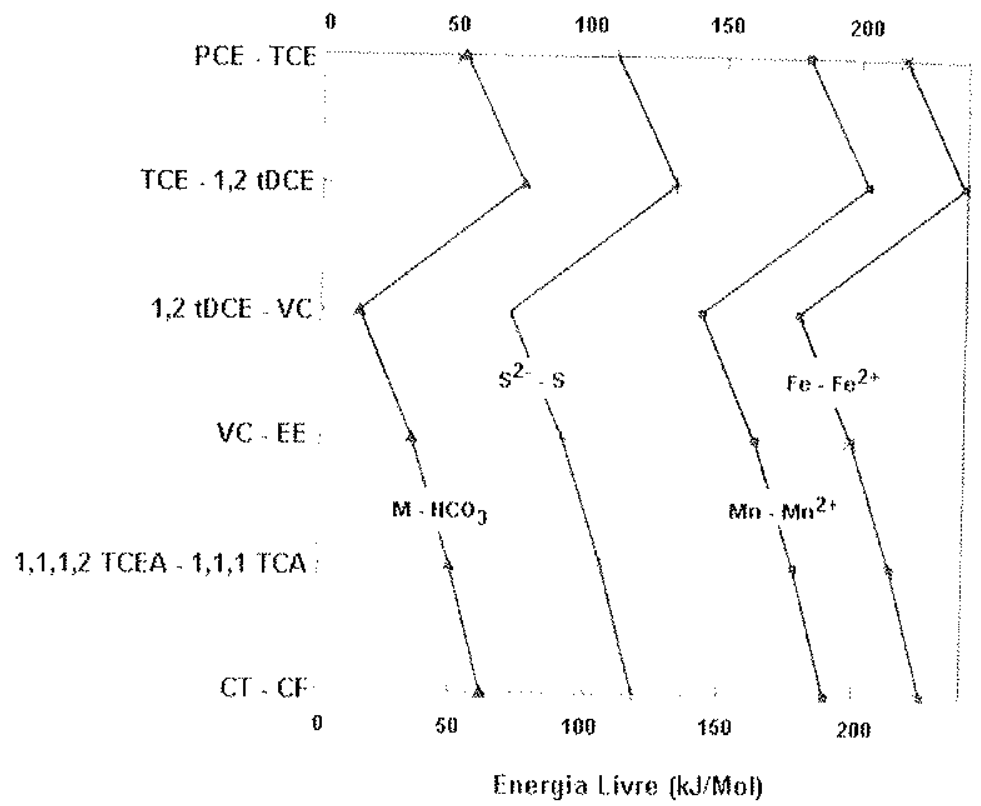

PCE = tetracloroeteno; TCE = tricloroeteno; 1,2 tDCE $=$ trans 1,2 dicloroeteno; $V C=$ cloreto de vinila; $\mathrm{EE}=$ eteno;

$1,1,1,2$ TCEA $=1,1,1,2$ tetracioroetano; $1,1,1 \mathrm{TCA}=1,1,1$ tricloroetano;

$\mathrm{CT}=$ tetracloreto de carbono; $\mathrm{CF}=$ clorofórmio;

Dentre os elementos avaliados, observamse que a oxidação de $\mathrm{Fe}^{0}$ para $\mathrm{Fe}^{2+}$ fornece o maior ganho de energia, indicando favorecimento da reação, uma das razões pela qual este metal é aplicado na degradação de solventes clorados.

6.2 Aplicação de ferro para degradação de solventes clorados

Segundo Gillham; O'Hannesin (1992) e Gusmão (1999), metais favorecem significativamente a degradação de compostos halogenados alifáticos. A razão de degradação destes compostos na presença de metais acresce em cerca de três a seis vezes a razão natural reportada por Vogel et al. (1987) em Gillham; O'Hannesin (1992).

O mecanismo de degradação aparenta ser predominantemente abiótico (ainda assim, sabe-se que a atividade microbiológica pode favorecer o processo de dehalogeneização) e exige a presença de condições altamente 
redutoras e de superfícies metálicas, as quais devem agir como doadoras de elétrons.

Barreiras sub-superficiais contendo metais em mistura com solo de granulometria adequada ao aqüifero estudado permitem o tratamento completo da pluma de contaminação através de método passivo. O desenho da barreira, em especial a sua espessura, depende da meia-vida de cada contaminante a ser tratado, da concentração inicial deste, da concentração alvo a ser alcançada após a passagem pela barreira e do fluxo da água subterrânea no local.

Para alguns dos compostos organoclorados analisados na Indústria Química alvo deste trabalho, Gillham \& O'Hannesin (1992) apresentam os tempos requeridos à redução em 50 \% na concentração após fluxo através de barreira reativa constituída por diversos reagentes metálicos (Tabela 2).

Tabela 2. Tempo, em minutos, para redução da concentração em $50 \%$. Modificado de Gillham \& O'Hannesin (1992).

\begin{tabular}{|c|c|c|c|c|c|}
\hline Metal & Clorofórmio & $\begin{array}{c}1,1,1 \\
\text { Tricloroetano }\end{array}$ & $\begin{array}{l}\text { Tetracloreto de } \\
\text { Carbonato }\end{array}$ & Tricloroetiteno & Tetracloroetileno \\
\hline Aço inoxidável & & $>40000$ & & $>40000$ & $>40000$ \\
\hline Cobre & & $>40000$ & & $>40000$ & $>40000$ \\
\hline Bronze & & $>40000$ & & $>40000$ & $>40000$ \\
\hline Alumínio & $\because$ & 9000 & & 40000 & 30000 \\
\hline Aço Doce & 6000 & 180 & 200 & 5000 & 10000 \\
\hline $\begin{array}{c}\text { Metal } \\
\text { Galvanizado }\end{array}$ & 1200 & 200 & 180 & $>40000$ & 5000 \\
\hline
\end{tabular}

De uma maneira geral, os tempos obtidos através da utilização de metal galvanizado foram menores do que os valores obtidos na utilização de outros metais. Apenas o tempo para degradação do Tricloroetileno (TCE) é menor na utilização do Aço Doce.

Orth; Gillham (1993) concluíram que na presença de pó de ferro eletrolítico é rápida a degradação do TCE, com tempo de degradação estimado em $3,25 \mathrm{~h}$ para a meia-vida deste contaminante. Após a normalização da coluna utilizada no experimento ao tempo de residência, foram observadas razões semelhantes de degradação para concentrações no intervalo de $1,27 \mathrm{mg} / \mathrm{L}$ a $61,0 \mathrm{mg} / \mathrm{L}$ de TCE. 
Pereira e Freire (2005) apresentam três rotas básicas para dehalogeneização redutiva de compostos orgânicos na presença de ferro zerovalente.

Na primeira rota, o ferro zero-valente transfere elétrons diretamente ao contaminante adsorvido na superfície metálica, como ilustrado na Figura 8.

Figura 8. Degradação de organoclorado ( $\mathrm{RCl}$ ) pela transferência direta de elétrons do ferro zero-valente $\left(\mathrm{Fe}^{0}\right)$. Modificado de Pereira e Freire (2005).

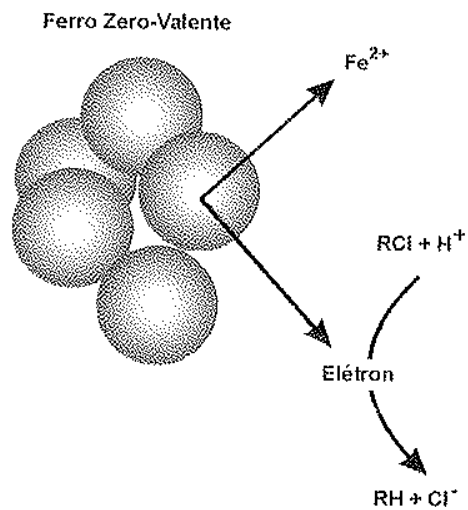

A corrosão do ferro metálico origina o ferro bivalente que reage com os compostos orgânicos halogenados, caracterizando a segunda rota possivel de dehalogeneização, indicada na Figura 9.

Figura 9. Dehalogeneização de organoclorado ( $R C l)$ na presença de ferro bivalente $\left(\mathrm{Fe}^{2 \cdot+}\right)$. Modificado de Pereira e Freire (2005).

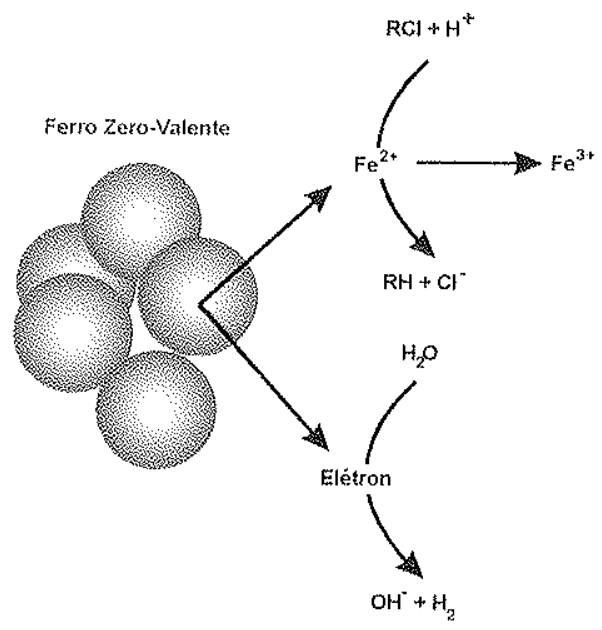


Ainda como produto da degradação do ferro zero-valente na presença de água, o hidrogênio $\left(\mathrm{H}_{2}\right)$ proporciona a dehalogeneizaçăo do composto organoclorado em reação (Figura 10) efetiva apenas na presença de catalisadores.

Figura 10. Dehalogeneização de organoclorado $(\mathrm{RCl})$ na presença de hidrogênio $\left(\mathrm{H}_{2}\right)$

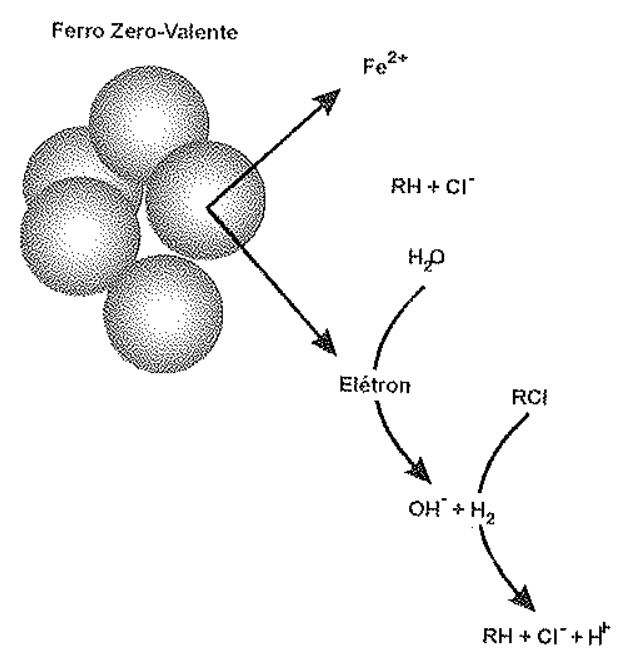

Além do ferro inserido no sistema de remediação, pode atuar com agente redutor o ferro presente no meio geológico onde é encontrada a pluma de contaminação.

Este metal é abundante na formação da crosta terrestre e na água subterrânea pode ocorrer na forma solúvel bivalente $\left(\mathrm{Fe}^{2+}\right)$ ou na trivalente $\left(\mathrm{Fe}^{3+}\right)$, insolúvel.

A forma insolúvel do ferro, normalmente encontrado como hidróxido $\mathrm{Fe}(\mathrm{OH})_{3}$, com o passar do tempo assume a forma mineral, como hematita, goetita e lepidocrosita, entre outras, que possuem solubilidades distintas.

A oxidação do ferro bivalente para ferro trivalente, por sua vez, pode ocorrer em velocidades variadas e dependentes das condições físico-químicas do meio, como temperatura, pH e concentração de oxigênio dissolvido. Sob uma mesma temperatura, a variação do $\mathrm{pH}$ condiciona a velocidade de oxidação do $\mathrm{Fe}^{2+}$, que aumenta na medida em que o pH aumenta.

A disponibilidade natural do ferro é, portanto, uma possivel alternativa para dehalogeneização de compostos organoclorados que pode ocorrer através de reações como a apresentada na Figura 9. 
Stucki et al. (2002) estudaram os efeitos das reações de óxido-redução do ferro presentes em esmectitas na interação com compostos orgânicos. Esmectitas em diferentes estados de oxidação (montmorilonita, esmectita ferruginosa e nontronita) foram submetidas a reações em meio aquoso contendo pentacloroetano, em ambiente controlado. Os resultados dos estudos indicaram adsorção do organoclorado aos argilo-minerais em taxas distintas e fortemente relacionadas à presença de ferro bivalente, produzindo tetracloroeteno como sub-produto da reação apresentada na Figura 11.

Figura 11. Reação de dehalogeneização de pentacloroetano para tetracloroeteno na presença de esmectita. (Modificada de Stucki et al., 2002)

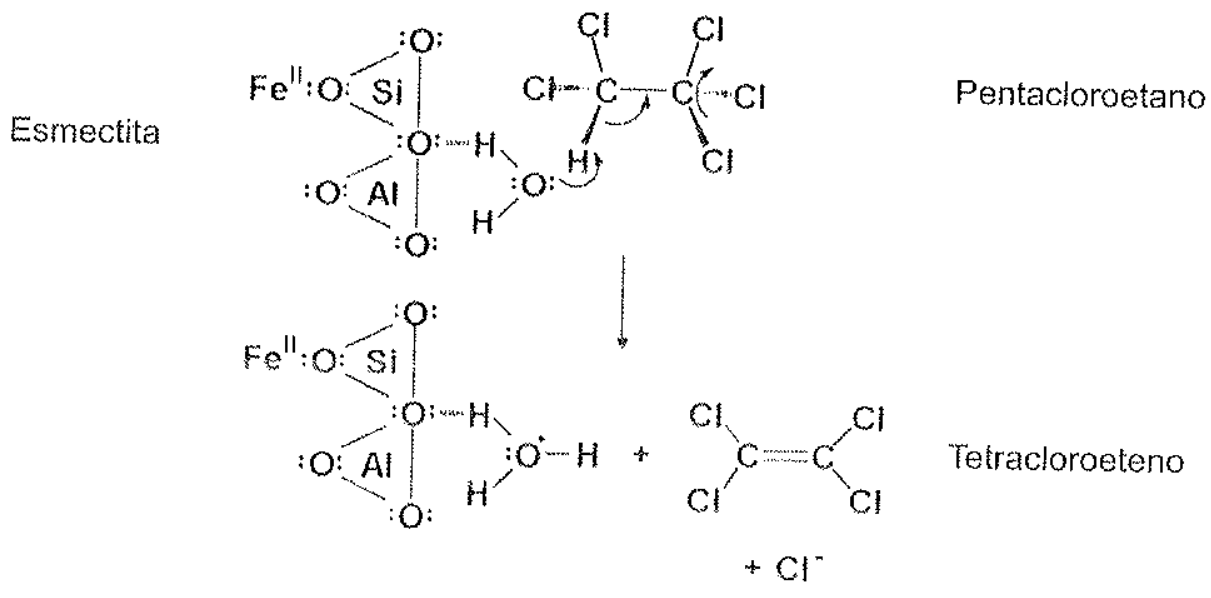




\section{IMPLANTAÇÃO DO SISTEMA DE REMEDIAÇÃO IN SITU}

\subsection{Aspectos Geológicos da Área Estudada}

A área de estudos localiza-se na região sul do município de São Paulo, no bairro de Parelheiros, e a geologia local é constituída por seqüencia de rochas metamórficas pré-cambrianas parcialmente cobertas por sedimentos terciários correlacionáveis aos da Bacia de São Paulo (Vieira et al., 1990) e por aluviões quaternários.

De acordo com Vieira et al. (1990), as rochas metamórficas da área de estudos são constituídas por sericita-xistos e filitos pertencentes ao Grupo Açungui, do Proterozóico Superior, conforme indicado no mapa da Figura 12.

As rochas descritas estão agrupadas no Complexo-Embu, definido por xistos, mica-xistos e corpos lenticulares de anfibolitos, quartizitos e rochas calciossilicatadas. 
Figura 12. Mapa geológico da região estudada (modificado de Vieira et al., 1990).

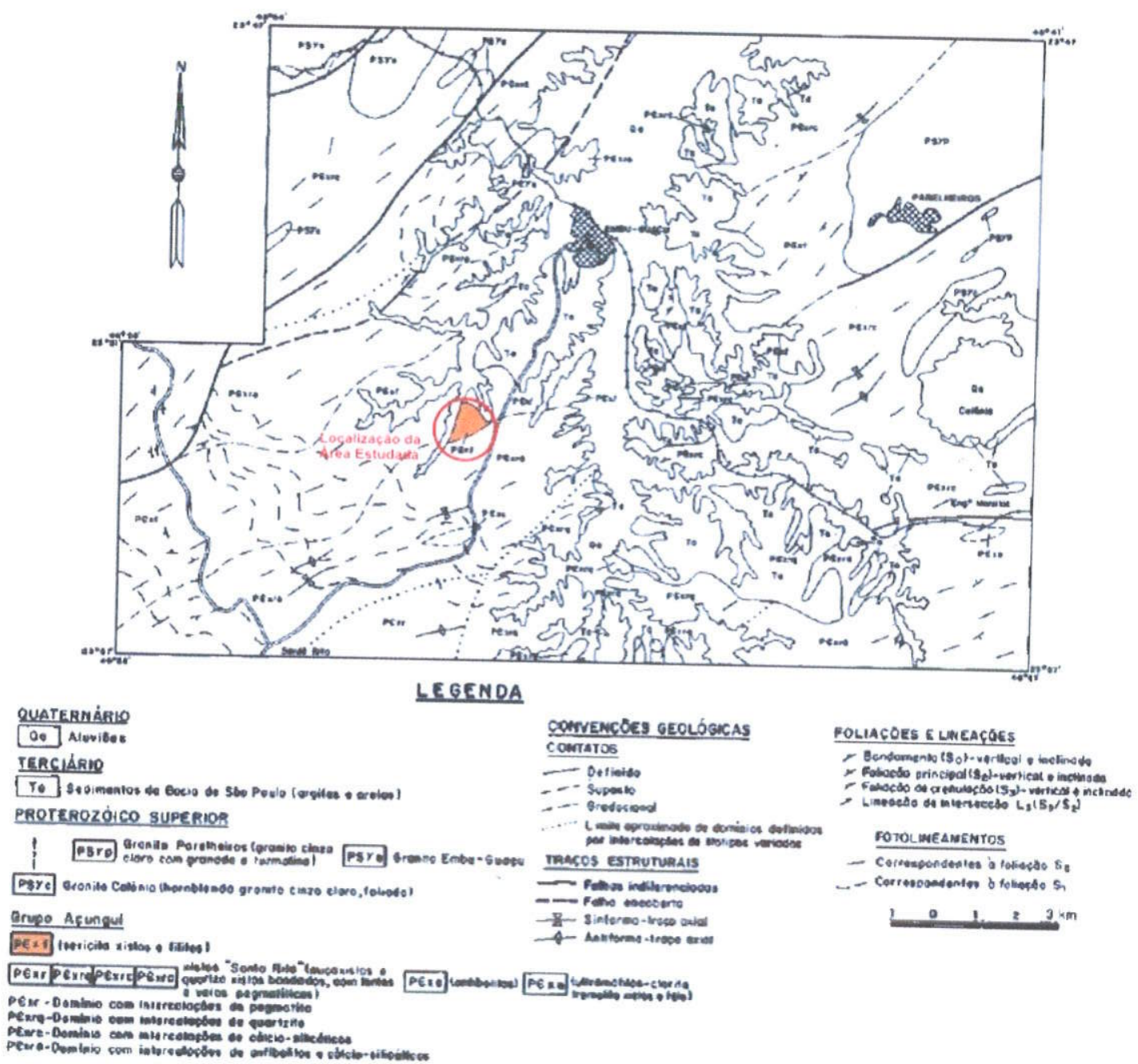

À jusante da indústria, a Estrada é constituída por aterro de constituição heterogênea, tendo sido identificados, durante a escavação para implantação das barreiras, blocos de rocha com estruturas parcialmente preservadas, como indica a Figura 13. 
Figura 13. Bloco de rocha encontrado a jusante da industria, na trincheira escavada para instalação das barreiras reativas

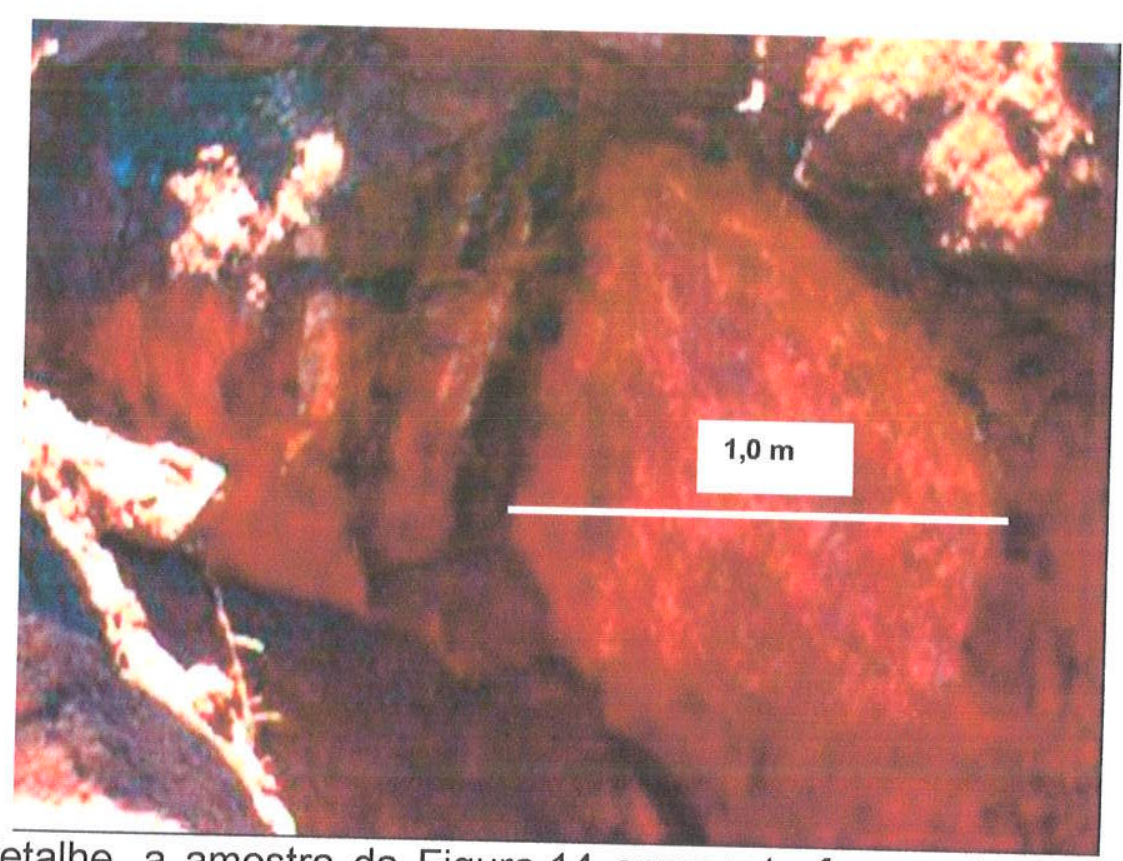

Em detalhe, a amostra da Figura 14 apresenta fragmento de rocha com bandamento parcialmente preservado, indicando alternância centimétrica de camadas quartzosas e micáceas.

Figura 14. Detalhe de amostra coletada na área de instalação das barreiras

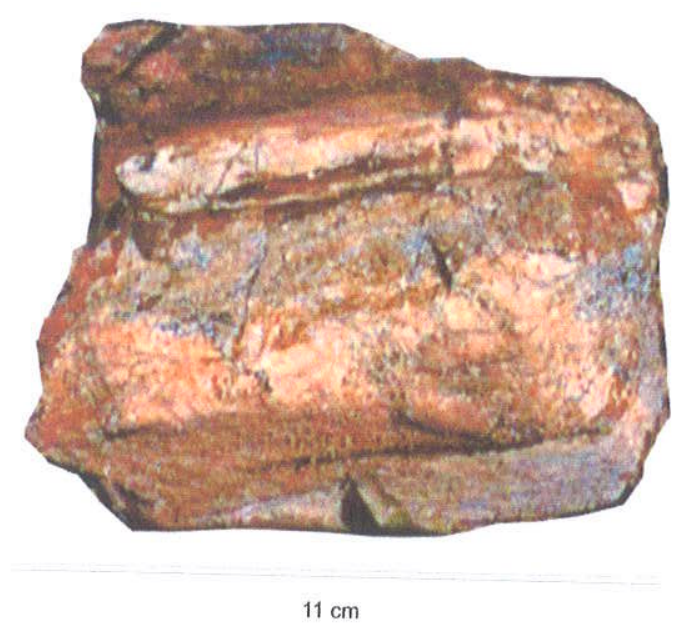

Apesar das estruturas parcialmente visíveis, os xistos presentes na área encontram-se geralmente muito alterados, razão pela qual o grau de metamorfismo é de difícil determinação, sendo considerado baixo em função da granulometria fina geralmente observada (Vieira, 1992). 
A geologia local, como identificada, é importante para este trabalho pelo fato de apresentar rochas que contêm argilo-minerais em sua composição e pelo fato destes serem ricos em ferro, que pode auxiliar na degradação dos compostos orgânicos clorados.

Minerais opacos freqüentemente distribuidos na interface entre a biotita e sillimanita fibrosa devem conter cristalizado o excesso de ferro e manganês bivalentes originados no processo matamórfico de substituição da mica pelo aluminossilicato (Vieira et. Al, 1992), de acordo com a Equação a seguir:

$$
2 \text { biotita }+14 \mathrm{H}^{+} \rightarrow \text { sillimanita fibrosa }+2 \mathrm{~K}^{+}+6(\mathrm{Fe}, \mathrm{Mn})^{2+}+9 \mathrm{H}_{2} \mathrm{O}+5 \text { quartzo }
$$

A disponibilidade dos metais manganês e ferro, especialmente este último, pode ter influência direta na degradação de compostos clorados por reações de redução, entretanto, o potencial de redução é raramente atingido, exceto sob condições muito redutoras e, em geral, na presença de bactérias (Pankow; Cherry, 1996). Ainda assim, de acordo com a reação apresentada anteriormente, o ferro disponivel encontra-se na forma bivalente e, portanto, pode contribuir para dehalogeneização de compostos orgânicos sob condições específicas, oxidando para a forma trivalente.

Esta possibilidade, discutida no item 5.2, é possivel e pode contribuir para a dehalogeneização natural dos contaminantes presentes na área avaliada, acelerando o processo de recuperação da área contaminada.

$\mathrm{Na}$ área estudada, o ferro bivalente ocorre naturalmente em água subterrânea, o que pode ser observado nas medidas do poço de monitoramento instalado a montante (PM SR01 M) do sistema de remediação (Tabela 42 apresentada no subitem 7.4), em concentrações que acompanham as variações de $\mathrm{pH}$ e Eh. 
A área foi avaliada através da instalação de 25 poços multiníveis de monitoramento (PMMN) do aqüífero freático, distribuídos de acordo com a Figura 15, sendo 13 poços com três níveis distintos de investigação e 12 com dois níveis, tendo sido determinado o fluxo preferencial da água subterrânea com sentido norte-sul.

Figura 15. Localização dos poços de monitoramento multiníveis na área de estudo.

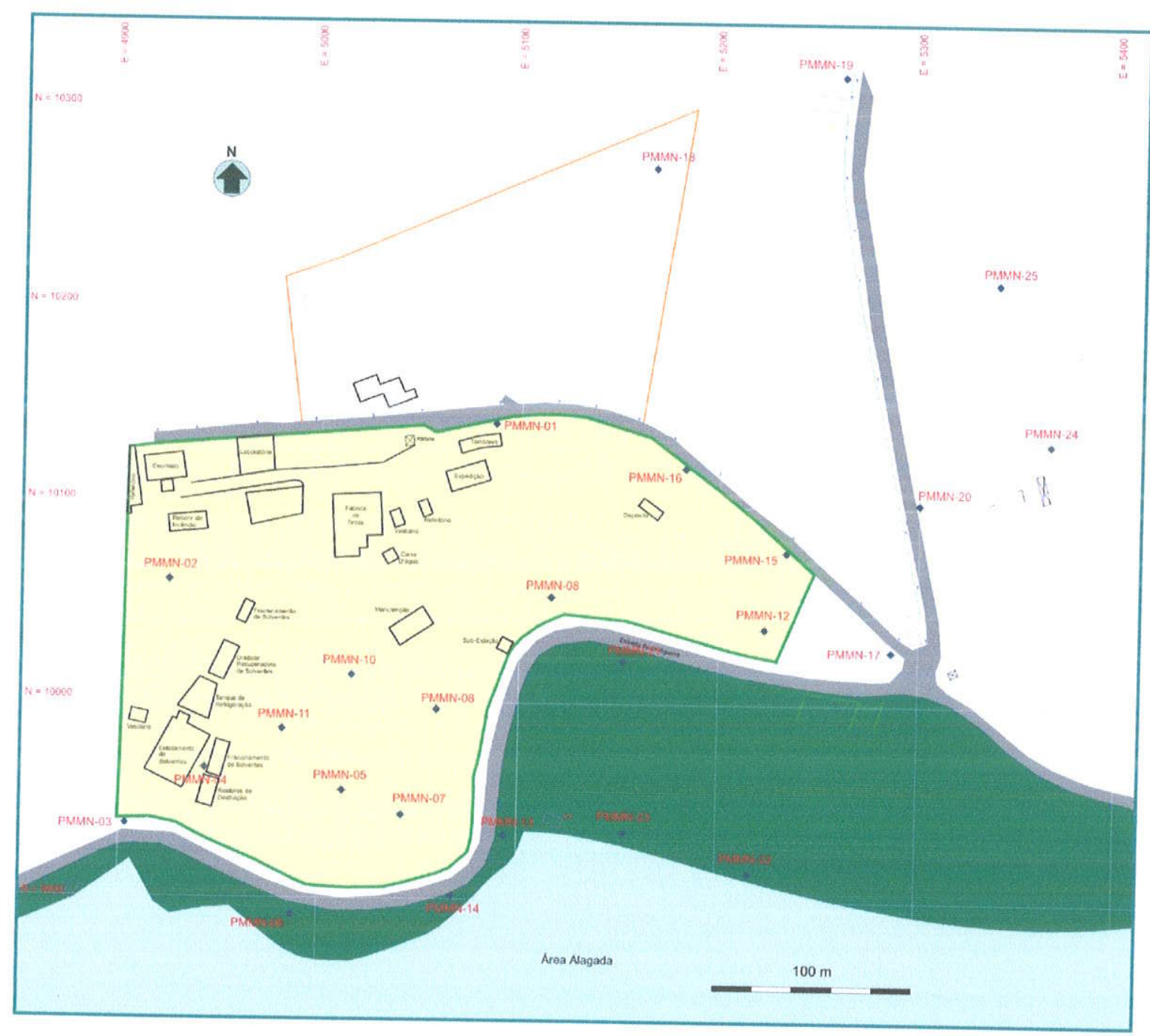

Os resultados obtidos ao longo dos monitoramentos dos poços multiníveis indicaram fluxo das águas subterrâneas no sentido preferencial norte-sul, na direção da zona de inundação da Represa, e uma pluma central de contaminação de distribuição relativamente homogênea na zona saturada do 
aqüífero freático, como ilustra a Figura 16. O eixo central da pluma de contaminação, constituída basicamente por compostos organoclorados e por hidrocarbonetos derivados de petróleo, foi determinado a jusante da área da indústria, configurando área potencialmente favorável à instalação da Barreira Reativa, conforme indicado na Figura 16.

Figura 16. Pluma principal de contaminação por solventes clorados na direção preferencial de fluxo norte-sul

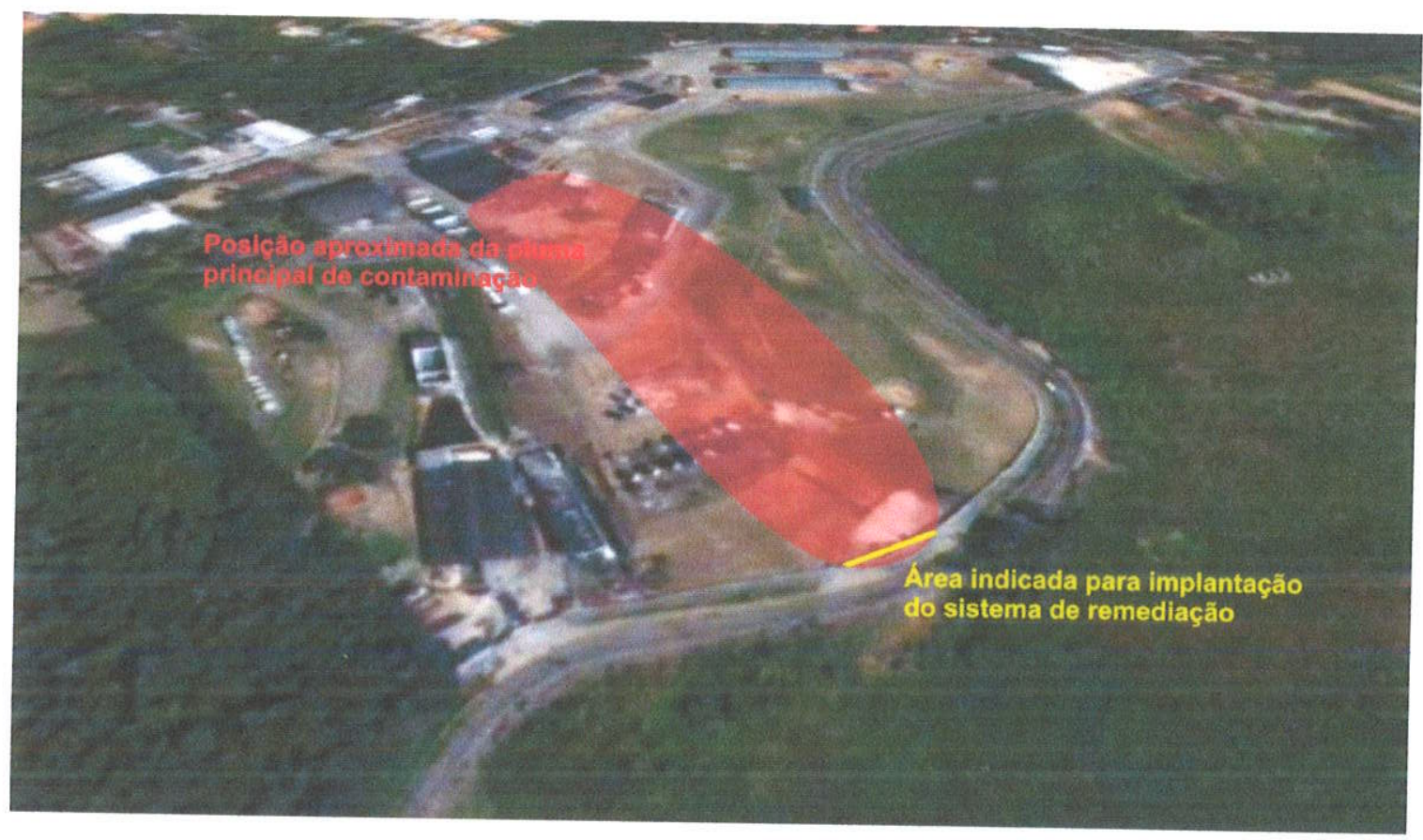

A Barreira Reativa foi dimensionada em escala piloto e não teve como objetivo interceptar toda a frente de contaminação, razão pela qual ensaios hidráulicos foram dispensados.

A determinação do padrão de fluxo com apresentado no subitem 6.2.1 teve como finalidade o dimensionamento da zona reativa da Barreira.

$\mathrm{Na}$ área em que foi instalada, a barreira ficou totalmente abaixo do nível do solo, dimensionada de acordo com o indicado na Figura 17. 
Figura 17. Distribuição aproximada do sistema instalado

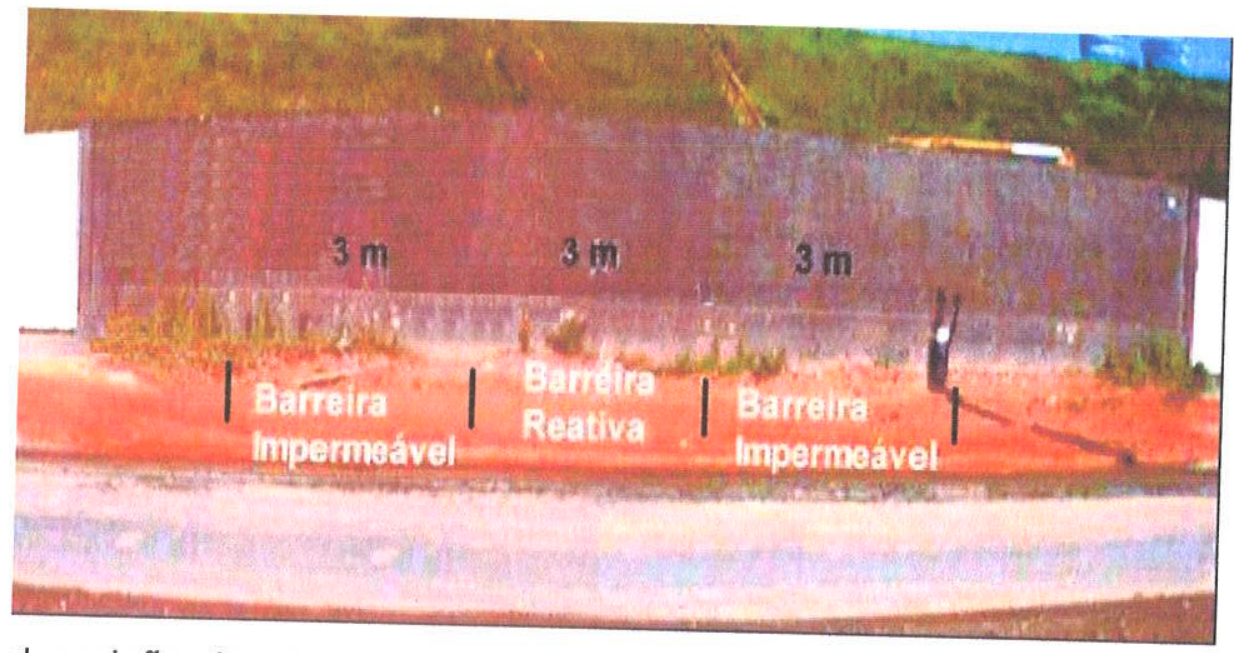

A descrição dos perfis de sondagens efetuadas no local indicou o topo da camada rochosa (solo pouco alterado) que constitui o embasamento local em profundidade aproximada de $6,0 \mathrm{~m}$.

\subsubsection{Dimensionamento da Zona Reativa}

Adotou-se o valor de 3,25 h para meia-vida do composto tricloroeteno, determinado por Orth e Gillham (1993), em experimento realizado na presença de pó de ferro eletrolítico.

A máxima concentração de TCE encontrada a partir das análises de químicas na área monitorada foi de $750,3 \mu \mathrm{g} / \mathrm{L}$.

Para efeito de cálculos considerou-se que a barreira reativa deveria ter a capacidade de redução das concentrações de TCE até o limite de $10 \mu \mathrm{g} / \mathrm{L}$, número conservador quando avalia-se que o valor máximo permitido para o padrão de potabilidade estabelecido pela Portaria 518 do Ministério da Saúde é de $70 \mu \mathrm{g} / \mathrm{L}$ para o TCE.

Com o intuito de aumentar ainda mais a eficiência de degradação do sistema de remediação, a máxima concentração de TCE considerada foi de $1.000 \mu \mathrm{g} / \mathrm{L}$, acima do máximo valor apresentado nas análises químicas.

Desta forma, a redução de $1.000 \mu \mathrm{g} / \mathrm{L}$, que é a concentração inicial de contaminante entrando na barreira reativa, para $10 \mu \mathrm{g} / \mathrm{L}$, a concentração final após as reações, corresponde a cerca de 8 meias-vidas de TCE. 
Para assegurar que a barreira reativa tenha a capacidade de desviar as linhas de fluxo da água subterrânea e, conseqüentemente, constituir ambiente mais condutivo que o meio ao natural redor, como parâmetro construtivo considerou-se uma condutividade hidráulica cerca de 100 vezes maior que a do aqüífero estudado. Assim sendo, a condutividade hidráulica atribuída à barreira é de aproximadamente $10^{-3} \mathrm{~cm} / \mathrm{s}$, correspondente a um material arenoso bem selecionado, segundo Fetter (1988). Para este mesmo material (areia média), Fetter (1988) atribui ainda uma porosidade especifica para fluxo mínima de $15 \%$. O gradiente hidráulico foi considerado o mesmo da área à montante, ou seja, $12 \%$ (Salles, 1999), constituindo medida conservadora.

Desta forma, utilizando-se a Lei de Darcy, obtém-se para os parâmetros apresentados uma velocidade de fluxo da água subterrânea na barreira impermeável de $69,12 \mathrm{~cm} /$ dia.

Como são necessárias $3,25 \mathrm{~h}$ para a redução de uma meia-vida (Orth e Gillham, 1993) de TCE, e como são necessárias 8 meias-vidas para degradação do contaminante até a concentração desejada, conclui-se que o contaminante deve permanecer residente na zona de reação por um periodo mínimo de 26 horas.

Utilizando-se a velocidade de fluxo da água subterrânea na barreira reativa, desconsiderando-se o efeito atenuante dos fatores de retardamento, obtém-se uma distância de $74,88 \mathrm{~cm}$ a ser percorrida pelo contaminante em zona com reagentes para a total degradaçâo. Esta distância representa a largura mínima da barreira reativa.

\subsubsection{Definição do Material Reativo}

O material reativo deve possuir composição eficiente na degradação dos compostos organoclorados, obedecendo a estágios de quebra conforme exemplificado na Equação a seguir, que apresenta a transformação de TCE para DCE com liberação de $\mathrm{Cl}$.

$$
\mathrm{FC}_{(s)}+\mathrm{CHCl}=\mathrm{CCl}_{2}+\mathrm{H}^{+} \rightarrow \mathrm{Fe}^{2+}+\mathrm{C}_{2} \mathrm{H}_{2}=\mathrm{CCl}_{2}+\mathrm{Cl}^{-}
$$


A residência do contaminante na barreira reativa deve permitir a dehalogeneização completa do composto, com perda gradativa de ions de cloro de acordo com a reação base apresentada na Equação anterior.

Orth e Gillham (1993) apresentam experimento prático que evidencia a degradação de TCE na presença de pó de ferro eletrolítico, com produção de DCE e cloreto de vinila em pequenas porcentagens no caso de tempo insuficiente para dehalogeneização completa do composto. O'Hannesin e Gillham (1992) em Orth e Gillham (1993), por sua vez, indicam que isômeros de DCE e cloreto de vinila são degradados na presença de ferro eletrolítico em tempos de residência adequados.

Para efeito de aplicação na área estudada, a granulometria do material reativo foi ampliada, de forma a promover a mistura homogênea com a areia média empregada no preenchimento da barreira reativa e evitar colmatação do sistema.

A granalha de aço empregada no sistema contém as propriedades reativas das granalhas de ferro e maior resistência à abrasão, fornecendo à barreira reativa uma vida útil mais extensa.

A granulometria da granalha deve ser semelhante à da areia a ser empregada no sistema, com diâmetro de 30 mesh, de forma a minimizar os efeitos de carreamento de partículas, colmatação da barreira, redução de permeabilidade do meio e mantendo conseqüentemente a perfeita eficiência do sistema de recuperação.

A Tabela 3 apresenta as especificações granulométricas da granalha angular IKK, de acordo com dados da empresa fornecedora. Na barreira foi utilizada granalha retida entre as peneiras No. 40 e No. 25, especificada pela IKK como SAE 25, a qual possui diâmetro de abertura mais próximo ao diâmetro da areia utilizada, ou seja, 30 mesh. 
Tabela 3. Especificações Granulométricas da Granaiha Angular

\begin{tabular}{|c|c|c|c|c|c|c|c|c|c|c|c|}
\hline \multirow{2}{*}{$\begin{array}{c}\text { ASTM } \\
\text { E 11 70 } \\
\text { Peneira } \\
\text { No. }\end{array}$} & \multirow{2}{*}{$\begin{array}{l}\text { Abertu } \\
\text { ra da } \\
\text { Peneir } \\
\text { a (mm) }\end{array}$} & \multicolumn{10}{|c|}{ Especificação Granulométrica da Granalha Angular } \\
\hline & & $\begin{array}{l}S A E \\
\text { G10 }\end{array}$ & $\begin{array}{l}\text { SAE } \\
\text { G12 }\end{array}$ & $\begin{array}{l}\text { SAE } \\
\text { G14 }\end{array}$ & $\begin{array}{l}\text { SAE } \\
\text { G16 }\end{array}$ & $\begin{array}{l}S A E \\
\text { G18 }\end{array}$ & $\begin{array}{l}\text { SAE } \\
\text { G25 }\end{array}$ & $\begin{array}{l}\text { SAE } \\
\text { G } 40\end{array}$ & $\begin{array}{l}\text { SAE } \\
G 50\end{array}$ & $\begin{array}{c}\text { SAE } \\
\text { G } 8 \\
0\end{array}$ & $\begin{array}{c}\text { SAE } \\
\text { G120 }\end{array}$ \\
\hline 7 & 2800 & 0 & - & . & . & - & - & . & 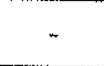 & . & - \\
\hline 8 & 2360 & - & 0 & - & - & - & - & - & - & - & - \\
\hline 10 & 2000 & $\begin{array}{l}80 \% \\
\min \end{array}$ & " & 0 & . & - & - & & - & " & " \\
\hline 12 & 1700 & $\begin{array}{l}97 \% \\
\text { min }\end{array}$ & $\begin{array}{l}80 \% \\
\min \end{array}$ & - & 0 & - & - & - & - & - & - \\
\hline 14 & 1400 & " & $\begin{array}{l}90 \% \\
\mathrm{~min}\end{array}$ & $\begin{array}{l}80 \% \\
\text { min }\end{array}$ & 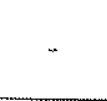 & 0 & - & $\cdots$ & - & - & - \\
\hline 16 & 1180 & - & - & $\begin{array}{l}90 \% \\
\min \end{array}$ & $\begin{array}{l}75 \% \\
\min \end{array}$ & - & 0 & - & - & - & - \\
\hline 18 & 1000 & - & - & - & $\begin{array}{l}85 \% \\
\text { min }\end{array}$ & $\begin{array}{l}75 \% \\
\min \end{array}$ & - & 0 & - & - & - \\
\hline 25 & 710 & - & - & - & . & $\begin{array}{l}85 \% \\
\mathrm{~min}\end{array}$ & $\begin{array}{l}70 \% \\
\min \end{array}$ & - & 0 & - & - \\
\hline 40 & 425 & - & - & - & - & - & $\begin{array}{l}80 \% \\
\min \end{array}$ & $\begin{array}{l}70 \% \\
\text { min }\end{array}$ & - & 0 & - \\
\hline 50 & 300 & - & - & - & - & - & - & $\begin{array}{l}80 \% \\
\text { min }\end{array}$ & $\begin{array}{l}65 \% \\
\text { min }\end{array}$ & - & 0 \\
\hline 80 & 180 & & & & & & & & $\begin{array}{l}75 \% \\
\text { min }\end{array}$ & $\begin{array}{l}65 \% \\
\min \end{array}$ & \\
\hline 120 & 125 & & & & & & & & & $\begin{array}{l}75 \% \\
\mathrm{~min}\end{array}$ & $\begin{array}{l}60 \% \\
\min \end{array}$ \\
\hline 200 & 75 & & & & & & & & & & $\begin{array}{l}70 \% \\
\min \end{array}$ \\
\hline
\end{tabular}




\subsection{Instalação da Barreira Reativa}

Empregou-se para instalação da barreira reativa uma retro-escavadeira modelo PC 150 (Figura 18).

Figura 18. Escavadeira utilizada na instalação do sistema de remediação

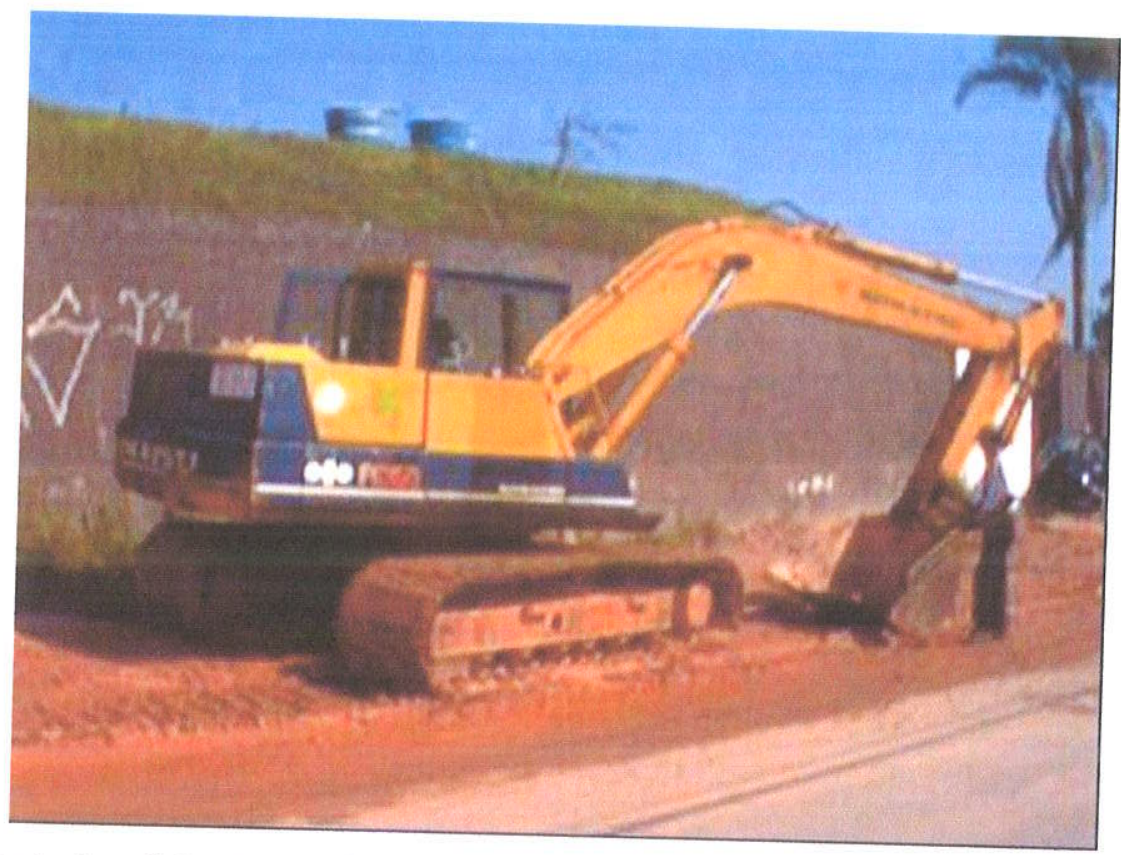

A trincheira foi construída com extensão de $3,0 \mathrm{~m}$ e sua largura foi prédefinida em 0,99 $\mathrm{m}$ a partir das concentrações dos compostos clorados obtidas nas etapas de avaliação da contaminação e a partir dos valores de meia-vida estabelecidos em Gilham; O'Hannesin (1992), sendo a largura mínima calculada para completa dehalogeneização dos contaminantes de interesse. Entretanto, em virtude do colapso de solo durante o processo de escavação, provocado pela raspagem da pá da escavadeira de largura de $1,20 \mathrm{~m}$, a trincheira foi escavada com largura aproximada de 1,50 m.

A escavação (Figura 19) não necessitou de escoramento, uma vez que a profundidade de $5,15 \mathrm{~m}$ foi atingida passando-se por solo de alteração (grau elevado) de rocha com matriz argilosa, compacto e estável, não tendo sido observada a migração de água subterrânea para a cava durante o processo. 
Figura 19. Escavação para Barreira Reativa

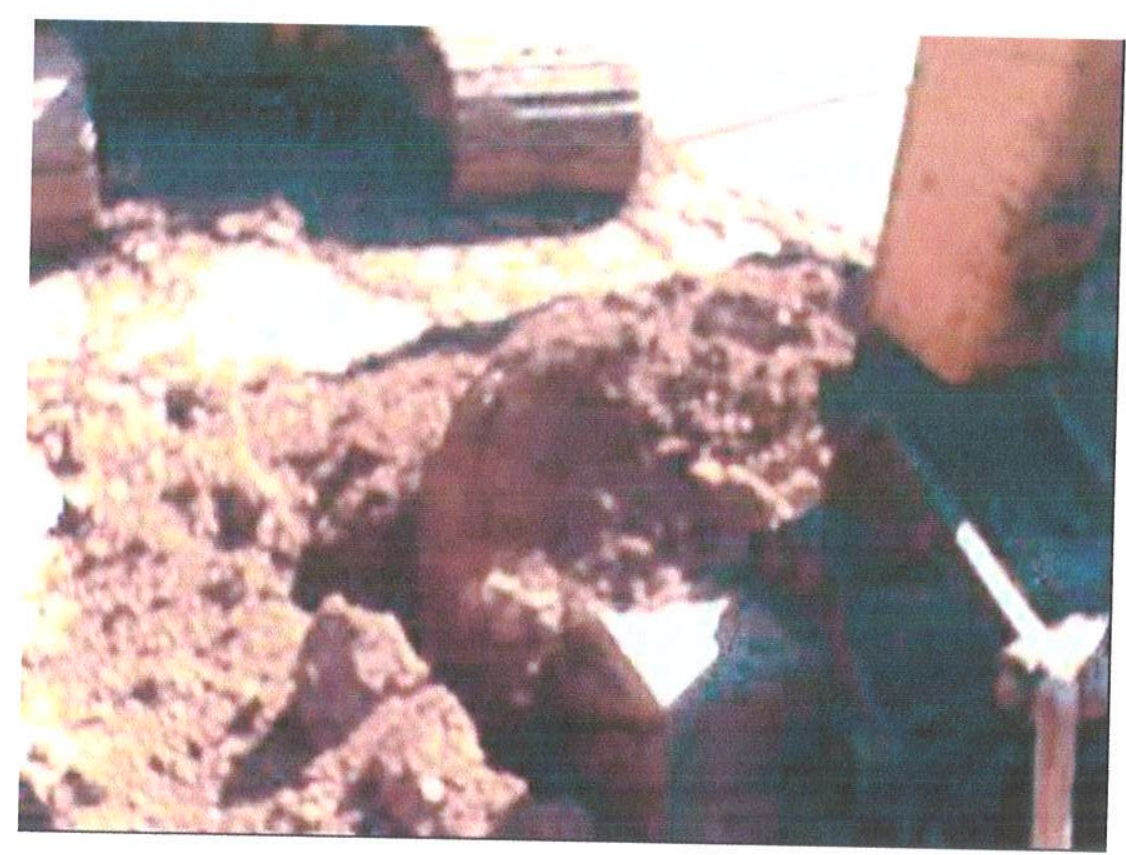

Durante a escavação da trincheira para inserção do material reativo e de duas trincheiras adjacentes a esta, destinadas à instalação das placas metálicas (barreira impermeável para direcionamento do fluxo da água subterrânea - sistema funnel and gate), não foi observada a migração imediata de água na profundidade estimada de interceptação do aqüífero freático. A migração lenta de água foi identificada após horas de trabalho, durante a cravação das placas metálicas, evidenciando a baixa condutividade hidráulica do meio avaliado.

$\mathrm{Na}$ profundidade de 5,15 m atingida pela escavação foi encontrada a transição para solo medianamente alterado, profundidade na qual procedeu-se a inserção das placas metálicas sob controle de nivelamento, obtendo-se posição vertical da estrutura.

As barreiras impermeáveis foram feitas individualmente, sendo iniciada pela colocação da placa leste. Após inserção da placa foi realizada cravação através de pressão vertical efetuada com o auxílio da pá da retro-escavadeira, processo atuante até posicionamento final da placa no nível do pavimento (Figura 20). 
Figura 20. Posicionamento vertical da placa leste após cravação

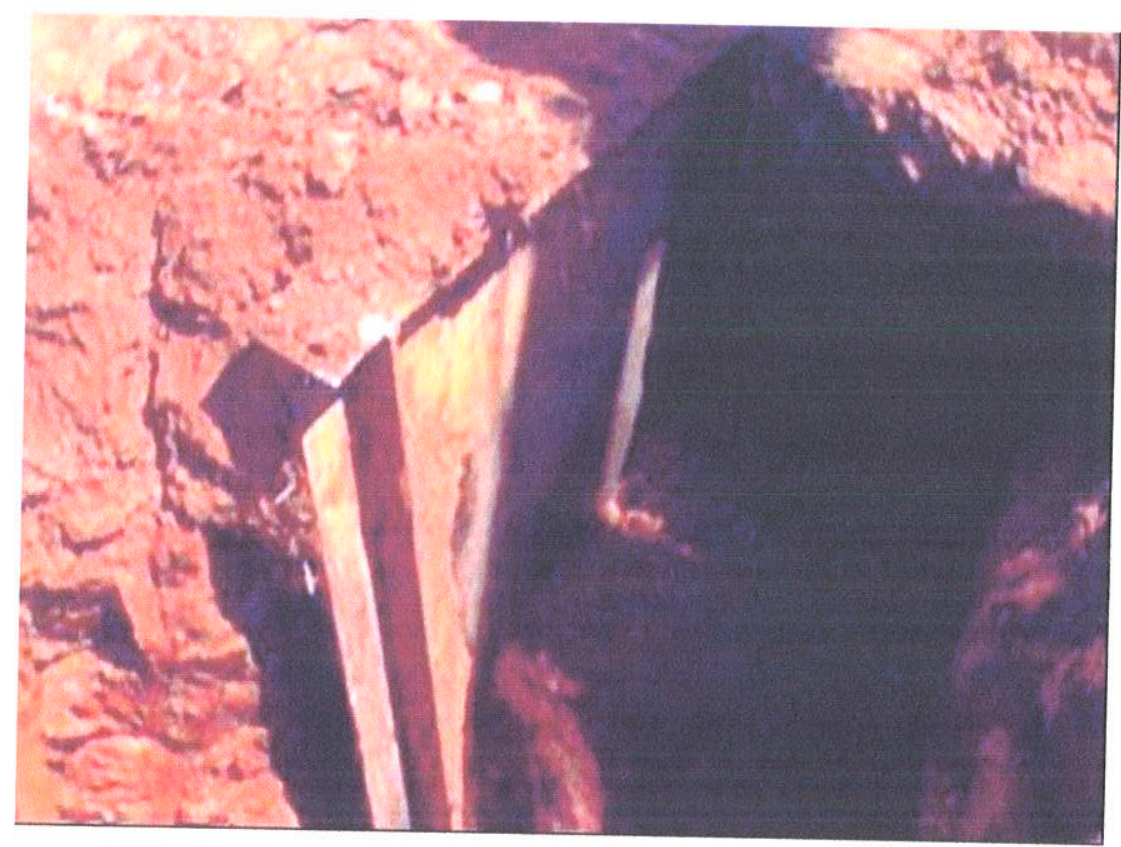

Finalizado o processo de inserção e cravação das placas, procedeu-se o preenchimento da cava por reposição do solo escavado. As placas, desta forma, foram mantidas sob o solo, conforme apresentado na Figura 21, reduzindo os efeitos de abrasão por atritos superficiais.

Figura 21. Detalhe da placa da barreira impermeável oeste, cravada sob a superfície do solo

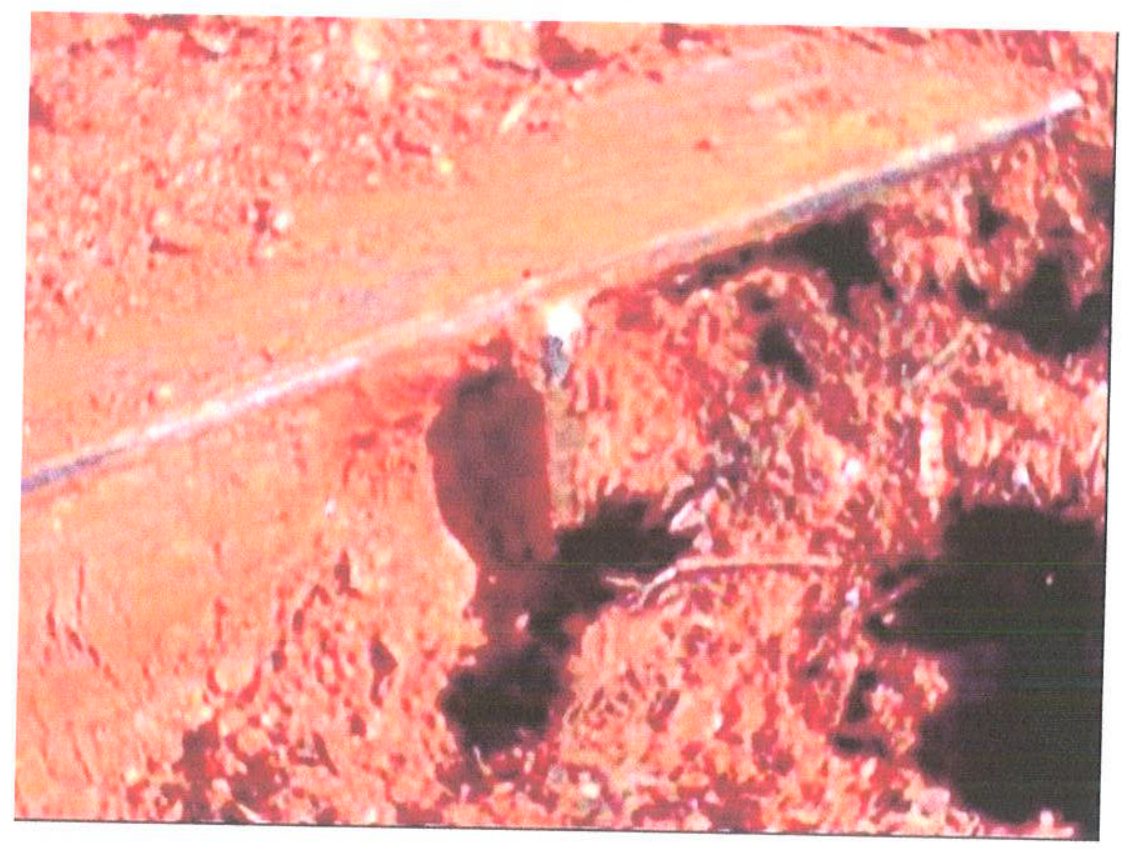


Previamente ao preenchimento da trincheira pelo material reativo, foi inserida placa guia em madeira (Figura 22), posicionada verticalmente, de forma a limitar a área de preenchimento. A largura final da Barreira Reativa, com a inserção da placa guia, ficou em 1,20 m.

Figura 22. Inserção de placa em madeira para redução da largura da Barreira Reativa

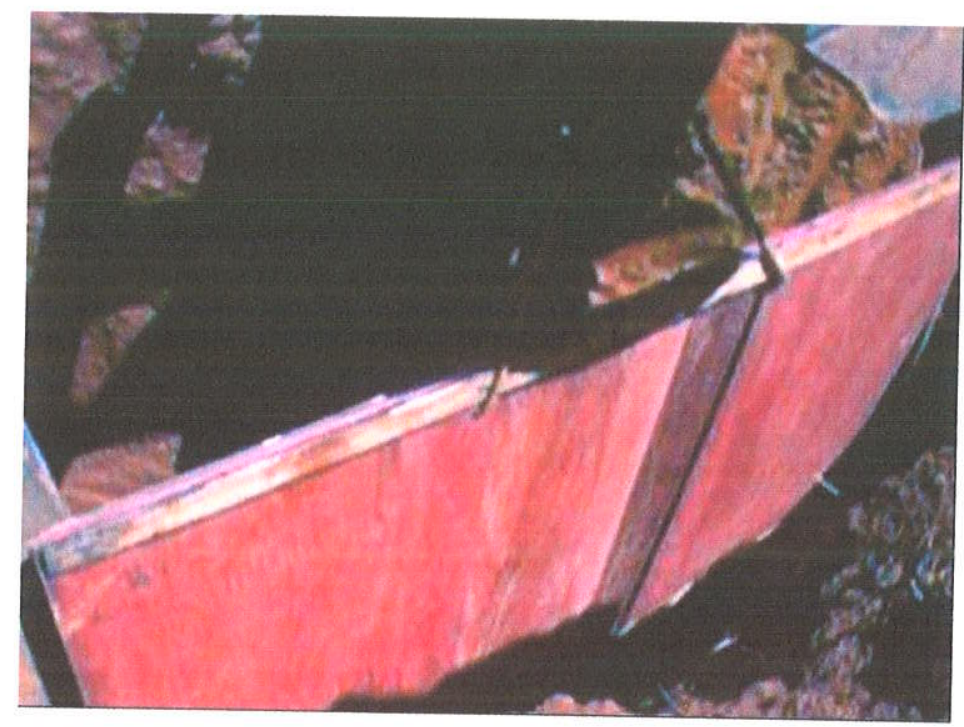

A composição final da mistura reativa (Figura 23) obedeceu à proporção de 6 toneladas de granalha para $16 \mathrm{~m}^{3}$ de areia. De acordo com Orth; Gillham (1993), é recomendada mistura composta por $15 \%$ em peso de ferro para $85 \%$ de areia. Considerando-se a densidade aproximada para areia seca, de $1,30 \mathrm{~g} / \mathrm{cm}^{3}$, a porcentagem final em peso da mistura reativa é de $77,61 \%$ de areia e $22,39 \%$ de granalha.

Figura 23. Matriz reativa de areia e granalha

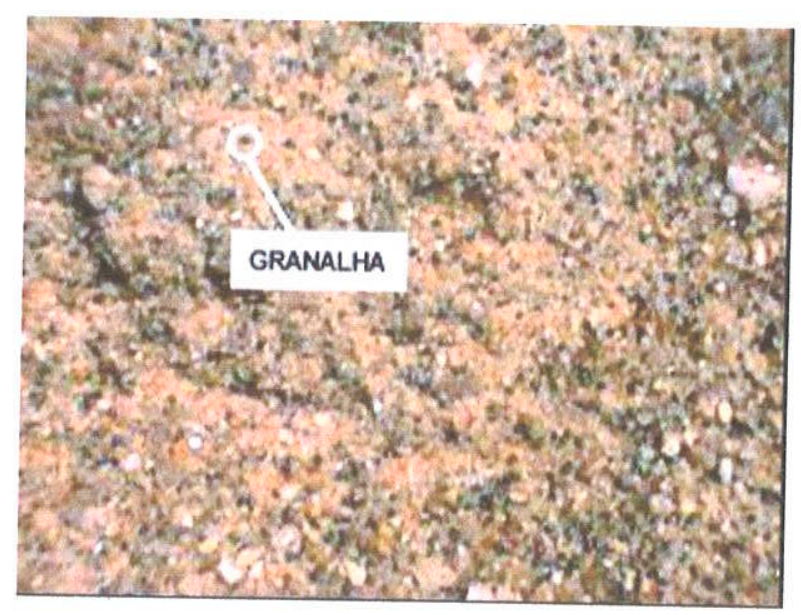


A mistura foi inserida na cava separada pela placa guia em madeira através de pá carregadeira modelo 930 (Figura 24). A ausência de água subterrânea migrante para o interior da trincheira e a estabilidade do solo escavado permitiu a inserção direta da mistura, sem necessidade de escoramento da vala.

Figura 24. Preenchimento da trincheira por mistura reativa

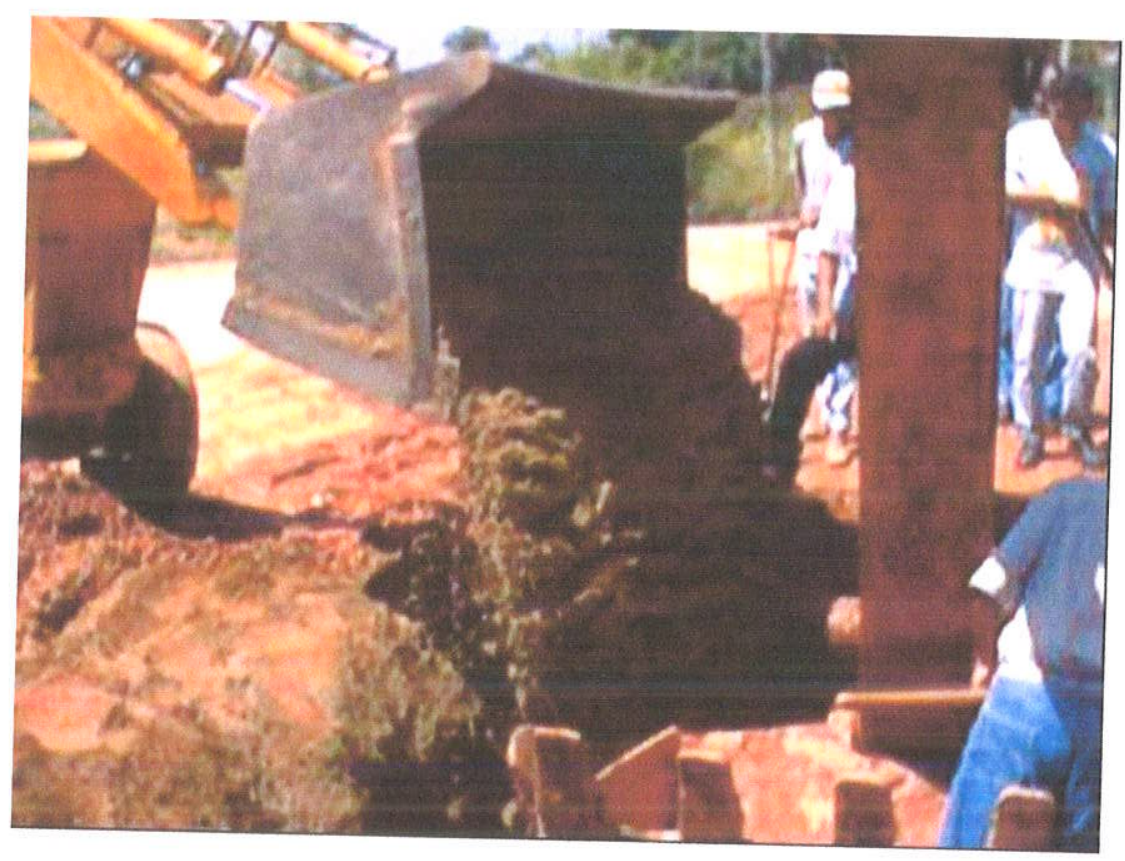

Os componentes, areia e granalha angulosa, com diâmetros de 30 mesh, foram colocados em betoneira para homogeneização da mistura final. A distribuição por igual da mistura ao longo de toda a trincheira foi feita por técnicos (Figura 25), tendo sido mantida superfície superior plana da mistura para homogeneização do sistema. 
Figura 25. Distribuição homogênea da mistura na vala

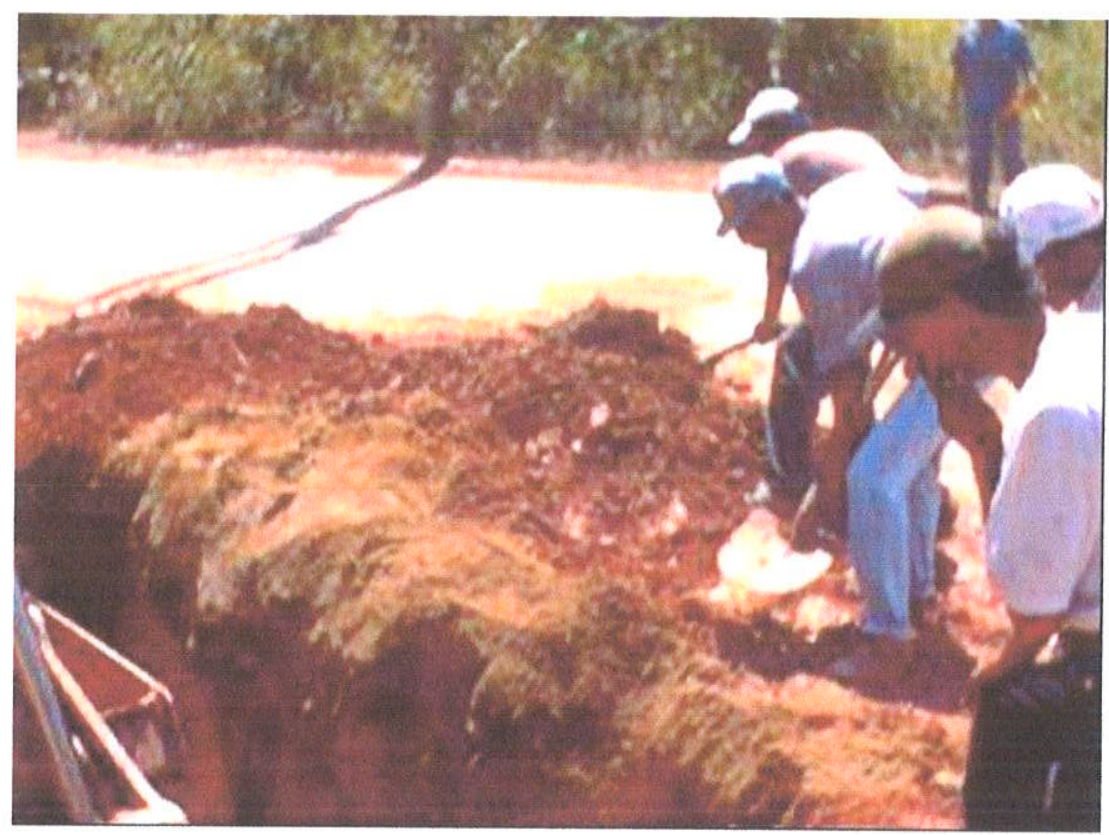

Ao fim do preenchimento da trincheira, a superfície do material reativo ficou nivelada a 1,00 m abaixo da superfície do terreno e a porção superior da trincheira foi preenchida por solo reposto.

Seguindo-se o raciocínio apresentado para o dimensionamento da zona reativa, para uma barreira reativa com condutividade hidráulica de $10^{-3} \mathrm{~cm} / \mathrm{s}$ (100 vezes maior que a condutividade do aqüífero avaliado), gradiente hidráulico aproximado de $12 \%$ e com material reativo apresentando porosidade efetiva para fluxo em torno de $15 \%$ (Fetter, 1988), calcula-se em $69,12 \mathrm{~cm} /$ dia a velocidade de fluxo de água subterrânea através da Barreira Reativa.

Como a largura final obtida para a Barreira Reativa foi de 1,20 m, estimase que o tempo de residência do contaminante (supondo velocidade de migração igual à da água subterrânea, ou seja, descartando-se fator de retardamento) no sistema é de aproximadamente 41,67 h.

O tempo de permanência da água subterrânea no sistema é 1,6 vezes superior ao tempo mínimo calculado (26 h) para degradação de $1000 \mu \mathrm{g} / \mathrm{L}$ de TCE para $10 \mu \mathrm{g} / \mathrm{L}$. 


\subsection{Instalação da Barreira Impermeável}

Foram instaladas duas placas metálicas para confecção da barreira impermeável, com intenção de direcionamento de fluxo da água subterrânea para a zona reativa do sistema funnel and gate.

As placas em aço carbono seguiram os padrões estabelecidos pela norma ASTM - A 36. Cada placa possui largura de $3,00 \mathrm{~m}$, com espessura de $1,27 \mathrm{~cm}$ (1/2 polegada) e comprimento total de $5,80 \mathrm{~m}$. A porção inferior da placa, especificamente $0,80 \mathrm{~m}$, foi cunhada de forma a propiciar maior penetração e fixação no substrato constituído por rocha alterada mole.

Cinco reforços laterais confeccionados em aço carbono, com espessura aproximada de $1,59 \mathrm{~cm}$ (5/8 de polegada) e largura aproximada de $10,16 \mathrm{~cm}$ (4 polegadas) foram soldados à placa metálica de forma a proporcionar maior resistência ao impacto durante a fixação ao substrato. Três reforços foram dispostos em um dos lados da placa e dois do outro lado, sendo os primeiros soldados nas duas extremidades e no centro da placa, com comprimento de $5,00 \mathrm{~m}$, e os outros dois reforços soldados nas duas lineaçôes com maior comprimento $(5,80 \mathrm{~m})$ da placa.

Uma placa menor, também em aço carbono, foi soldada na porção superior, com pontos de fixação na placa principal e no eixo transversal dos cinco reforços. Esta placa tem comprimento de 3,00 m, largura de 0,20 m, com espessura de $1,27 \mathrm{~cm}$ (1/2 polegada) e desempenha a função de atenuante de pressão durante o processo de fixação da placa.

O solo de alteração resultante da litologia encontrada no local é essencialmente argiloso e apresenta grande quantidade de minerais micáceos. Porções arenosas são atribuidas às lentes de metarenitos.

As atribuições geotécnicas do solo local podem ser enquadradas, de acordo com os valores apresentados na Tabela 4, dentro do intervalo compreendido por solos argilosos de consistência muito mole à média, com índices de resistência à penetração variando entre 0 e 8 golpes, o que permite a cravação das placas metálicas por pressão da caçamba da escavadeira hidráulica a ser utilizada no processo 
Tabela 4. Relação entre Tipo de Solo e Índice de Resistência à Penetração (IRP)

\begin{tabular}{|c|c|c|c|}
\hline Material & IRP & Estado & Pressâo Admissivel $\left(\mathrm{Kg} / \mathrm{cm}^{2}\right)$ \\
\hline \multirow{6}{*}{ ARGILA } & $0-2$ & muito mole & 0,0 a 0,45 \\
\hline & $2-4$ & mole & 0,45 a 0,90 \\
\hline & $4-8$ & consistência média & 0,90 a 1,80 \\
\hline & $8-15$ & rija & 1,80 a 3,60 \\
\hline & $15-30$ & muito rija & 3,60 a 7,20 \\
\hline & $>30$ & dura & $>7,20$ \\
\hline \multirow{5}{*}{ AREIA } & $0-4$ & muito fofa & - \\
\hline & $4-10$ & fofa & até 0,80 \\
\hline & $10-30$ & compacidade média & 0,80 a 3,00 \\
\hline & $30-50$ & compacta & 3,00 a 5,00 \\
\hline & $>50$ & muito compacta & $>5,00$ \\
\hline
\end{tabular}

A seqüência de atividades para a instalação das placas obedeceu:

- Escavação inicial de vala, por Escavadeira Hidráulica PC 150, com profundidade aproximada de $5,15 \mathrm{~m}$, largura aproximada de $1,20 \mathrm{~m}$ e comprimento aproximado de $3,10 \mathrm{~m}$;

- Inserção da placa metálica, com nivelamento garantindo a verticalidade da mesma;

- Instalação das duas placas metálicas, uma a leste e outra a oeste da barreira reativa, a placa leste instalada sob ângulo direcional aproximado de $\mathrm{N} 85^{\circ}$ e a placa oeste instalada sob ângulo direcional aproximado de N 285

- Após colocação da placa na vala escavada, fixou-se por pressão vertical utilizando-se a caçamba da escavadeira até posicionamento da placa no nível do pavimento;

- Finalizou-se com a reposição do solo escavado e compactação do material. 


\subsection{Configuração Final do Sistema Funnel and Gate}

Dentro das especificações técnicas apresentadas até então, instalou-se a barreira reativa a jusante da Indústria Química, em localização de acordo com a Figura 26, que também localiza a seção A-B, a qual possibilita visualizar, na Figura 27, a configuração da barreira reativa em profundidade.

Figura 26. Localização em planta da Barreira Reativa e da seção estratigráfica A-B.

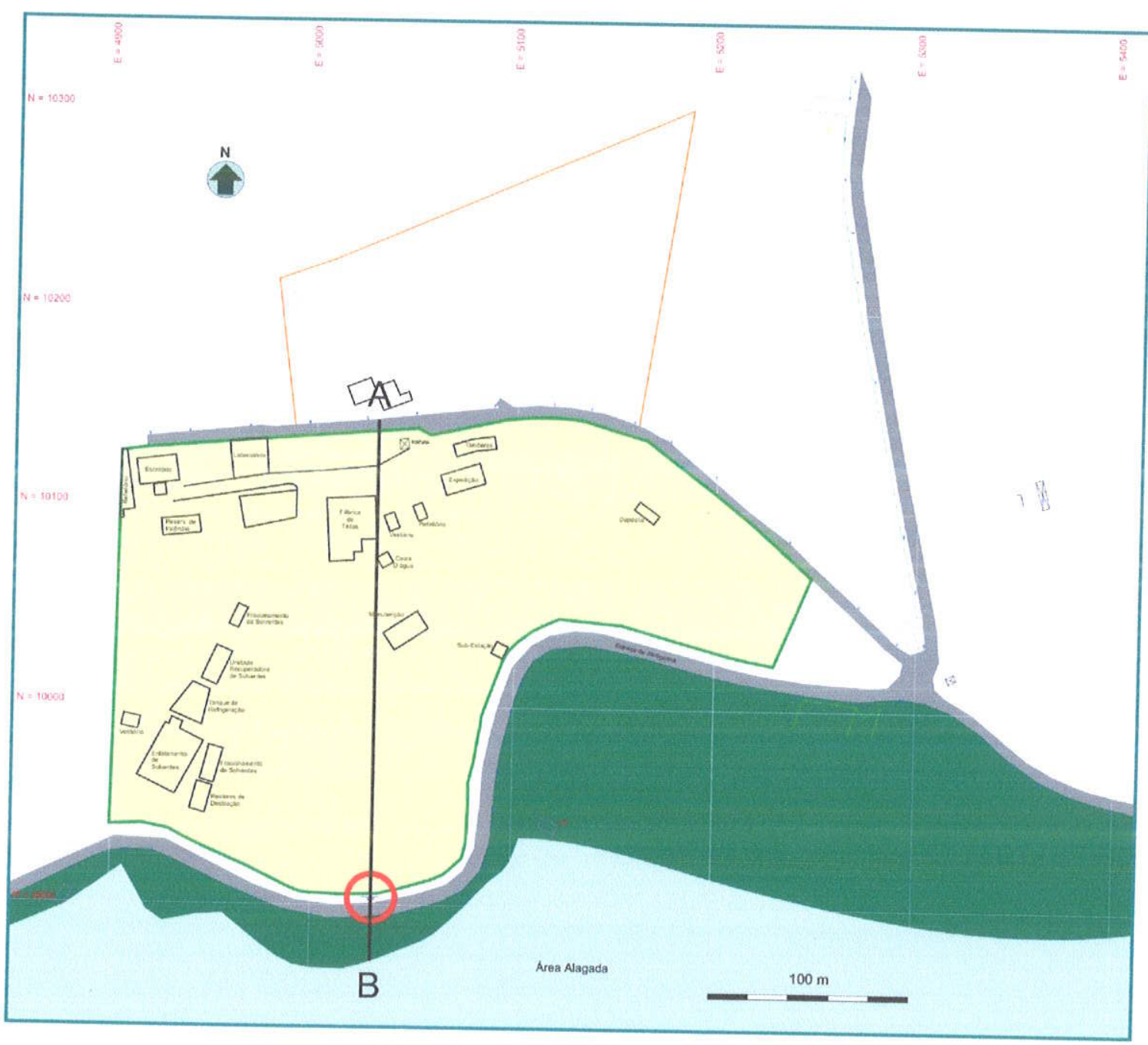


Figura 27. Seção estratigráfica A-B

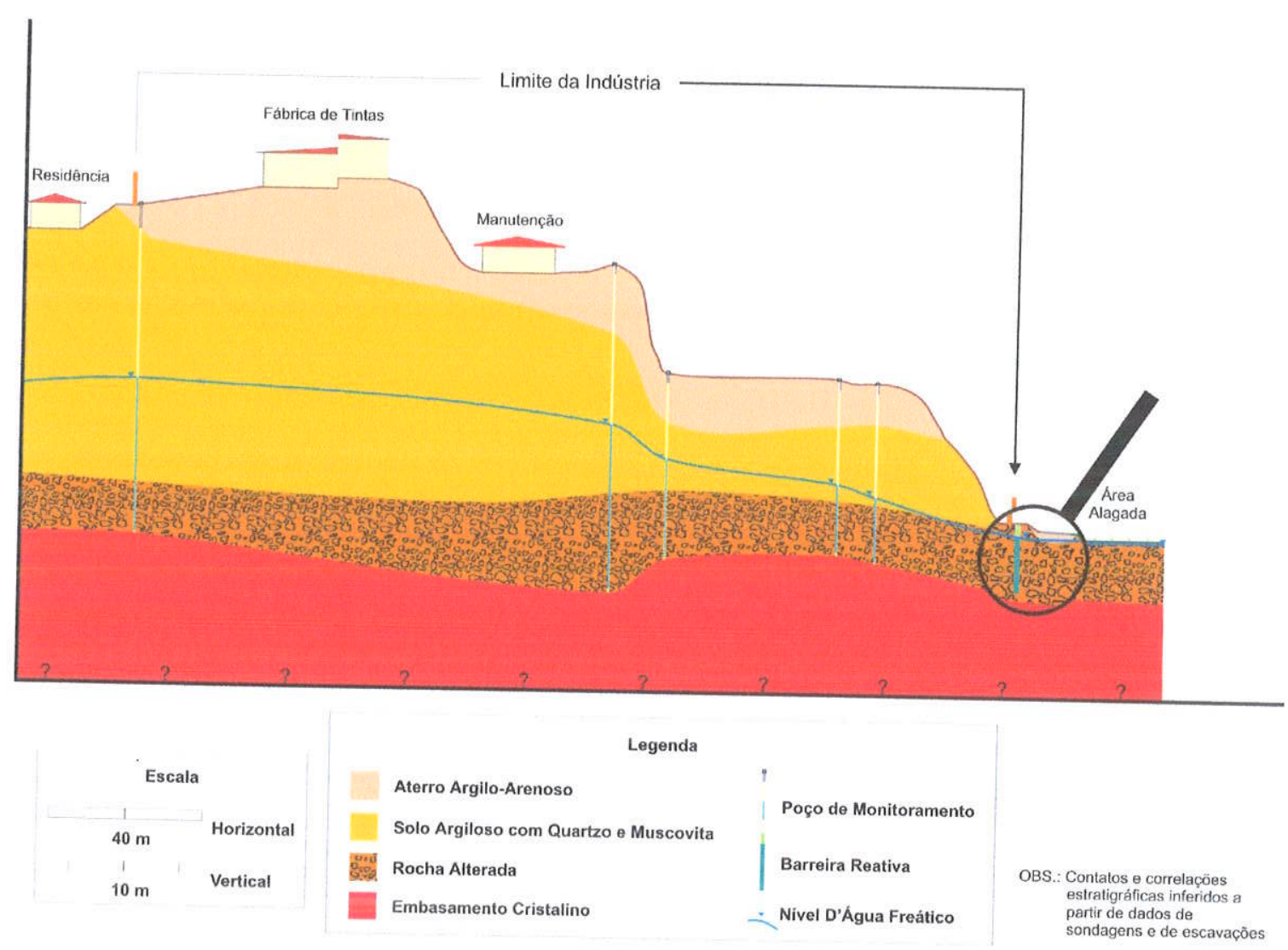

A base da Barreira reativa ficou inserida, de acordo com a Figura 27, em meio poroso constituído por solo derivado de alteração de rocha, sendo considerado para efeito do estudo o seu assentamento sob o topo da camada impermeável (o embasamento cristalino é pouco fraturado na região estudada), no entanto, com a possibilidade de fluxo eventual sob o sistema de remediação. 


\subsection{Monitoramento do Sistema Funnel and Gate}

\subsubsection{Malha de Monitoramento}

Para monitoramento da eficiência da barreira reativa foram instalados inicialmente dois PMs, sendo um a montante, denominado PM SR01 M e instalado a cerca de 4,0 $\mathrm{m}$ de distância da face norte da barreira reativa e outro a jusante, denominado PM SR02 $\mathrm{J}$ e distante cerca de 1,0 $\mathrm{m}$ da face sul da barreira.

O sistema de monitoramento foi completado quando foram instalados os poços PM SR01 J e PM SR01 B, instalados a 6,0 $\mathrm{m}$ da parede sul da barreira reativa e no interior da barreira reativa, respectivamente.

O equipamento utilizado na perfuração foi trado mecanizado, havendo necessidade de utilização de alavancas para prosseguimento do furo até profundidades abaixo do limite de perfuração em solo de alteração de rocha pouco alterada.

Para averiguação da eficiência do processo de degradação ocasionado pela inserção da barreira reativa, os dados obtidos do poço PM SR01 J foram descartados. Justifica-se o descarte dos dados obtidos através do PM SR01 J pelas seguintes características.

As bocas dos poços PM SR01M e PMSR01 J encontram-se praticamente no mesmo nível topográfico, e distam aproximadamente $9,0 \mathrm{~m}$ uma da outra. A máxima diferença determinada no monitoramento do nível d'água (NA) nos dois poços foi de $0,47 \mathrm{~m}$ (NA no PM SR01 M igual a $1,41 \mathrm{~m}$ a partir da boca do poço e igual a $0,94 \mathrm{~m}$ a partir da boca do PM SR01 J) e confere, com base nos dados apresentados, um gradiente hidráulico máximo de $5,22 \%$.

O solo local possui porosidade efetiva para fluxo (medida em laboratório) igual a $12 \%$, valor sugerido por Fetter (1988) como máximo para solos argiloarenosos e condizente com o tipo de solo identificado no local, e condutividade hidráulica (medida em campo) variando entre $8,1 \times 10^{-4} \mathrm{~cm} / \mathrm{s}$ e $3,0 \times 10^{-6} \mathrm{~cm} / \mathrm{s}$, o que confere à água subterrânea a velocidade máxima de fluxo de $0,3 \mathrm{~m} / \mathrm{dia}$. 
Desta forma, a água subterrânea deve percorrer o percurso entre os poços PM SR01 M E PM SR01 J em um tempo mínimo de cerca de 29 dias $e$, portanto, amostras coletadas no mesmo evento de monitoramento dos poços extremos de montante e jusante não refletem as eventuais interações provocadas pelo sistema de remediação avaliado.

$\mathrm{Na}$ velocidade da água subterrânea tem-se o menor tempo necessário para que a água percorra a distância entre os poços PM SR01 M e PM SR01 J, mas a velocidade de transporte dos contaminantes orgânicos não atinge esta velocidade em função dos fatores de retardamento decorrentes da presença de matéria orgânica no meio avaliado (Salles 1999).

Além da distância e do tempo necessário para que a água subterrânea a percorra, outro fator importante colabora para o descarte dos dados obtidos no monitoramento do PM SR01 J. As dimensões laterais das barreiras reativa e impermeáveis não permitem afirmar que o poço distante cerca de 6,0 $\mathrm{m}$ de sua parede sul intercepte apenas a água após a passagem pela zona reativa, ou seja, a configuração do fluxo local provavelmente faz com que haja interceptação de água subterrânea e contaminantes que passaram ao lado do sistema piloto de remediação. Desta forma, os dados monitorados no PM SR01 J, para a finalidade deste estudo, não são confiáveis.

Com base nas informações apresentadas, a configuração final da malha de poços de monitoramento ficou como apresentada na Figura 28. 
Figura 28. Seção local com os poços de monitoramento do sistema de remediação

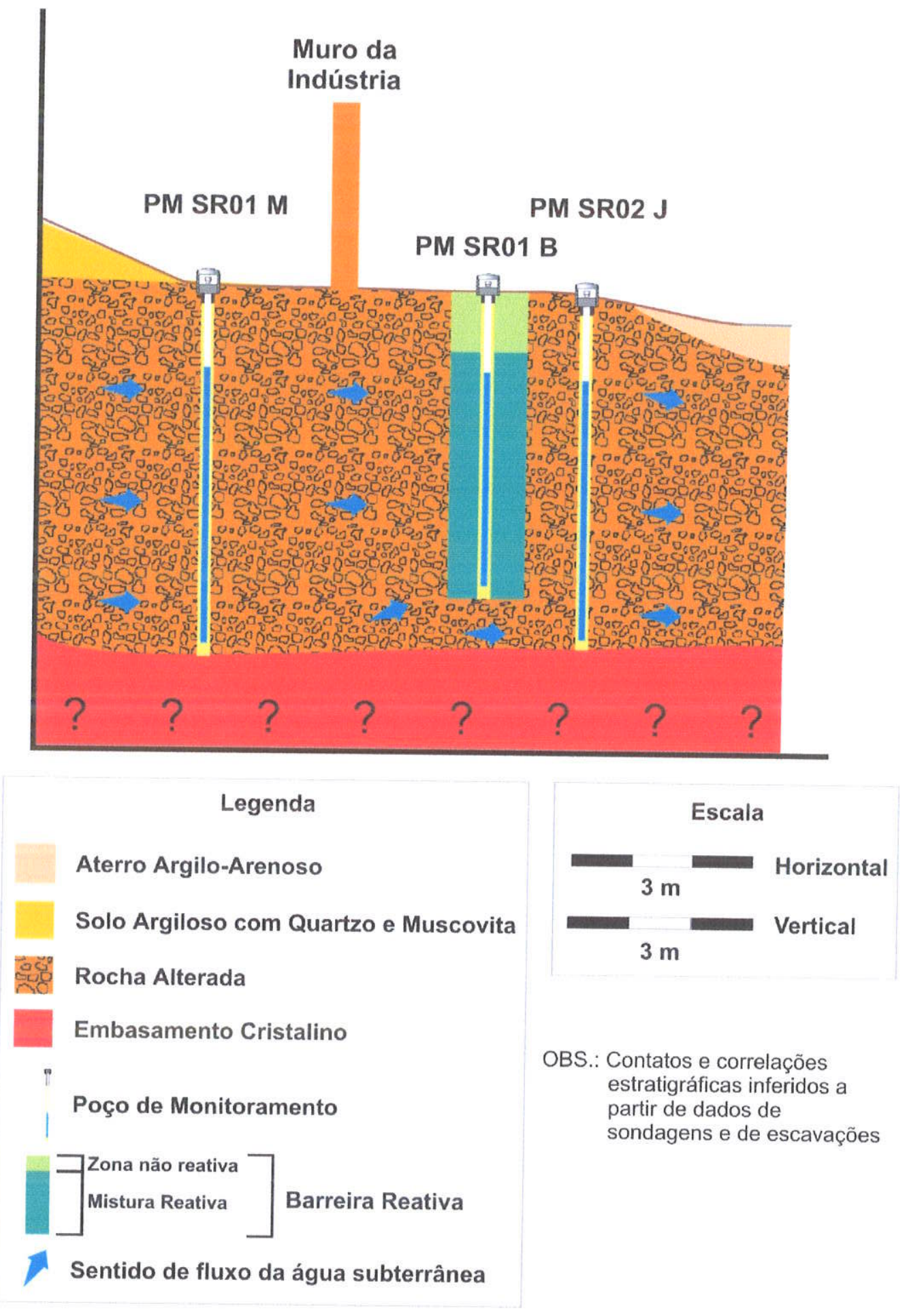

Considerando ainda a velocidade de 0,3 m/dia, estima-se que a água subterrânea percorra o trajeto entre o PM SR 01 M e o PM SR 02 J, distantes cerca de 5,0 m um do outro, em cerca de 16 dias. Este dado permite afirmar que, possivelmente, amostras coletadas do PM SR $01 \mathrm{M}$ em um evento de 
monitoramento deverão ser interceptadas no PM SR $02 \mathrm{~J}$ apenas no evento seguinte, por isso, a comparação dos resultados para avaliação da eficiência da remediação não se dá necessariamente no mesmo evento de amostragem.

\subsubsection{Parâmetros de Monitoramento}

Apesar do sistema de remediação ter sido monitorado desde o mês inicial de instalação, nem todos os parâmetros foram analisados desde os primeiros eventos.

Para a interpretação neste trabalho foram selecionados os compostos de interesse que pudessem indicar uma seqüência lógica de degradação, de forma que pudesse ser avaliada eficiência da barreira reativa. Desta forma, selecionaram-se compostos dentre aqueles analisados pelo laboratório CEIMIC Análises Ambientais S/C Ltda para determinação de compostos orgânicos voláteis (VOCs, do inglês volatile organic compounds) pelo método EPA 8260 da USEPA (United States Environmental Protection Agency).

Ainda assim, a partir do terceiro evento de monitoramento houve uma modificação na lista de VOCs analisados, sendo substituídas as análises de 1,2-dicloroeteno por análises de trans-1,2-dicloroeteno e cis-1,2-dicloroeteno. A relaçâo final de VOCs selecionados para verificação da eficiência do projeto de remediação adotado é apresentada na Tabela 5.

Tabela 5. Relação dos compostos orgânicos voláteis (VOC) selecionados para avaliação do sistema de remediação

\begin{tabular}{|c|c|c|}
\hline Seqüiência de Etanos & Seqüència de Etenos & $\begin{array}{l}\text { Seqüència do tetracloreto } \\
\text { de carbono }\end{array}$ \\
\hline $1,1,2,2$ tetracloroetano & tetracloroeteno & tetracloreto de carbono \\
\hline $1,1,1$ tricloroetano & tricloroeteno & clorofórmio \\
\hline $1,1,2$ tricloroetano & 1,1 dicloroeteno & cloreto de metileno \\
\hline 1,2 dicloroetano & 1,2 dicloroeteno & \\
\hline 1,1 dicloroetano & Cis 1,2 dicloroeteno & \\
\hline \multirow[t]{2}{*}{ cloroetano } & trans 1,2 dicloroeteno & \\
\hline & cloreto de vinila & \\
\hline
\end{tabular}


As amostras de água subterrânea foram coletadas com amostradores individuais em polietileno, seguindo-se os procedimentos de amostragem descritos em ABNT NBR 13.895 (1997). As amostras coletadas foram analisadas seguindo-se os métodos 8020 - Head Space e CETESB - 4.800 M791t para determinação dos compostos orgânicos voláteis selecionados inicialmente como compostos de interesse.

Em campo, no ato da coleta das amostras de água subterrânea, foram efetuadas medidas para determinação de $\mathrm{pH}$. Eh e temperatura e em laboratório as amostras de água subterrânea foram analisadas para determinação das concentrações de ferro total, ferro bivalente, ferro trivalente e sólidos totais dissolvidos. 


\section{RESULTADOS OBTIDOS E DISCUSSÃO}

A origem da contaminação e as atividades da indústria (fabricação de solventes a partir de matérias primas diversas, como borra de tintas) não permitem definir a composição da pluma inicial de contaminantes, desta forma inviabilizando o balanço de massa para avaliar a quantidade de contaminantes degradados pelo sistema de remediação adotado.

No entanto, algumas considerações a este respeito podem ser feitas com base nas concentrações determinadas nos poços de monitoramento instalados para acompanhamento do processo de remediação.

Os compostos analisados foram divididos em grupos que representam possíveis rotas de degradação, indicadas pelas seqüências de etenos, etanos e tetracloreto de carbono.

\subsection{Monitoramento das Concentrações de Etenos}

As Tabelas e Gráficos apresentados a seguir ilustram as concentrações de Etenos obtidas na seqüência cronológica de monitoramento dos poços, sendo:

Verde - Cor atribuída aos dados do PM SR01 M;

Amarela - Cor atribuída aos dados do PM SR01 B;

Laranja - Cor atribuída aos dados do PM SR02 J;

Nas Tabelas, dados em branco indicam ausência do contaminante em questão em concentração superior ao limite de detecção do aparelho e células na cor cinza indicam que o composto não foi analisado naquele evento de monitoramento. 
Tabela 6. Resultados analíticos da sequência dos Etenos Concentrações em $\mu \mathrm{g} / \mathrm{L}$

PM SR01 M; PM SR01 B; PM SR02 J

\begin{tabular}{|l|l|l|l|}
\cline { 2 - 4 } \multicolumn{1}{c|}{} & \multicolumn{3}{c|}{ Mês 1 } \\
\hline composto & PMSR01M & PMSR01B & PMSR02J \\
\hline tetracloroeteno & & & \\
\hline tricloroeteno & & & \\
\hline 1,1 dicloroeteno & & & \\
\hline 1,2 dicloroeteno & & & \\
\hline cis 1,2 dicloroeteno & & & \\
\hline trans 1,2 dicloroeteno & & & \\
\hline cloreto de vinila & & & \\
\hline
\end{tabular}
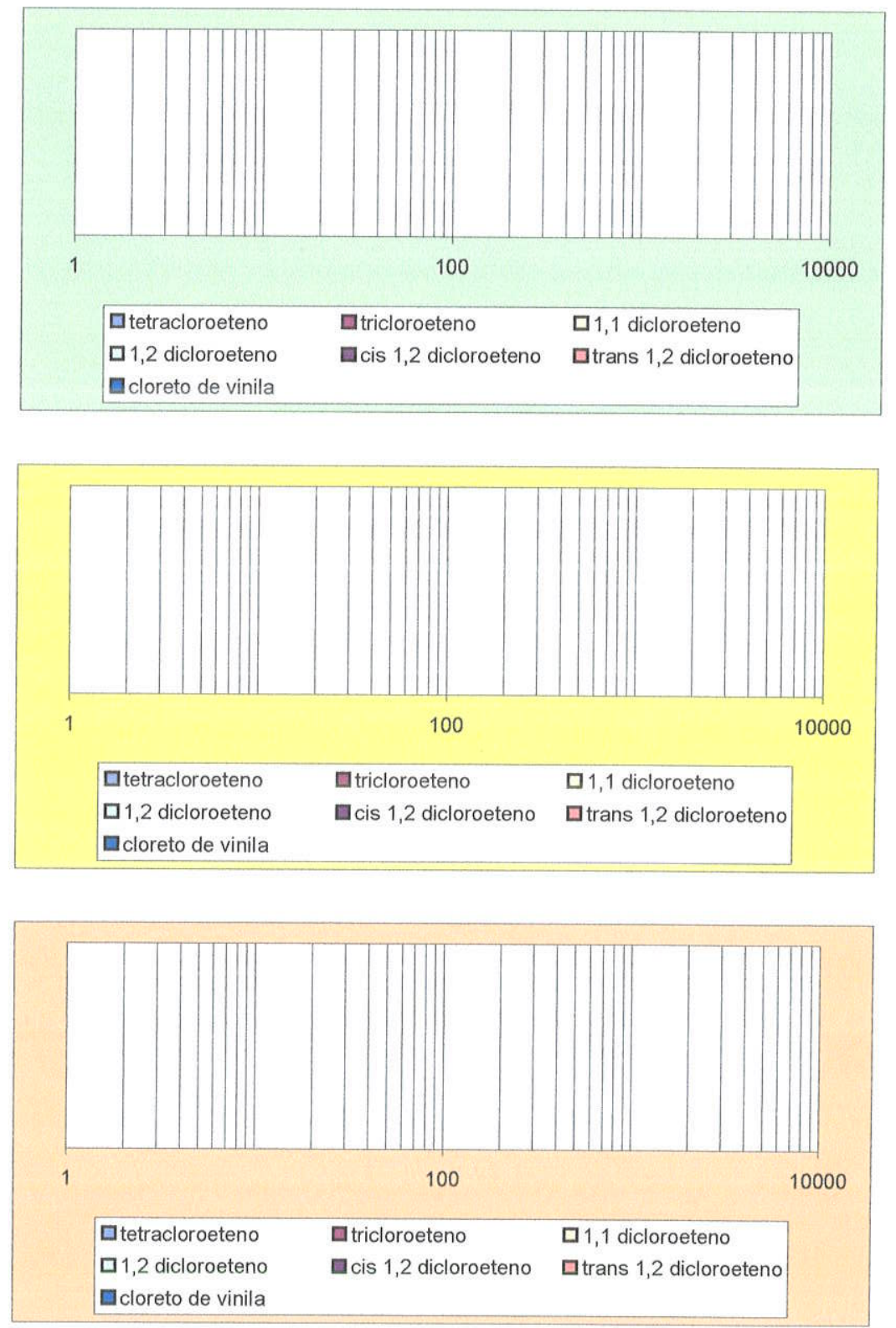
Tabela 7. Resultados analíticos da sequência dos Etenos Concentrações em $\mu \mathrm{g} / \mathrm{L}$

PM SR01 M; PM SR01 B; PM SR02 J

\begin{tabular}{|l|c|c|c|}
\cline { 2 - 4 } \multicolumn{1}{c|}{} & \multicolumn{3}{c|}{ Mês 2 } \\
\hline composto & PMSR01M & PMSR01B & PMSR02J \\
\hline tetracloroeteno & & & \\
\hline tricloroeteno & & & \\
\hline 1,1 dicloroeteno & & & \\
\hline 1,2 dicloroeteno & 62 & & \\
\hline cis 1,2 dicloroeteno & & & \\
\hline trans 1,2 dicloroeteno & & & \\
\hline cloreto de vinila & 95 & & \\
\hline
\end{tabular}
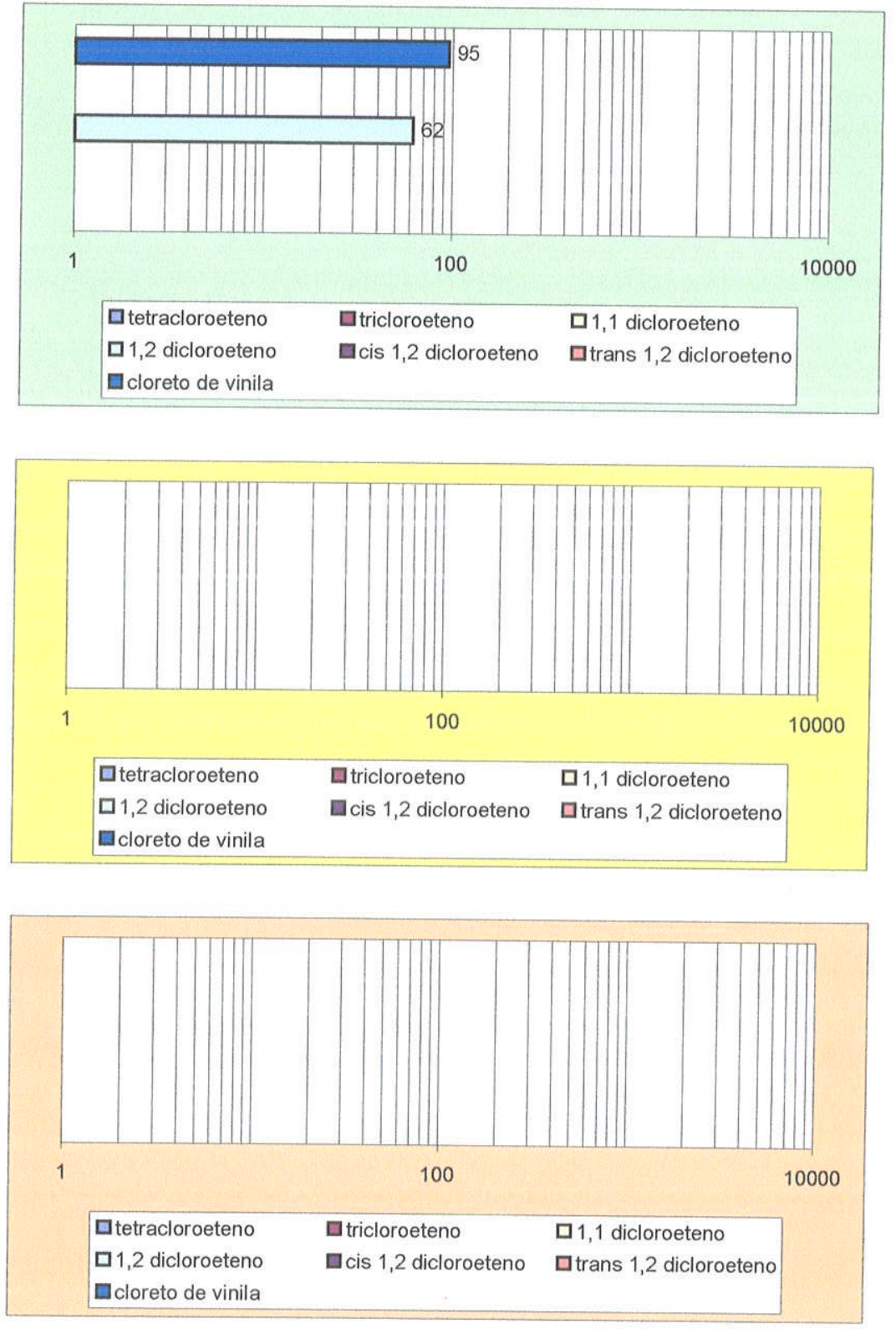
Tabela 8. Resultados analíticos da sequência dos Etenos

Concentrações em $\mu \mathrm{g} / \mathrm{L}$

PM SR01 M; PM SR01 B; PM SR02 J

\begin{tabular}{|l|c|c|c|}
\cline { 2 - 4 } \multicolumn{1}{c|}{} & \multicolumn{3}{c|}{ Mês 3 } \\
\hline composto & PMSR01M & PMSR01B & PMSR02J \\
\hline tetracloroeteno & & & \\
\hline tricloroeteno & 35 & & \\
\hline 1,1 dicloroeteno & 155 & & \\
\hline 1,2 dicloroeteno & & & \\
\hline cis 1,2 dicloroeteno & 38 & 13 & \\
\hline trans 1,2 dicloroeteno & 118 & 29 & \\
\hline cloreto de vinila & 174 & 38 & \\
\hline
\end{tabular}
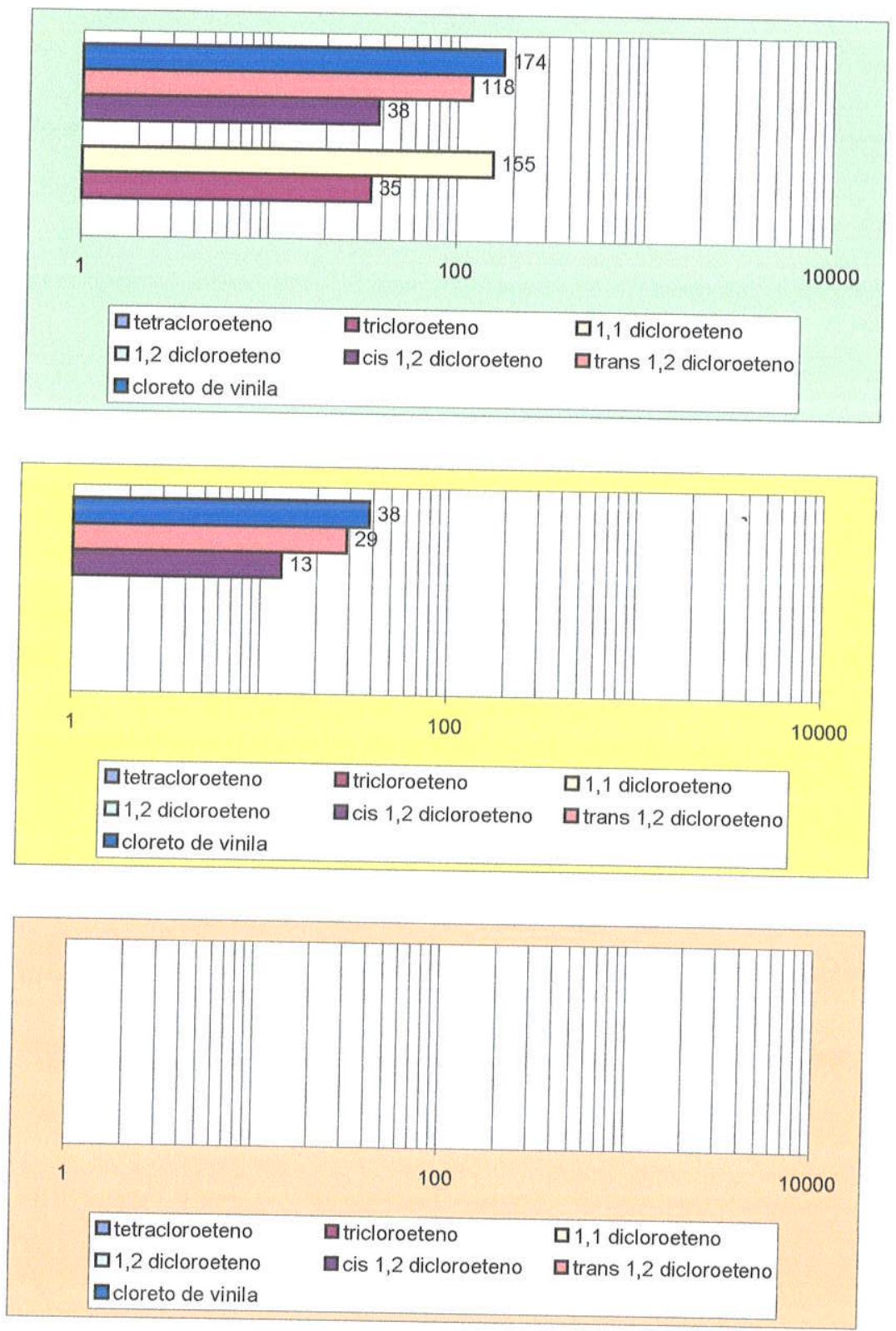
Tabela 9. Resultados analíticos da sequência dos Etenos Concentrações em $\mu \mathrm{g} / \mathrm{L}$

PM SR01 M; PM SR01 B; PM SR02 J

\begin{tabular}{|l|c|c|c|}
\cline { 2 - 4 } \multicolumn{1}{c|}{} & \multicolumn{3}{c|}{ Mês 4 } \\
\hline composto & PMSR01M & PMSR01B & PMSR02J \\
\hline tetracloroeteno & & & \\
\hline tricloroeteno & 31 & 8 & \\
\hline 1,1 dicloroeteno & 62 & & \\
\hline 1,2 dicloroeteno & & & \\
\hline cis 1,2 dicloroeteno & 34 & 57 & \\
\hline trans 1,2 dicloroeteno & 92 & 101 & \\
\hline cloreto de vinila & 104 & 108 & \\
\hline
\end{tabular}
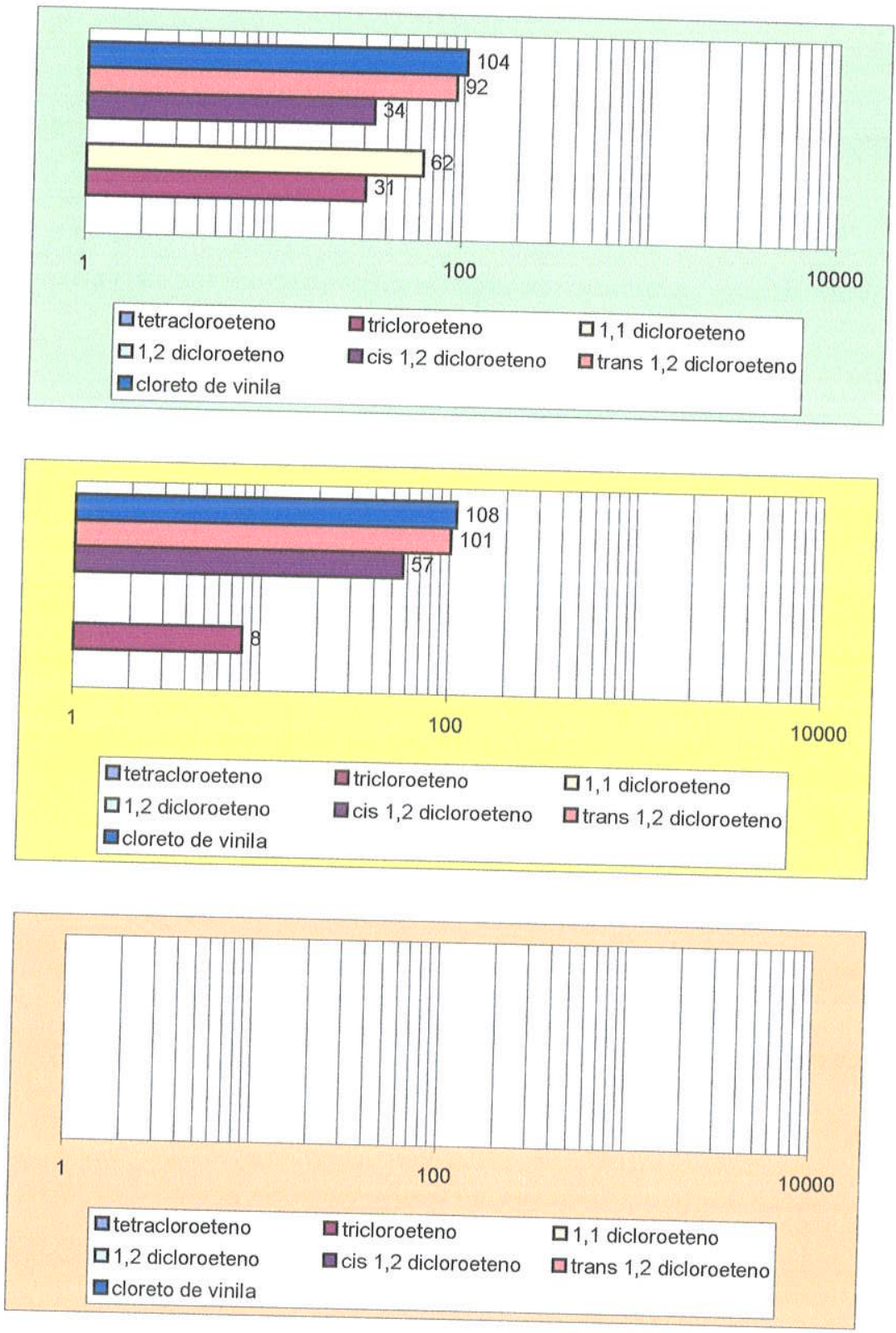
Tabela 10. Resultados analíticos da sequência dos Etenos

Concentrações em $\mu \mathrm{g} / \mathrm{L}$

PM SR01 M; PM SR01 B; PM SR02 J

\begin{tabular}{|l|c|c|c|}
\cline { 2 - 4 } \multicolumn{1}{c|}{} & \multicolumn{3}{c|}{ Mês 5 } \\
\hline composto & PMSR01M & PMSR01B & PMSR02J \\
\hline tetracloroeteno & & & \\
\hline tricloroeteno & 10 & 7 & \\
\hline 1,1 dicloroeteno & & 6 & \\
\hline 1,2 dicloroeteno & & & \\
\hline cis 1,2 dicloroeteno & 7 & 62 & \\
\hline trans 1,2 dicloroeteno & & 95 & \\
\hline cloreto de vinila & 6 & 142 & \\
\hline
\end{tabular}
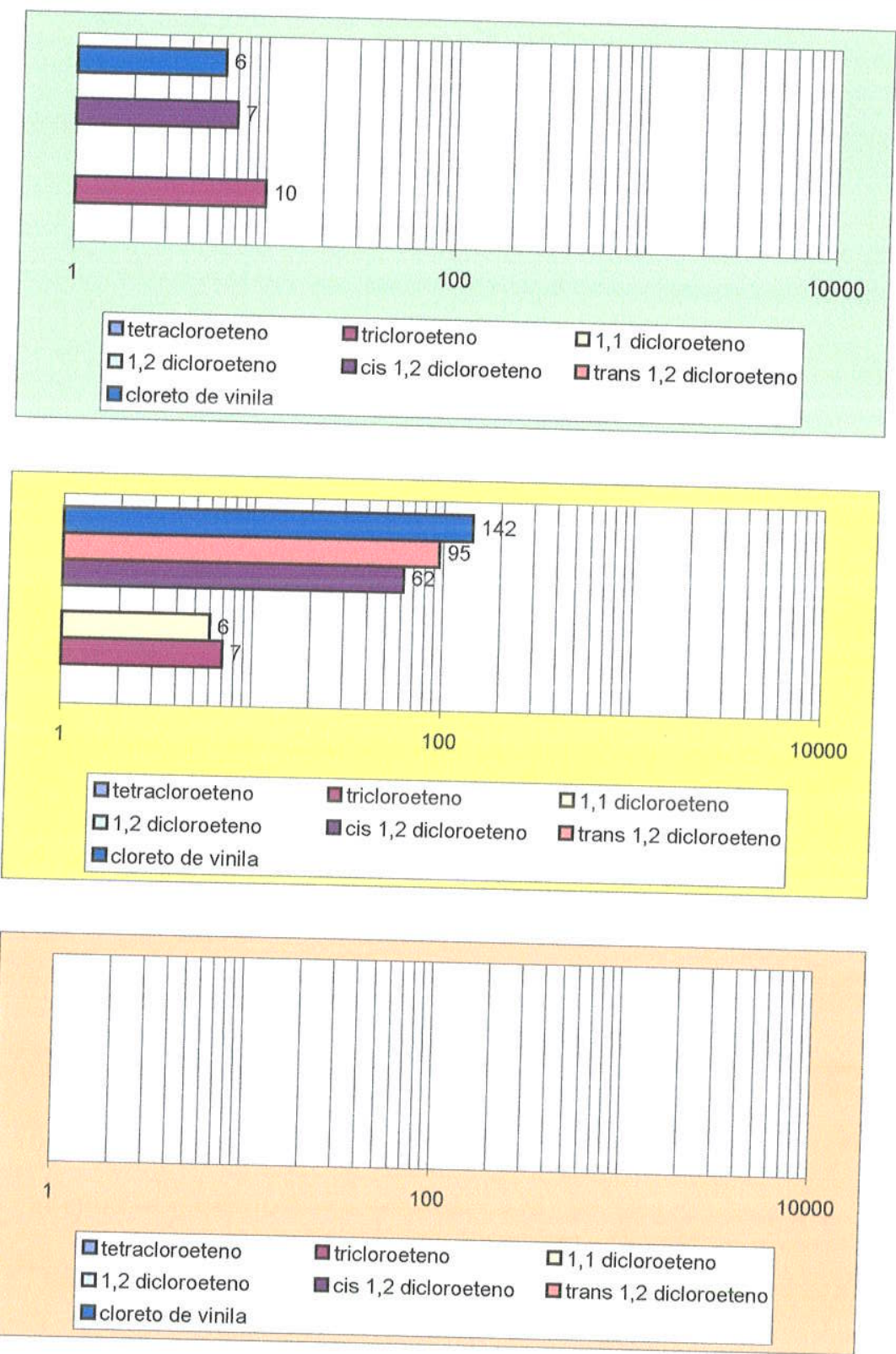
Tabela 11. Resultados analíticos da sequência dos Etenos

Concentrações em $\mu \mathrm{g} / \mathrm{L}$

PM SR01 M; PM SR01 B; PM SR02 J

\begin{tabular}{|l|c|c|c|}
\cline { 2 - 4 } \multicolumn{1}{c|}{} & \multicolumn{3}{c|}{ Mês 6 } \\
\hline composto & PMSR01M & PMSR01B & PMSR02J \\
\hline tetracloroeteno & & & \\
\hline tricloroeteno & 32 & & \\
\hline 1,1 dicloroeteno & 18 & & \\
\hline 1,2 dicloroeteno & & & \\
\hline cis 1,2 dicloroeteno & 44 & 66 & \\
\hline trans 1,2 dicloroeteno & 113 & 96 & \\
\hline cloreto de vinila & 108 & 109 & \\
\hline
\end{tabular}
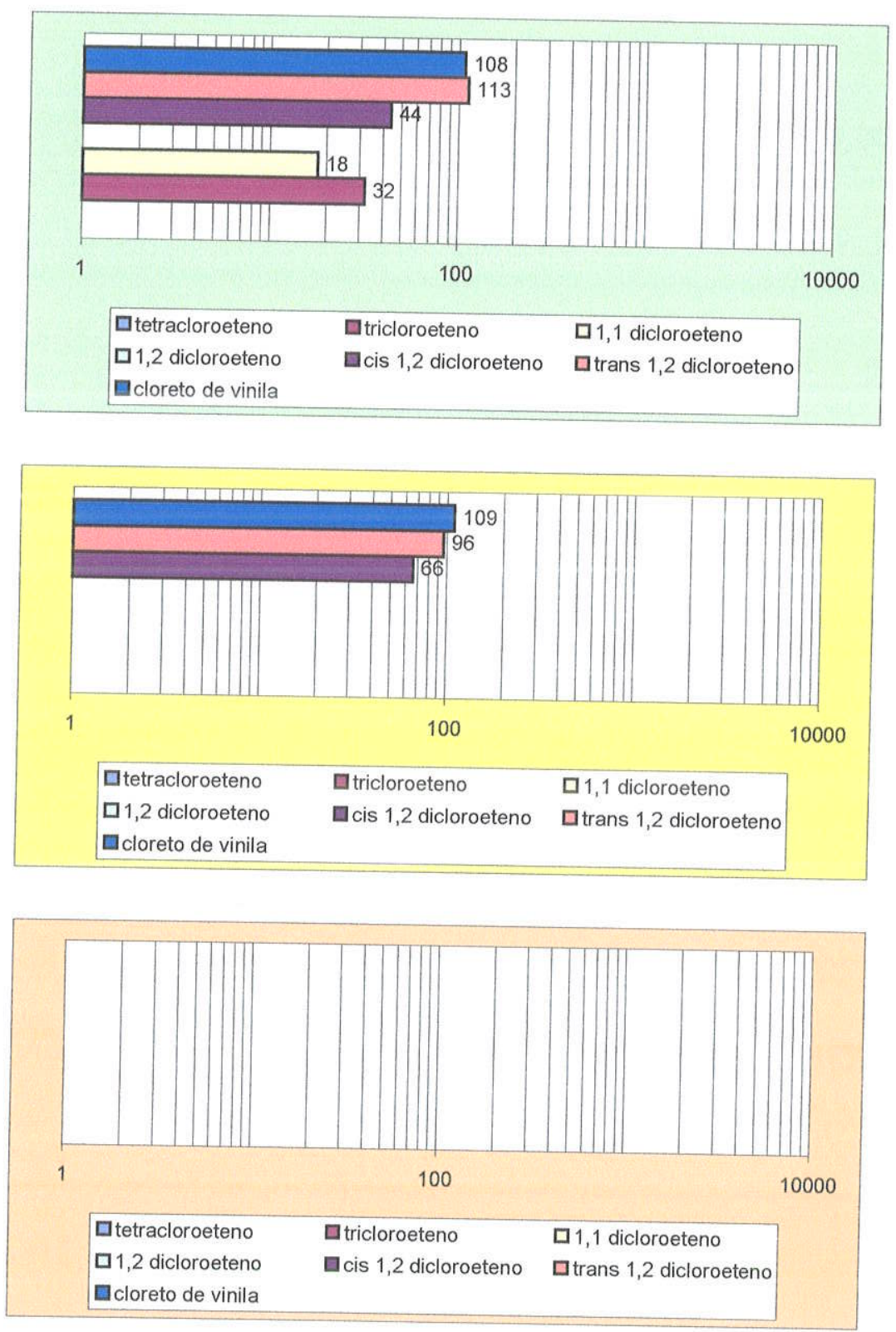
Tabela 12. Resultados analíticos da sequência dos Etenos

Concentrações em $\mu \mathrm{g} / \mathrm{L}$

PM SR01 M; PM SR01 B; PM SR02 J

\begin{tabular}{|l|c|c|c|}
\cline { 2 - 4 } \multicolumn{1}{c|}{} & \multicolumn{3}{c|}{ Mês 7 } \\
\hline composto & PMSR01M & PMSR01B & PMSR02J \\
\hline tetracloroeteno & & & \\
\hline tricloroeteno & & & \\
\hline 1,1 dicloroeteno & & & \\
\hline 1,2 dicloroeteno & & & \\
\hline cis 1,2 dicloroeteno & 16 & & \\
\hline trans 1,2 dicloroeteno & 34 & 12 & \\
\hline cloreto de vinila & 136 & 55 & \\
\hline
\end{tabular}
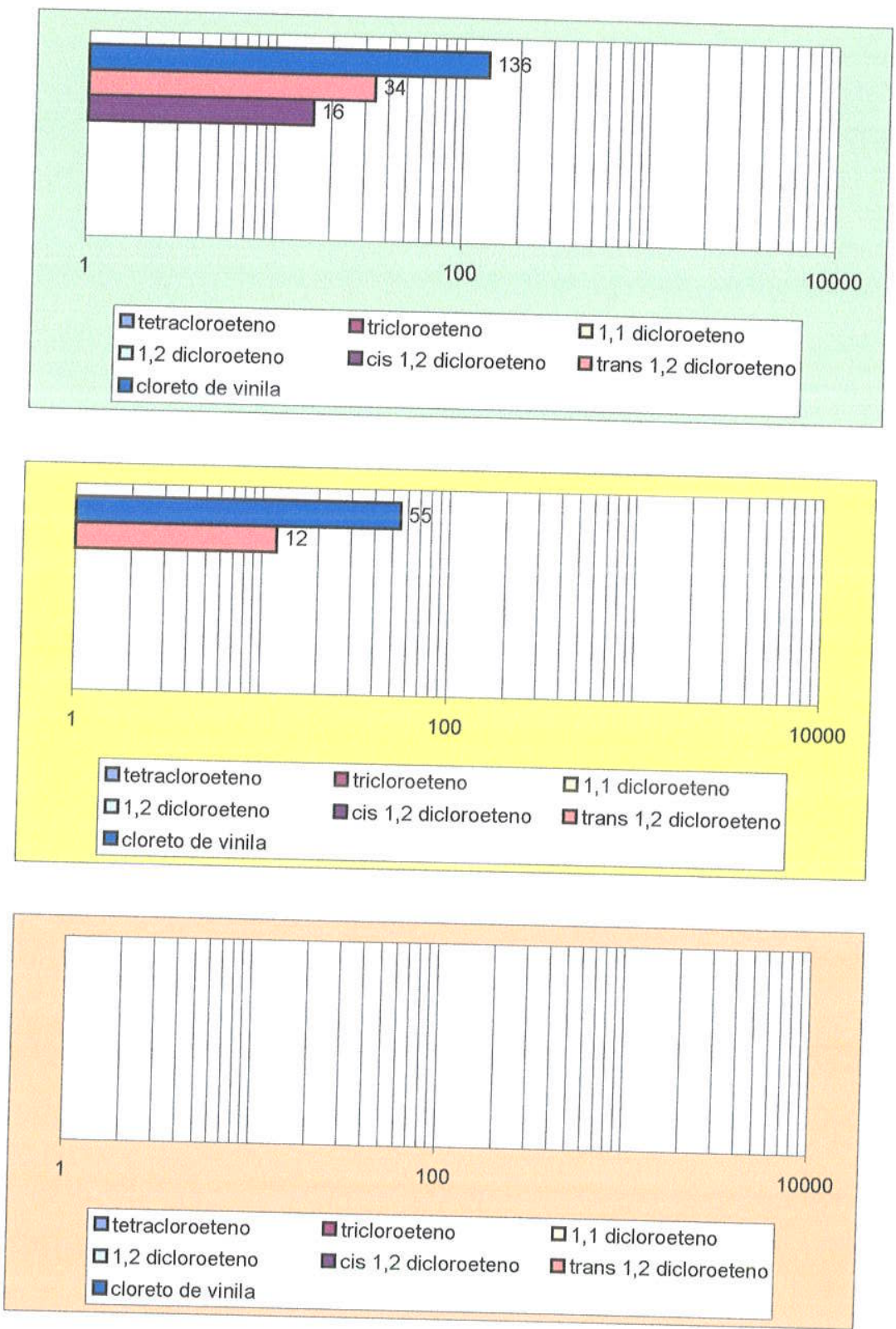
Tabela 13. Resultados analíticos da sequência dos Etenos

Concentrações em $\mu \mathrm{g} / \mathrm{L}$

PM SR01 M; PM SR01 B; PM SR02 J

\begin{tabular}{|l|c|c|c|}
\cline { 2 - 4 } \multicolumn{1}{c|}{} & \multicolumn{3}{c|}{ Mês 8 } \\
\hline composto & PMSR01M & PMSR01B & PMSR02J \\
\hline tetracloroeteno & & & \\
\hline tricloroeteno & 118 & & \\
\hline 1,1 dicloroeteno & 147 & & \\
\hline 1,2 dicloroeteno & & & \\
\hline trans 1,2 dicloroeteno & 594 & 72 & \\
\hline cloreto de vinila & 323 & 110 & \\
\hline
\end{tabular}
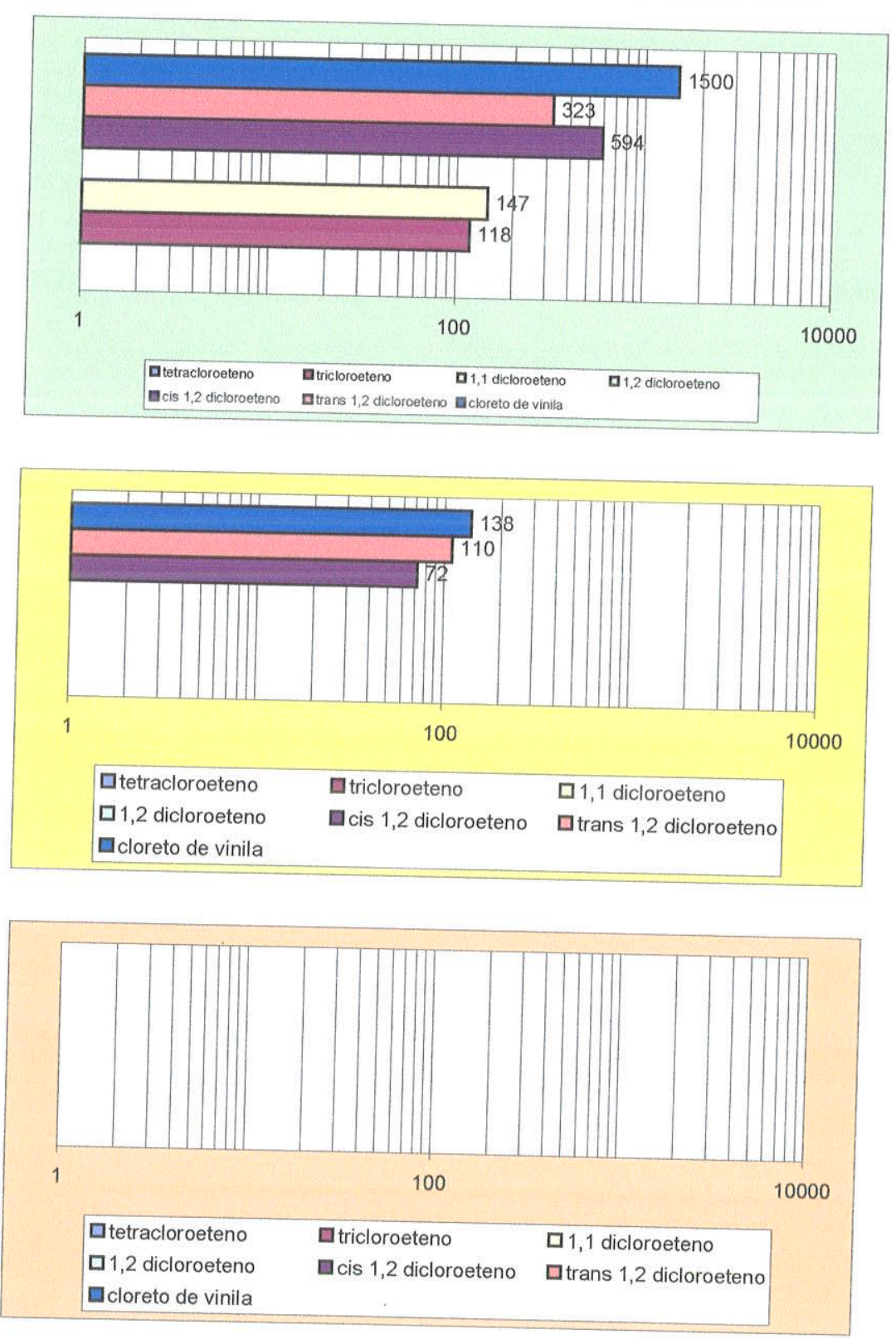
Tabela 14. Resultados analíticos da sequência dos Etenos Concentrações em $\mu \mathrm{g} / \mathrm{L}$

PM SR01 M; PM SR01 B; PM SR02 J

\begin{tabular}{|l|c|c|c|}
\cline { 2 - 4 } \multicolumn{1}{c|}{} & \multicolumn{3}{c|}{ Mês 9 } \\
\hline composto & PMSR01M & PMSR01B & PMSR02J \\
\hline tetracloroeteno & & & \\
\hline tricloroeteno & & & \\
\hline 1,1 dicloroeteno & & & \\
\hline 1,2 dicloroeteno & & & \\
\hline cis 1,2 dicloroeteno & 6 & & \\
\hline trans 1,2 dicloroeteno & 250 & 17 & \\
\hline cloreto de vinila & 6725 & 67 & \\
\hline
\end{tabular}
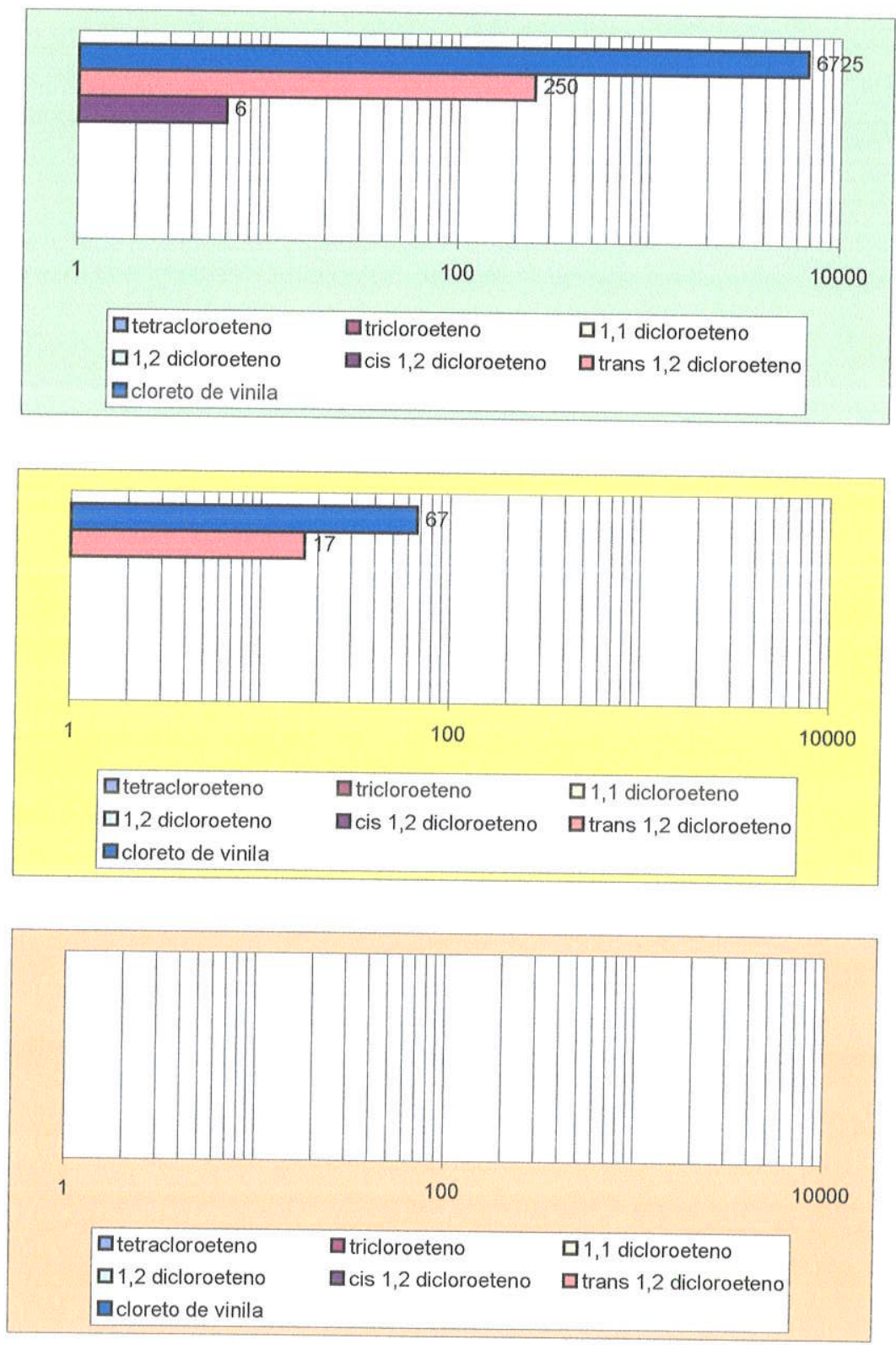
Tabela 15. Resultados analíticos da sequência dos Etenos Concentrações em $\mu \mathrm{g} / \mathrm{L}$

PM SR01 M; PM SR01 B; PM SR02 J

\begin{tabular}{|l|c|c|c|}
\hline & \multicolumn{3}{|c|}{ Mês 10 } \\
\hline composto & PMSR01M & PMSR01B & PMSR02J \\
\hline tetracloroeteno & 4 & & \\
\hline tricloroeteno & 12 & 3 & \\
\hline 1,1 dicloroeteno & 6 & 4 & \\
\hline 1,2 dicloroeteno & & & \\
\hline cis 1,2 dicloroeteno & 13 & 34 & \\
\hline trans 1,2 dicloroeteno & 147 & 75 & \\
\hline cloreto de vinila & 3050 & 146 & \\
\hline
\end{tabular}
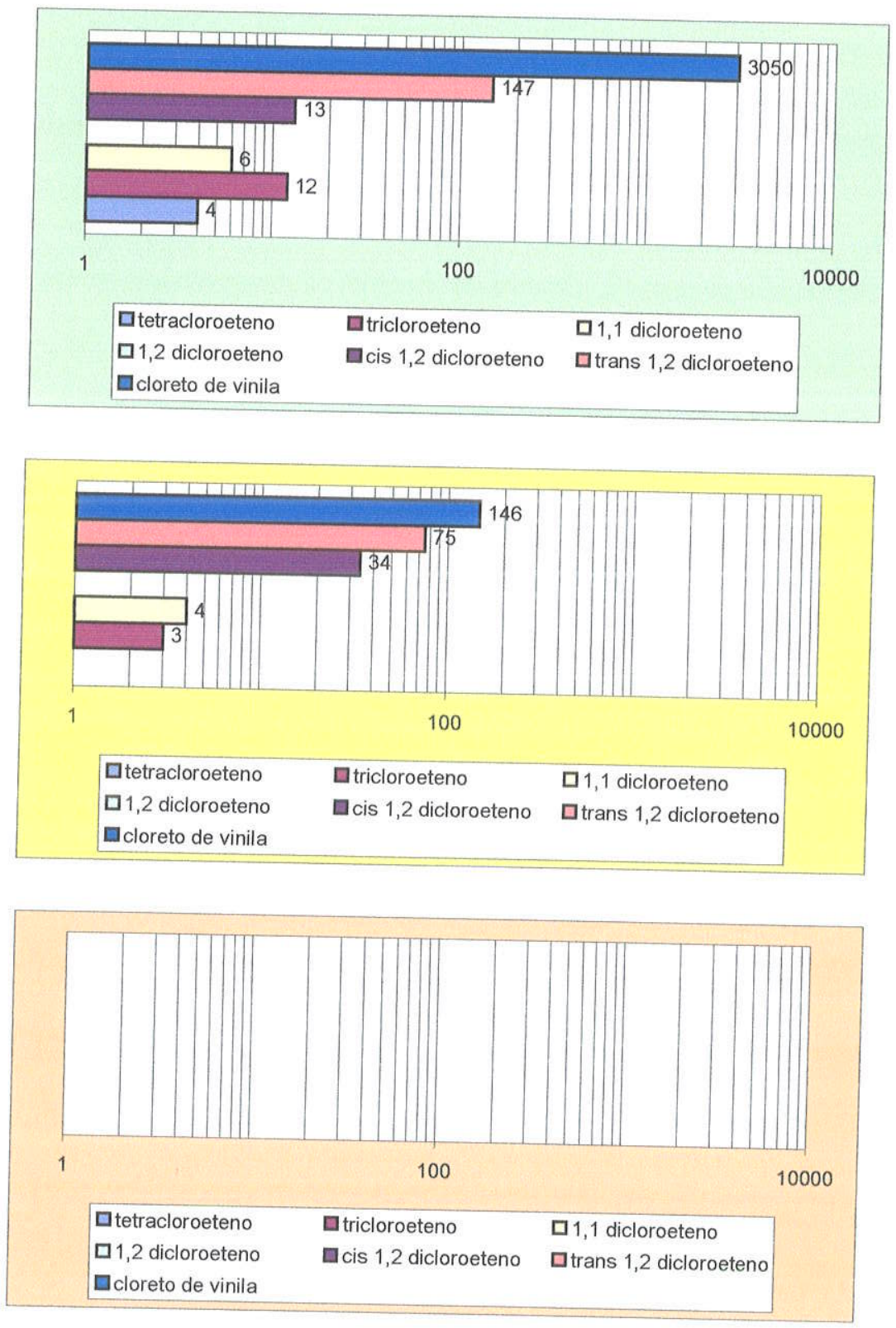
Tabela 16. Resultados analíticos da sequência dos Etenos

Concentrações em $\mu \mathrm{g} / \mathrm{L}$

PM SR01 M; PM SR01 B; PM SR02 J

\begin{tabular}{|l|c|c|c|}
\cline { 2 - 4 } \multicolumn{1}{c|}{} & \multicolumn{3}{c|}{ Mês 11 } \\
\hline composto & PMSR01M & PMSR01B & PMSR02J \\
\hline tetracloroeteno & 6 & & 116 \\
\hline tricloroeteno & 20 & & 178 \\
\hline 1,1 dicloroeteno & & 4 & 40 \\
\hline 1,2 dicloroeteno & & & 309 \\
\hline cis 1,2 dicloroeteno & 16 & 32 & 317 \\
\hline trans 1,2 dicloroeteno & 69 & 81 & 320 \\
\hline cloreto de vinila & 310 & 118 & \\
\hline
\end{tabular}
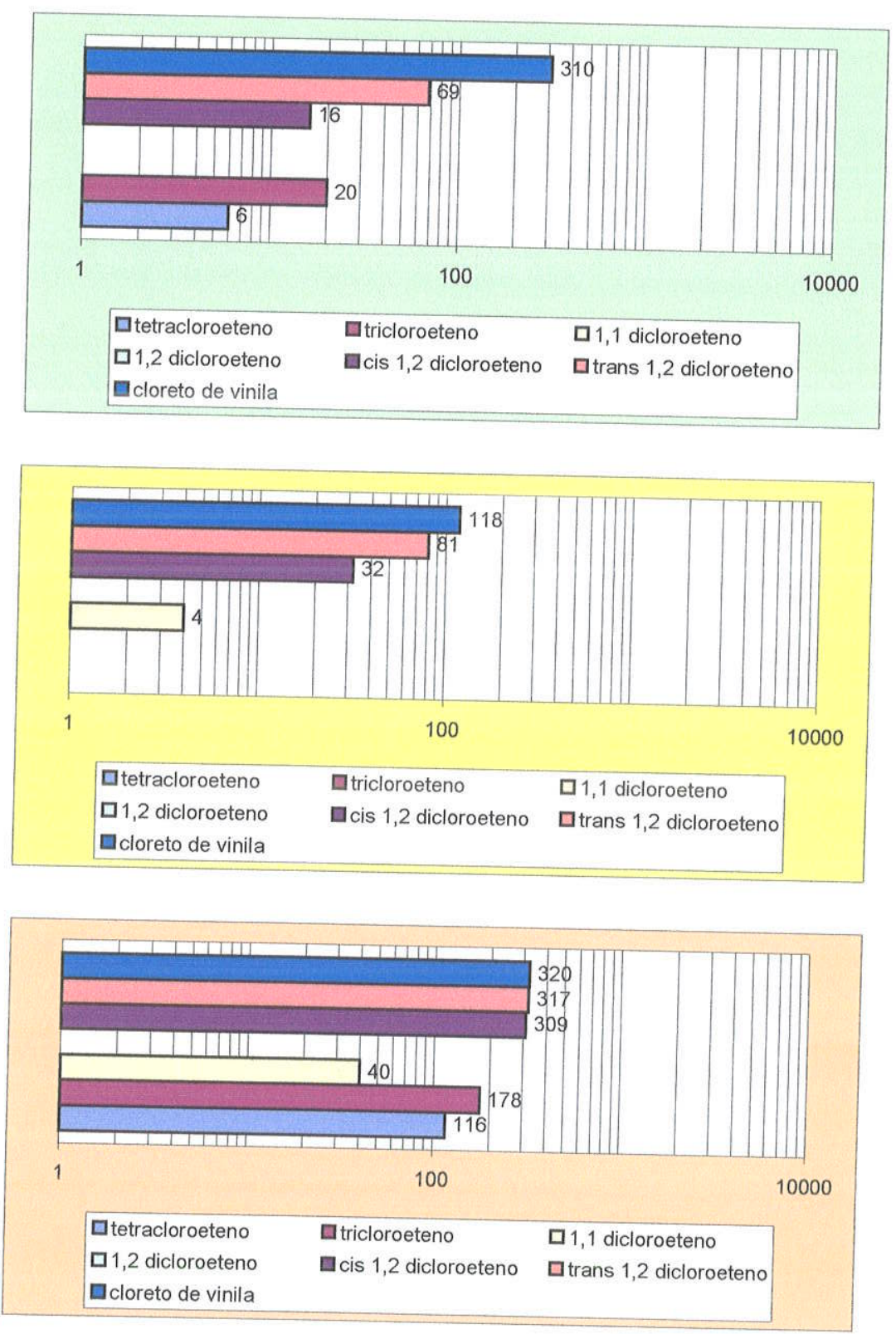
Tabela 17. Resultados analíticos da sequência dos Etenos Concentrações em $\mu \mathrm{g} / \mathrm{L}$

PM SR01 M; PM SR01 B; PM SR02 J

\begin{tabular}{|l|c|c|c|}
\cline { 2 - 4 } \multicolumn{1}{c|}{} & \multicolumn{3}{c|}{ Mês 12 } \\
\hline Composto & PMSR01M & PMSR01B & PMSR02J \\
\hline tetracloroeteno & & & \\
\hline tricloroeteno & & & \\
\hline 1,1 dicloroeteno & & & \\
\hline 1,2 dicloroeteno & & & \\
\hline cis 1,2 dicloroeteno & & & \\
\hline trans 1,2 dicloroeteno & 23 & 48 & \\
\hline cloreto de vinila & 280 & 73 & \\
\hline
\end{tabular}
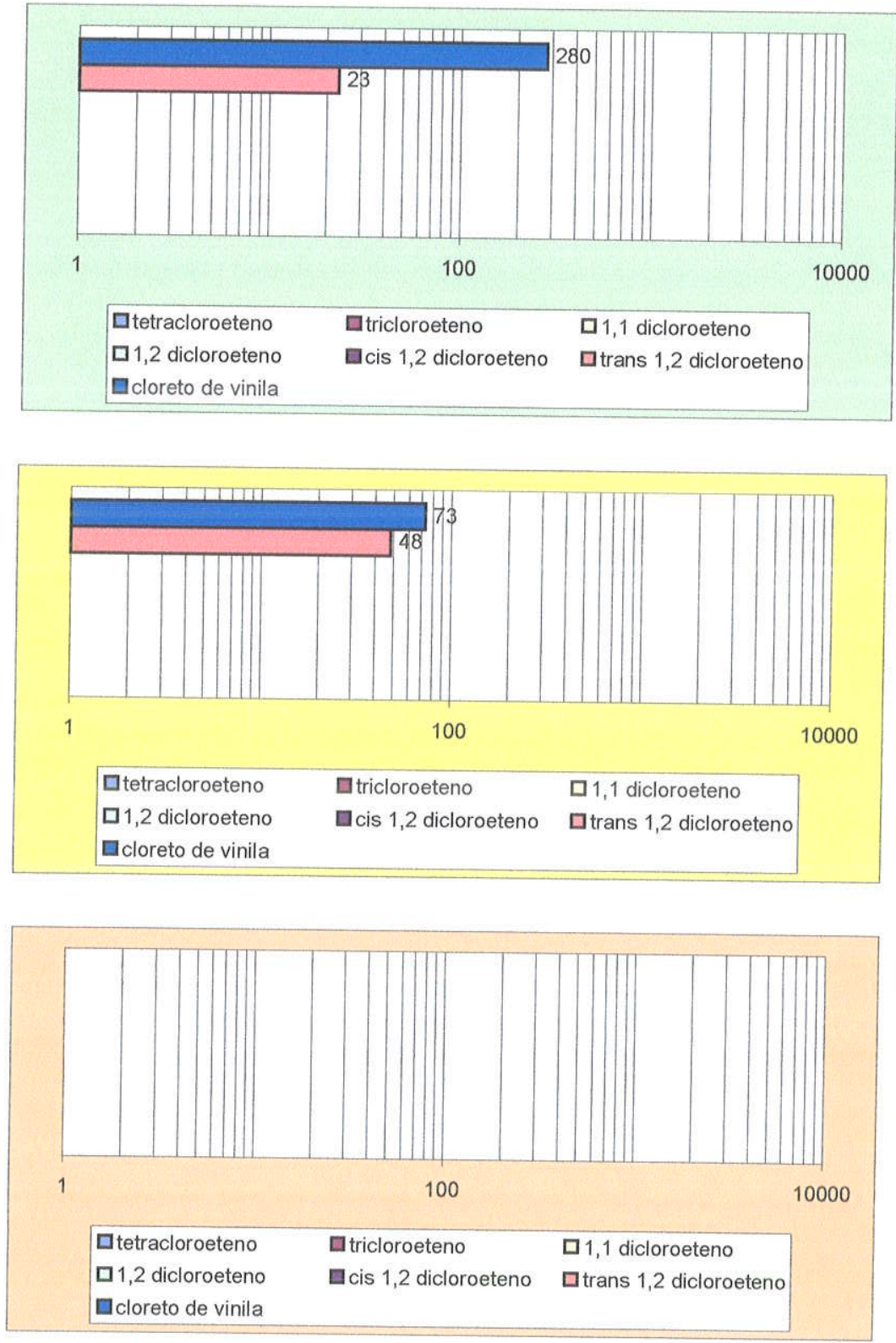
Ao longo do ano hidrológico em que foi realizado o monitoramento dos poços, foi excelente a eficiência do sistema de remediação na degradação de compostos clorados com duplas ligaç̃̃es em suas fórmulas estruturais (etenos).

A afirmação anterior é justificada por concentrações de tetracloroeteno, tricloroeteno, 1,1-dicloroteno, 1,2-dicloroeteno (soma das concentrações dos isômeros trans e cis) e cloreto de vinila freqüentemente identificadas nas amostras coletadas no poço de montante e nulas em todos as amostras do período coletadas no poço de jusante.

Com exceção do primeiro evento de monitoramento apresentado (Mês 1), que indicou ausência de contaminantes acima dos limites de detecção em todos os poços, o compostos cloreto de vinila foi identificado em todas as amostras do poço de montante, atingindo pico de concentração de $6.725 \mu \mathrm{g} / \mathrm{L}$ na amostra coletada no Mês 9 . Destaca-se que independente das concentrações determinadas no poço de montante, o composto cloreto de vinila foi eliminado totalmente na barreira reativa, não sendo observado no poço PM SR02 J.

A seqüencia dos resultados positivos é interrompida no evento de monitoramento do Mês 11, no qual as concentrações obtidas são anômalas $e$, para um mesmo contaminante, apresentam-se por vezes superiores no poço de jusante em relação ao poço de montante, como é o caso do cis 1,2 dicloroeteno.

Os resultados do evento seguinte de monitoramento, no Mês 12, no entanto, retomam a eficiência até então observada, o que permite inferir que os resultados do mês anterior foram originados a partir de algum erro de procedimento não descrito e possivelmente ocorrido no ato da amostragem ou no manuseio das amostras durante a etapa analítica.

Poderia ser considerada a hipótese de fluxo de água subterrânea contaminada acima da zona reativa da barreira, ocasionando a identificação de contaminantes no poço a jusante, mas esta hipótese pode ser descartada pelo fato de que os níveis d'água medidos em cada um dos poços de monitoramento encontraram-se, no Mês 11, nas maiores profundidades em 
comparação às medidas nos demais eventos.

O rebaixamento do nível d'água observado no evento de monitoramento do Mês 11 poderia ter ocasionado a passagem de contaminantes por sob a barreira reativa, indicando a não impermeabilização da camada de base, no entanto, por se tratar de fase dissolvida de contaminante, seria de se esperar que o mesmo ocorresse em outros eventos de monitoramento, mas a ausência de contaminantes no poço de jusante nos demais eventos permite descartar esta hipótese.

\subsection{Monitoramento das concentrações de Etanos}

Tal como apresentados para a seqüência de Etenos, as Tabelas e Gráficos apresentados a seguir apresentam e ilustram as concentrações de Etanos obtidas na seqüência cronológica de monitoramento dos poços, sendo:

Verde - Cor atribuída aos dados do PM SR01 M;

Amarela - Cor atribuída aos dados do PM SR01 B;

Laranja - Cor atribuída aos dados do PM SR02 J;

Reitera-se que, nas Tabelas, dados em branco indicam ausência do contaminante em questão em concentração superior ao limite de detecção do aparelho e células na cor cinza indicam que o composto não foi analisado naquele evento de monitoramento. 
Tabela 18. Resultados analíticos da sequência dos Etanos

Concentrações em $\mu \mathrm{g} / \mathrm{L}$

PM SR01 M; PM SR01 B; PM SR02 J

\begin{tabular}{|l|c|c|c|}
\cline { 2 - 4 } \multicolumn{1}{c|}{} & \multicolumn{3}{c|}{ Mês 1 } \\
\hline $1,1,2,2$ tetracloroetano & PMSR01M & PMSR01B & PMSR02J \\
\hline $1,1,1$ tricloroetano & & & \\
\hline $1,1,2$ tricloroetano & & & \\
\hline 1,2 dicloroetano & & & \\
\hline 1,1 dicloroetano & & & \\
\hline cloroetano & 32 & & 1100 \\
\hline
\end{tabular}
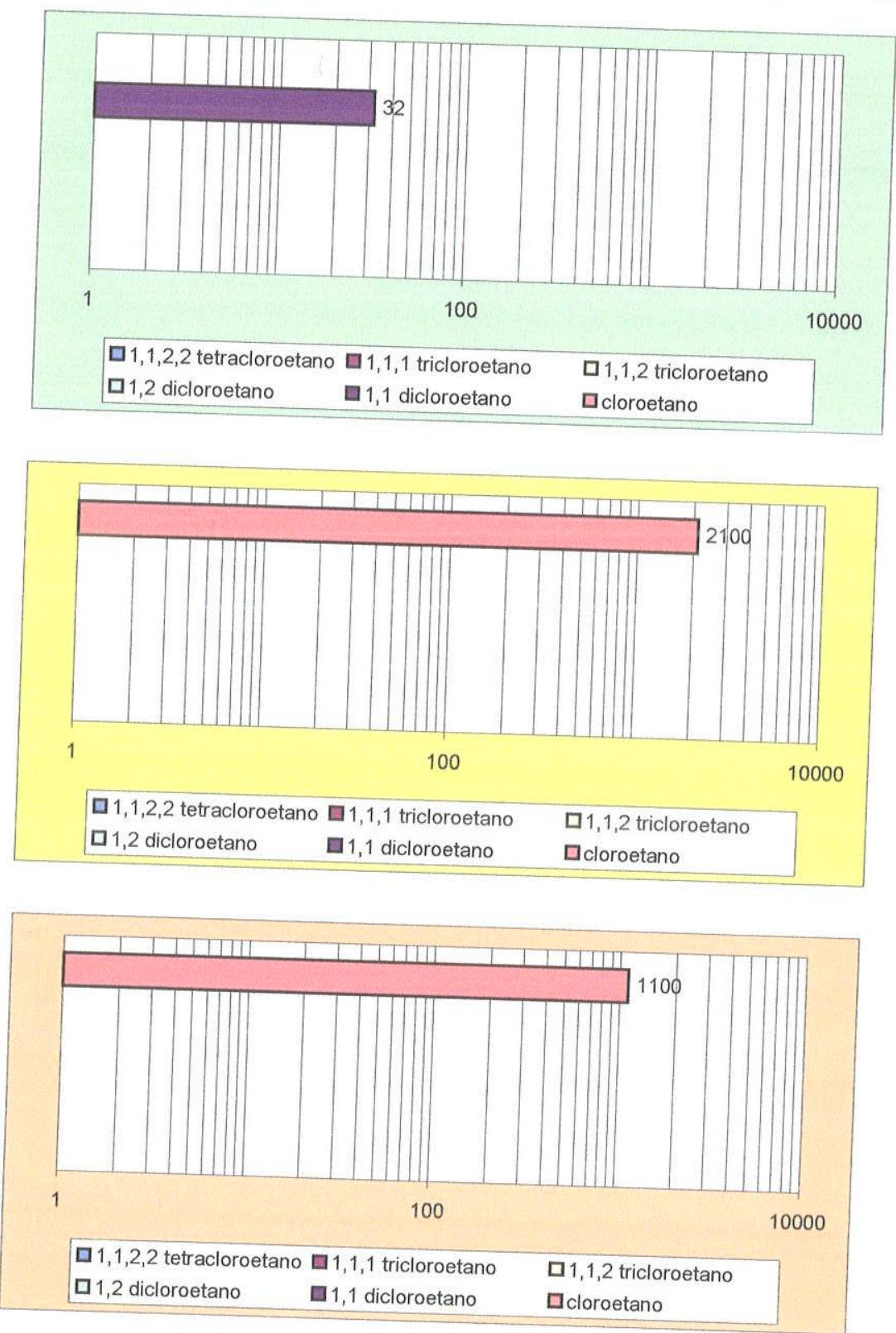
Tabela 19. Resultados analíticos da sequência dos Etanos

Concentrações em $\mu \mathrm{g} / \mathrm{L}$

PM SR01 M; PM SR01 B; PM SR02 J

\begin{tabular}{|l|c|c|c|}
\cline { 2 - 4 } \multicolumn{1}{c|}{} & \multicolumn{3}{c|}{ Mês 2 } \\
\hline $1,1,2,2$ tetracloroetano & PMSR01M & PMSR01B & PMSR02J \\
\hline $1,1,1$ tricloroetano & & & \\
\hline $1,1,2$ tricloroetano & & & \\
\hline 1,2 dicloroetano & 22 & & \\
\hline 1,1 dicloroetano & 25 & & \\
\hline cloroetano & 90 & & 1040 \\
\hline
\end{tabular}
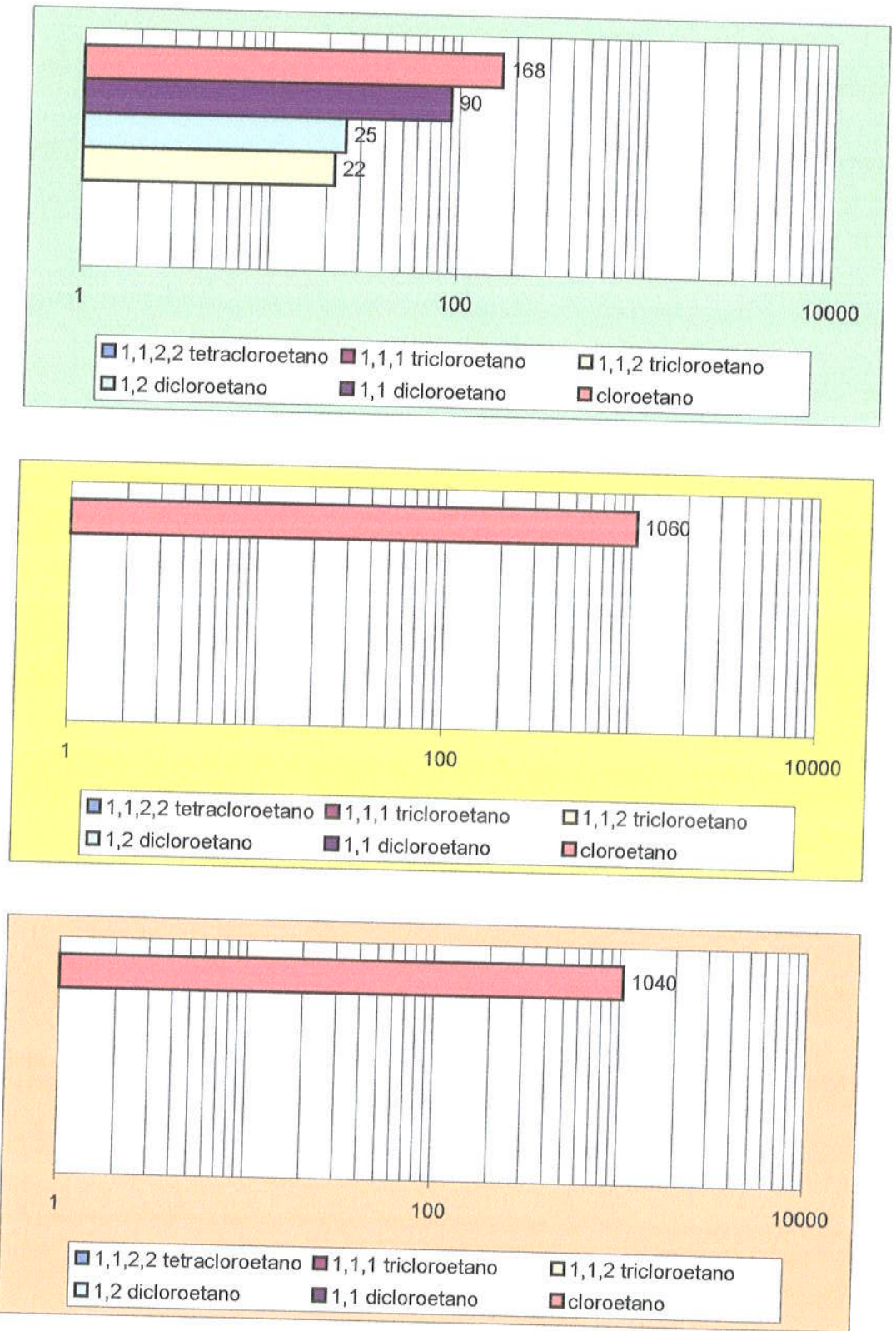
Tabela 20. Resultados analíticos da sequência dos Etanos

Concentrações em $\mu \mathrm{g} / \mathrm{L}$

PM SR01 M; PM SR01 B; PM SR02 J

\begin{tabular}{|l|c|c|c|}
\cline { 2 - 4 } \multicolumn{1}{c|}{} & \multicolumn{3}{c|}{ Mês 3 } \\
\hline composto & PMSR01M & PMSR01B & PMSR02J \\
\hline $1,1,2,2$ tetracloroetano & & & \\
\hline $1,1,1$ tricloroetano & & & \\
\hline $1,1,2$ tricloroetano & 181 & & \\
\hline 1,2 dicloroetano & 173 & 34 & \\
\hline 1,1 dicloroetano & 525 & 400 & \\
\hline cloroetano & 307 & 3700 & 600 \\
\hline
\end{tabular}
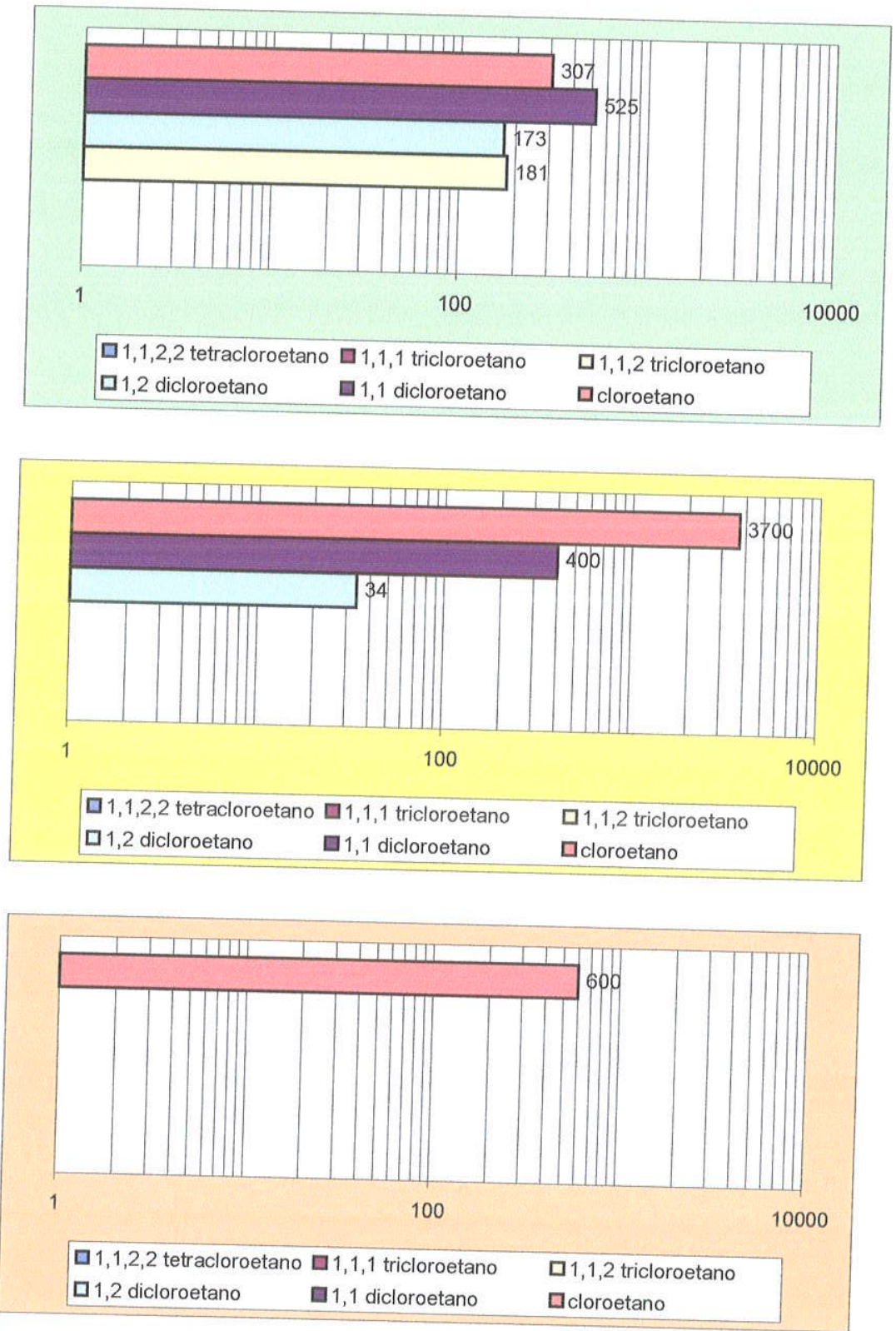
Tabela 21. Resultados analíticos da sequência dos Etanos

Concentrações em $\mu \mathrm{g} / \mathrm{L}$

PM SR01 M; PM SR01 B; PM SR02 J

\begin{tabular}{|l|c|c|c|}
\cline { 2 - 4 } \multicolumn{1}{c|}{} & \multicolumn{3}{c|}{ Mês 4 } \\
\hline composto & PMSR01M & PMSR01B & PMSR02J \\
\hline $1,1,2,2$ tetracloroetano & & & \\
\hline $1,1,1$ tricloroetano & & & \\
\hline $1,1,2$ tricloroetano & 208 & 30 & \\
\hline 1,2 dicloroetano & 212 & 109 & 9 \\
\hline 1,1 dicloroetano & 350 & 700 & \\
\hline cloroetano & 170 & 4580 & 650 \\
\hline
\end{tabular}
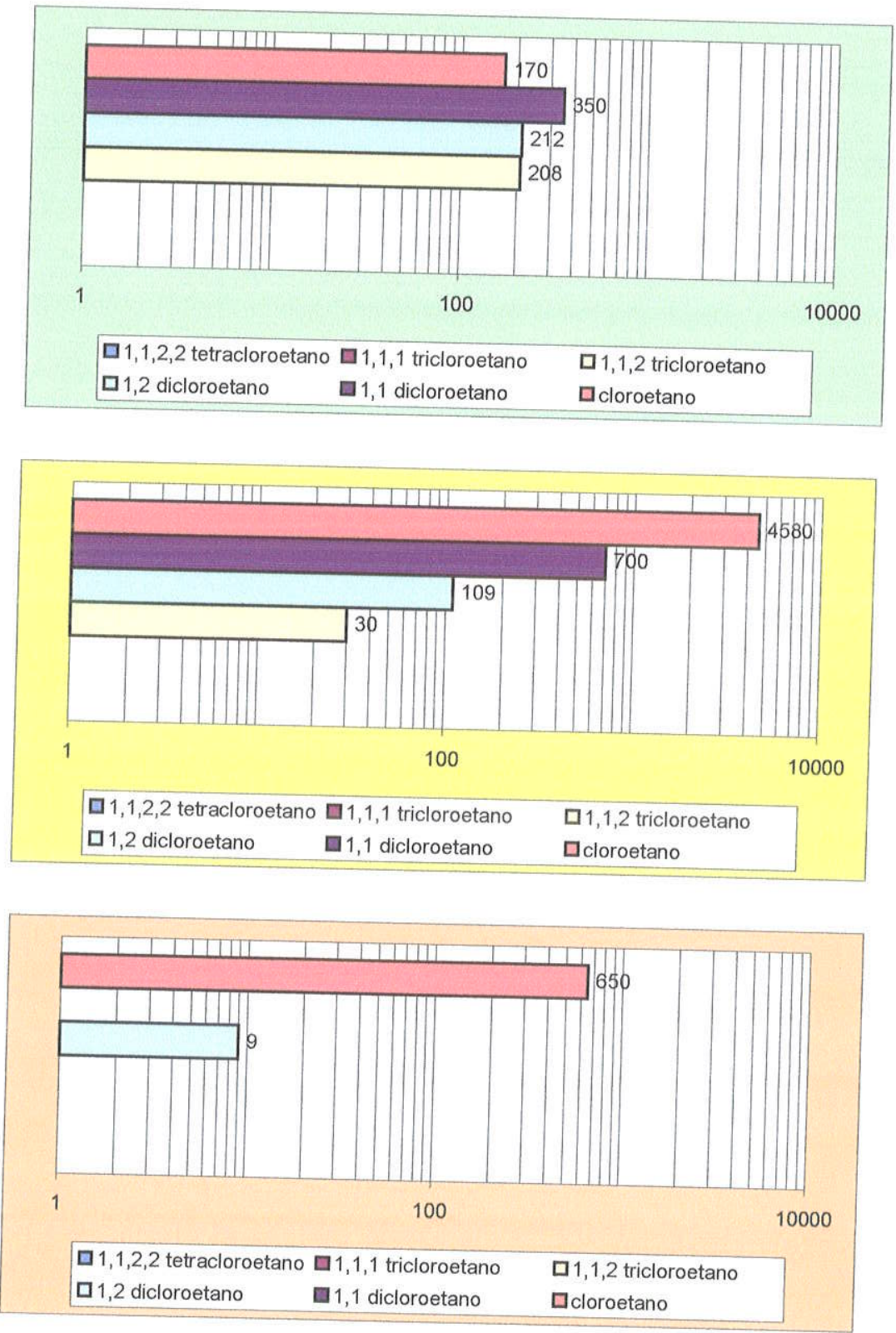
Tabela 22. Resultados analíticos da sequência dos Etanos Concentrações em $\boldsymbol{\mu g} / \mathbf{L}$

PM SR01 M; PM SR01 B; PM SR02 J

\begin{tabular}{|l|c|c|c|}
\cline { 2 - 4 } \multicolumn{1}{c|}{} & \multicolumn{3}{c|}{ Mês 5 } \\
\hline composto & PMSR01M & PMSR01B & PMSR02J \\
\hline $1,1,2,2$ tetracloroetano & & & \\
\hline $1,1,1$ tricloroetano & & & \\
\hline $1,1,2$ tricloroetano & 97 & 31 & \\
\hline 1,2 dicloroetano & 60 & 103 & 7 \\
\hline 1,1 dicloroetano & 42 & 825 & \\
\hline cloroetano & 10 & 7150 & 730 \\
\hline
\end{tabular}
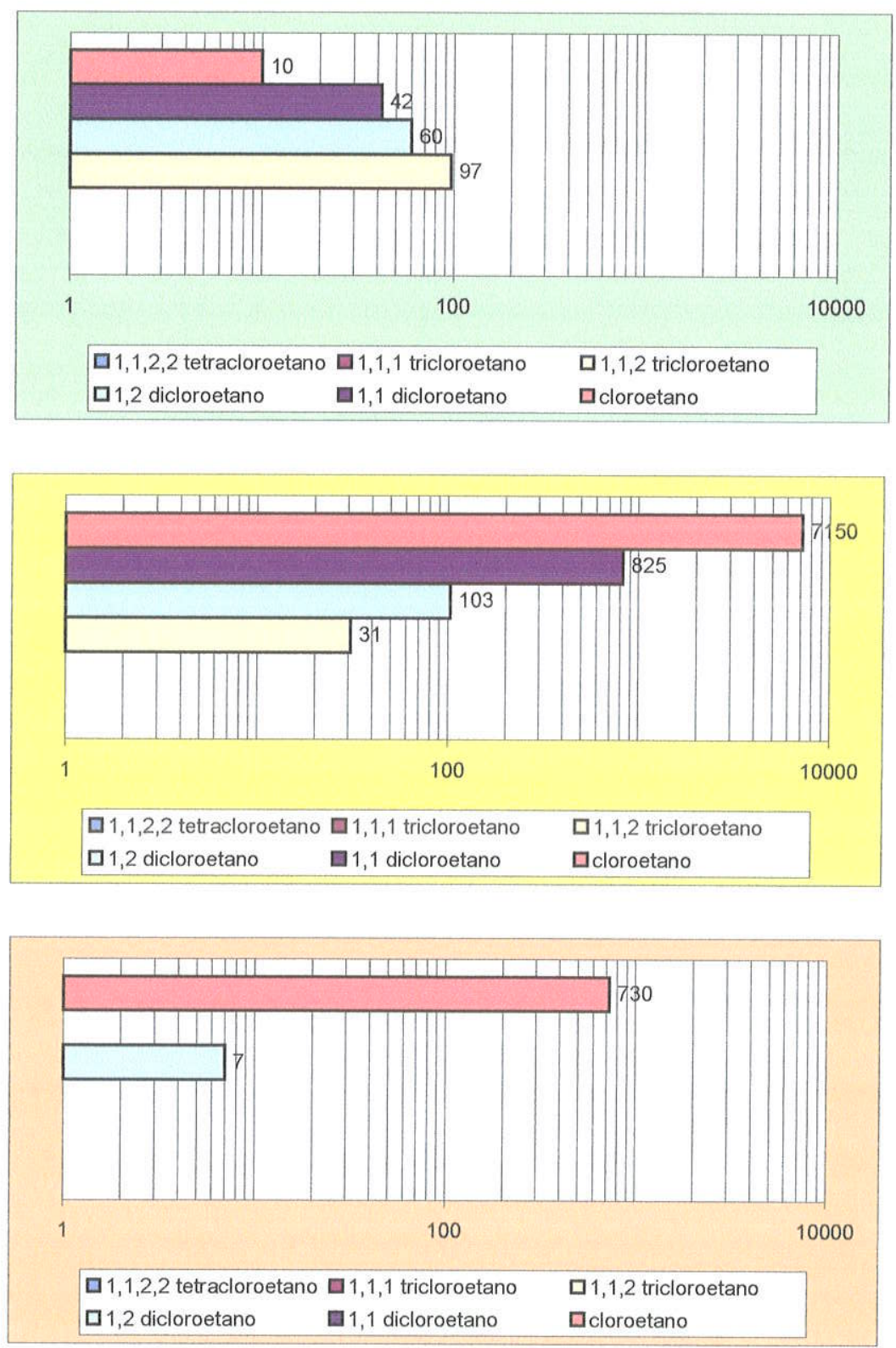
Tabela 23. Resultados analíticos da sequência dos Etanos

Concentrações em $\mu \mathrm{g} / \mathrm{L}$

PM SR01 M; PM SR01 B; PM SR02 J

\begin{tabular}{|l|c|c|c|}
\cline { 2 - 4 } \multicolumn{1}{c|}{} & \multicolumn{3}{c|}{ Mês 6 } \\
\hline composto & PMSR01M & PMSR01B & PMSR02J \\
\hline $1,1,2,2$ tetracloroetano & & & \\
\hline $1,1,1$ tricloroetano & & & \\
\hline $1,1,2$ tricloroetano & 300 & 39 & \\
\hline 1,2 dicloroetano & 147 & 123 & \\
\hline 1,1 dicloroetano & 365 & 650 & \\
\hline cloroetano & 173 & 4525 & 470 \\
\hline
\end{tabular}
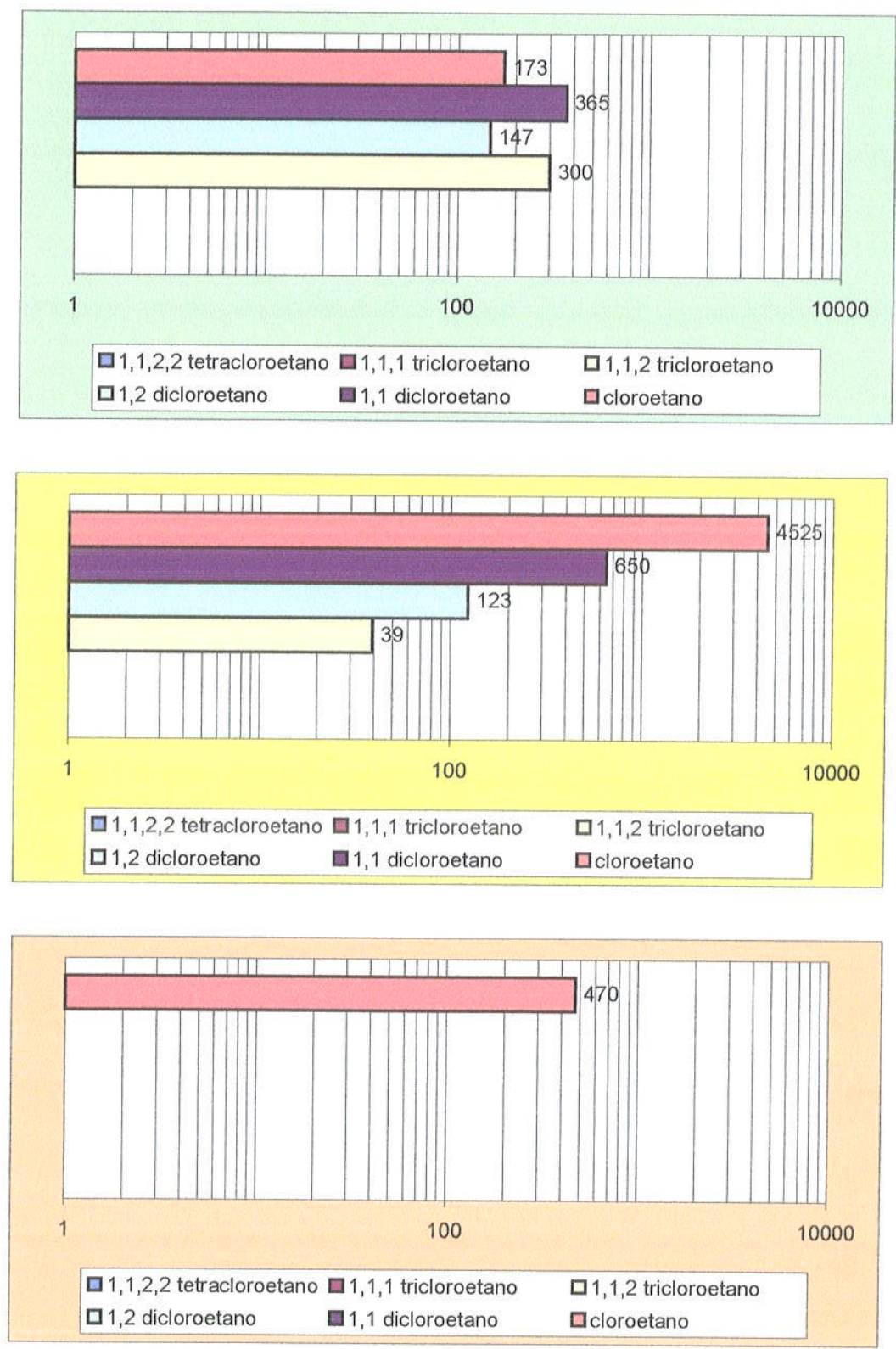
Tabela 24. Resultados analíticos da sequência dos Etanos Concentrações em $\mu \mathrm{g} / \mathrm{L}$ PM SR01 M; PM SR01 B; PM SR02 J

\begin{tabular}{|l|c|c|c|}
\cline { 2 - 4 } \multicolumn{1}{c|}{} & \multicolumn{3}{c|}{ Mês 7 } \\
\hline composto & PMSR01M & PMSR01B & PMSR02J \\
\hline $1,1,2,2$ tetracloroetano & & & \\
\hline $1,1,1$ tricloroetano & & & \\
\hline $1,1,2$ tricloroetano & & 27 & \\
\hline 1,2 dicloroetano & 13 & 291 & \\
\hline 1,1 dicloroetano & 97 & 3300 & 450 \\
\hline cloroetano & 20 & & \\
\hline
\end{tabular}
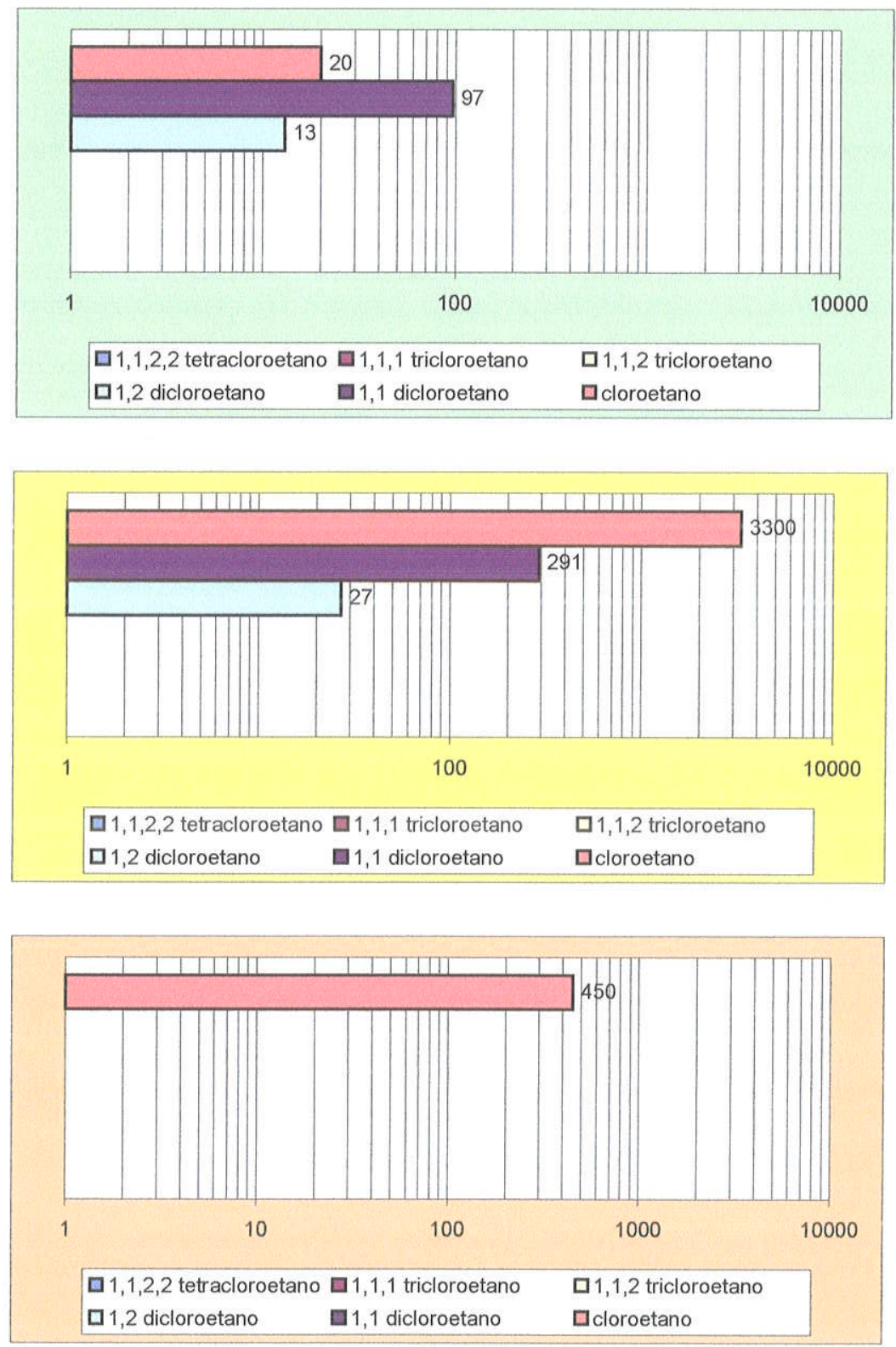
Tabela 25. Resultados analíticos da sequência dos Etanos

Concentrações em $\mu \mathrm{g} / \mathrm{L}$

PM SR01 M; PM SR01 B; PM SR02 J

\begin{tabular}{|l|c|c|c|}
\cline { 2 - 4 } \multicolumn{1}{c|}{} & \multicolumn{3}{c|}{ Mês 8 } \\
\hline composto & PMSR01M & PMSR01B & PMSR02J \\
\hline $1,1,2,2$ tetracloroetano & & & \\
\hline $1,1,1$ tricloroetano & & & \\
\hline $1,1,2$ tricloroetano & 5500 & 42 & \\
\hline 1,2 dicloroetano & 603 & 172 & \\
\hline 1,1 dicloroetano & 2700 & 1070 & \\
\hline cloroetano & 191 & 6300 & 1400 \\
\hline
\end{tabular}
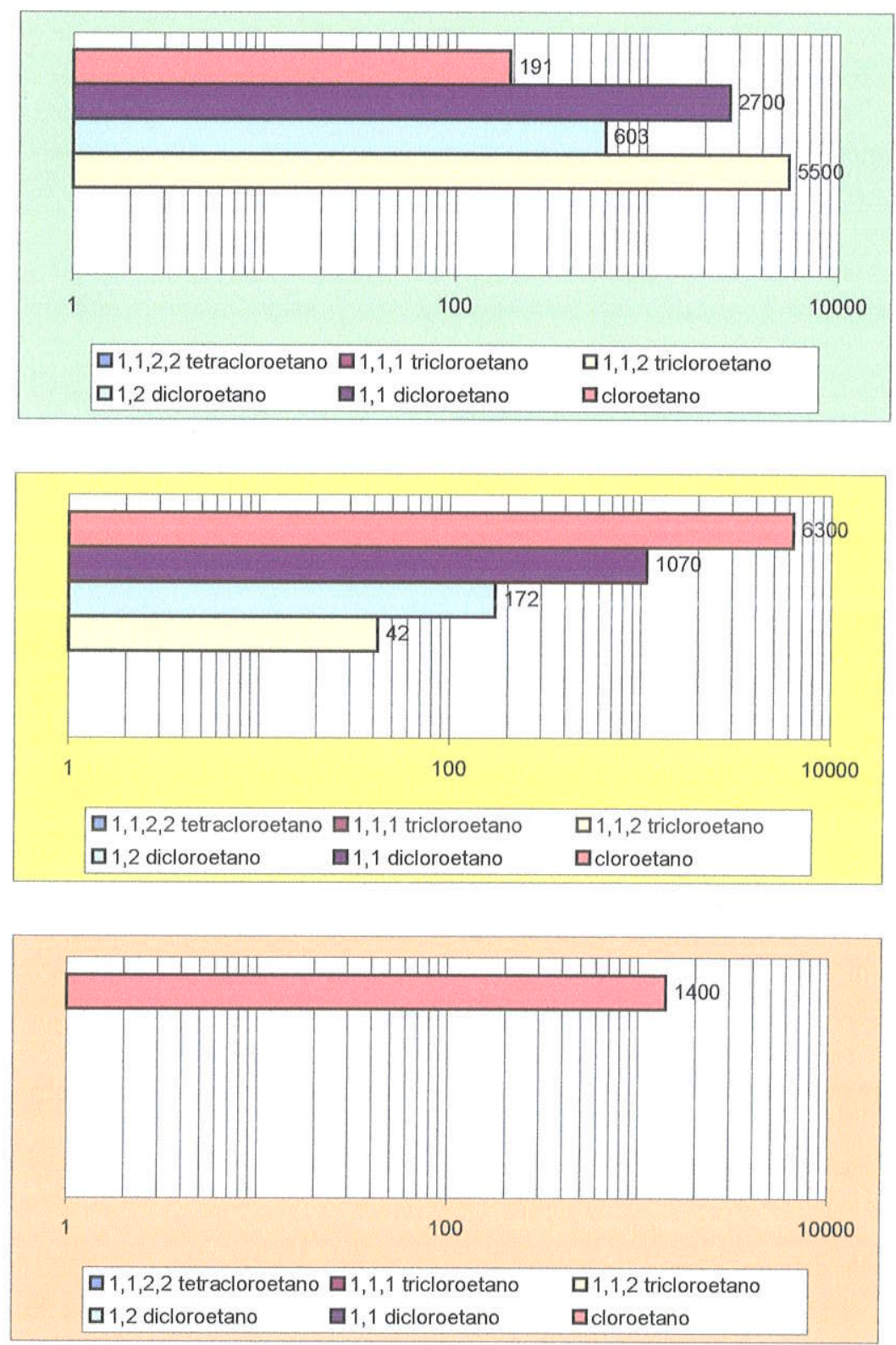
Tabela 26. Resultados analíticos da sequência dos Etanos

Concentrações em $\mu \mathrm{g} / \mathrm{L}$

PM SR01 M; PM SR01 B; PM SR02 J

\begin{tabular}{|l|c|c|c|}
\cline { 2 - 4 } \multicolumn{1}{c|}{} & \multicolumn{3}{c|}{ Mês 9 } \\
\hline composto & PMSR01M & PMSR01B & PMSR02J \\
\hline $1,1,2,2$ tetracloroetano & & & \\
\hline $1,1,1$ tricloroetano & & & \\
\hline $1,1,2$ tricloroetano & 5500 & & \\
\hline 1,2 dicloroetano & & & \\
\hline 1,1 dicloroetano & 4200 & 375 & \\
\hline cloroetano & & 11125 & 2200 \\
\hline
\end{tabular}
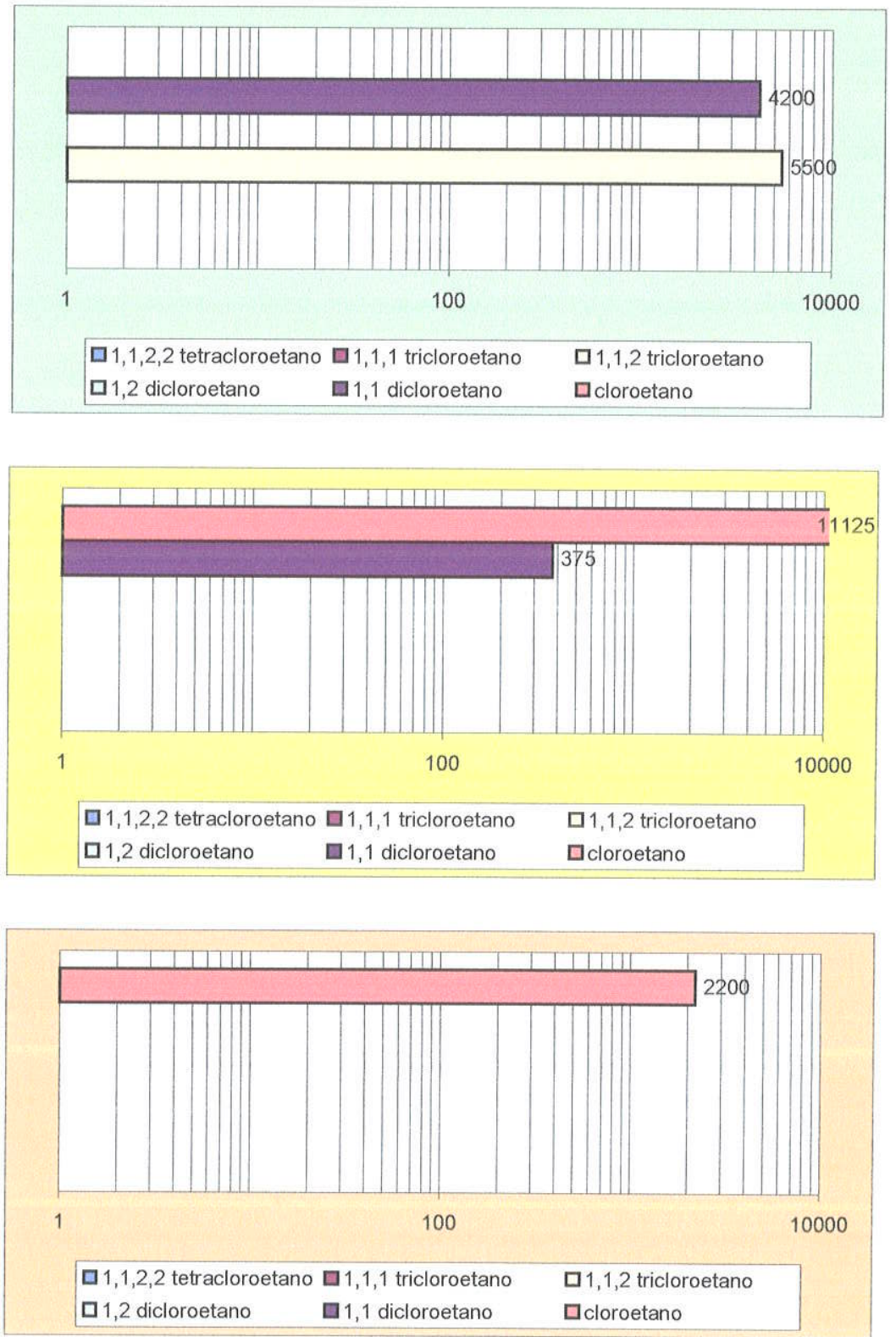
Tabela 27. Resultados analíticos da sequência dos Etanos Concentrações em $\mu \mathrm{g} / \mathrm{L}$

PM SR01 M; PM SR01 B; PM SR02 J

\begin{tabular}{|l|c|c|c|}
\hline & \multicolumn{3}{|c|}{ Mês 10 } \\
\hline composto & PMSR01M & PMSR01B & PMSR02J \\
\hline $1,1,2,2$ tetracloroetano & & & \\
\hline $1,1,1$ tricloroetano & & & \\
\hline $1,1,2$ tricloroetano & 2590 & 24 & \\
\hline 1,2 dicloroetano & 990 & 82 & \\
\hline 1,1 dicloroetano & 3500 & 824 & 4 \\
\hline cloroetano & 380 & 8600 & 1950 \\
\hline
\end{tabular}
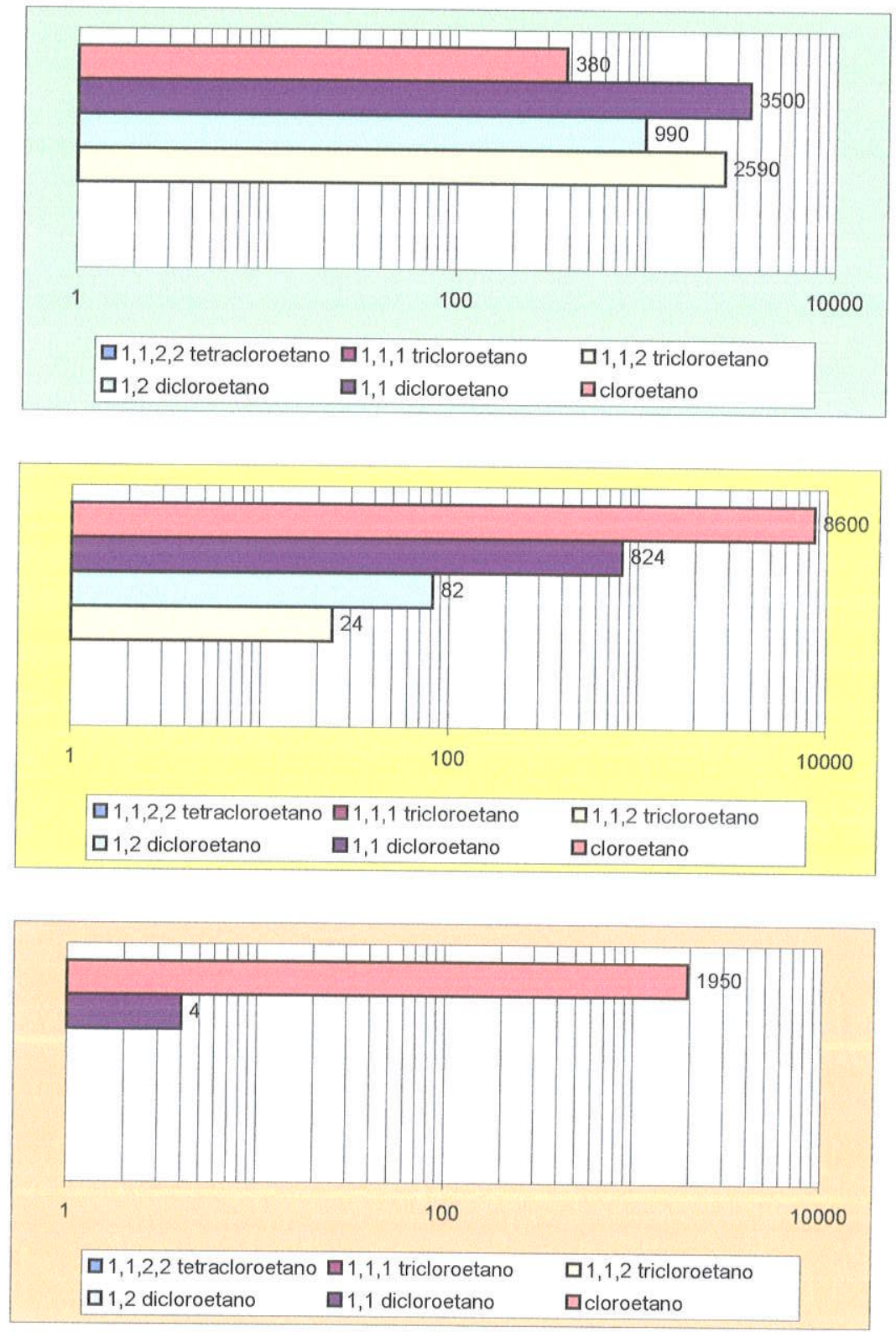
Tabela 28. Resultados analíticos da sequência dos Etanos

Concentrações em $\mu \mathrm{g} / \mathrm{L}$

PM SR01 M; PM SR01 B; PM SR02 J

\begin{tabular}{|l|c|c|c|}
\cline { 2 - 4 } \multicolumn{1}{c|}{} & \multicolumn{3}{c|}{ Mês 11 } \\
\hline composto & PMSR01M & PMSR01B & PMSR02J \\
\hline $1,1,2,2$ tetracloroetano & & & \\
\hline $1,1,1$ tricloroetano & & & 95 \\
\hline $1,1,2$ tricloroetano & 550 & 12 & 7180 \\
\hline 1,2 dicloroetano & 275 & 70 & 3140 \\
\hline 1,1 dicloroetano & 2500 & 650 & 3140 \\
\hline cloroetano & 100 & 6350 & 210 \\
\hline
\end{tabular}
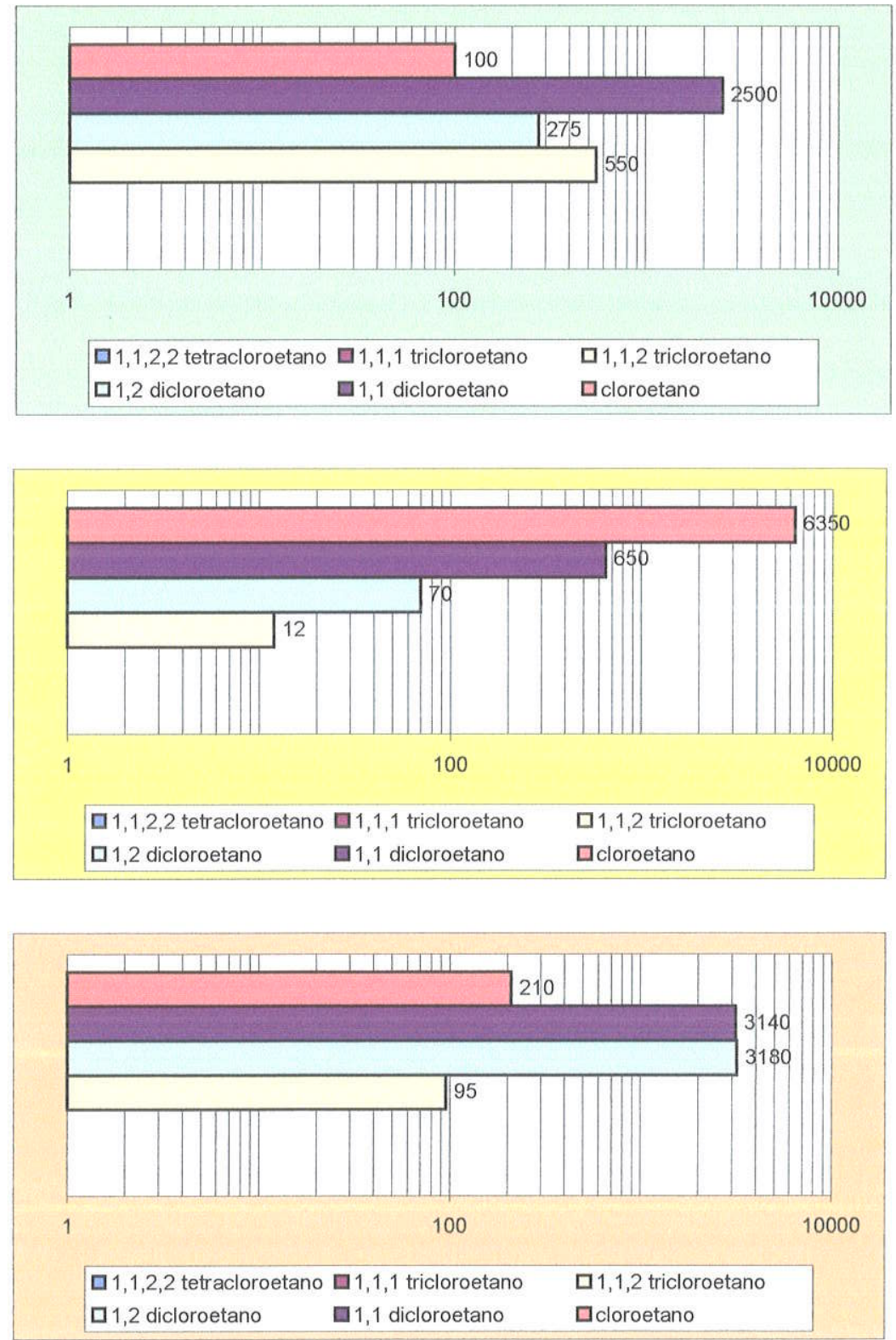
Tabela 29. Resultados analíticos da sequência dos Etanos

Concentrações em $\mu \mathrm{g} / \mathrm{L}$

PM SR01 M; PM SR01 B; PM SR02 J

\begin{tabular}{|l|c|c|c|}
\cline { 2 - 4 } \multicolumn{1}{c|}{} & \multicolumn{3}{c|}{ Mês 12 } \\
\hline composto & PMSR01M & PMSR01B & PMSR02J \\
\hline $1,1,2,2$ tetracloroetano & & & \\
\hline $1,1,1$ tricloroetano & & & \\
\hline $1,1,2$ tricloroetano & 3 & 4 & 7 \\
\hline 1,2 dicloroetano & 31 & & 11 \\
\hline 1,1 dicloroetano & 245 & 500 & 74 \\
\hline cloroetano & 1850 & 6350 & \\
\hline
\end{tabular}
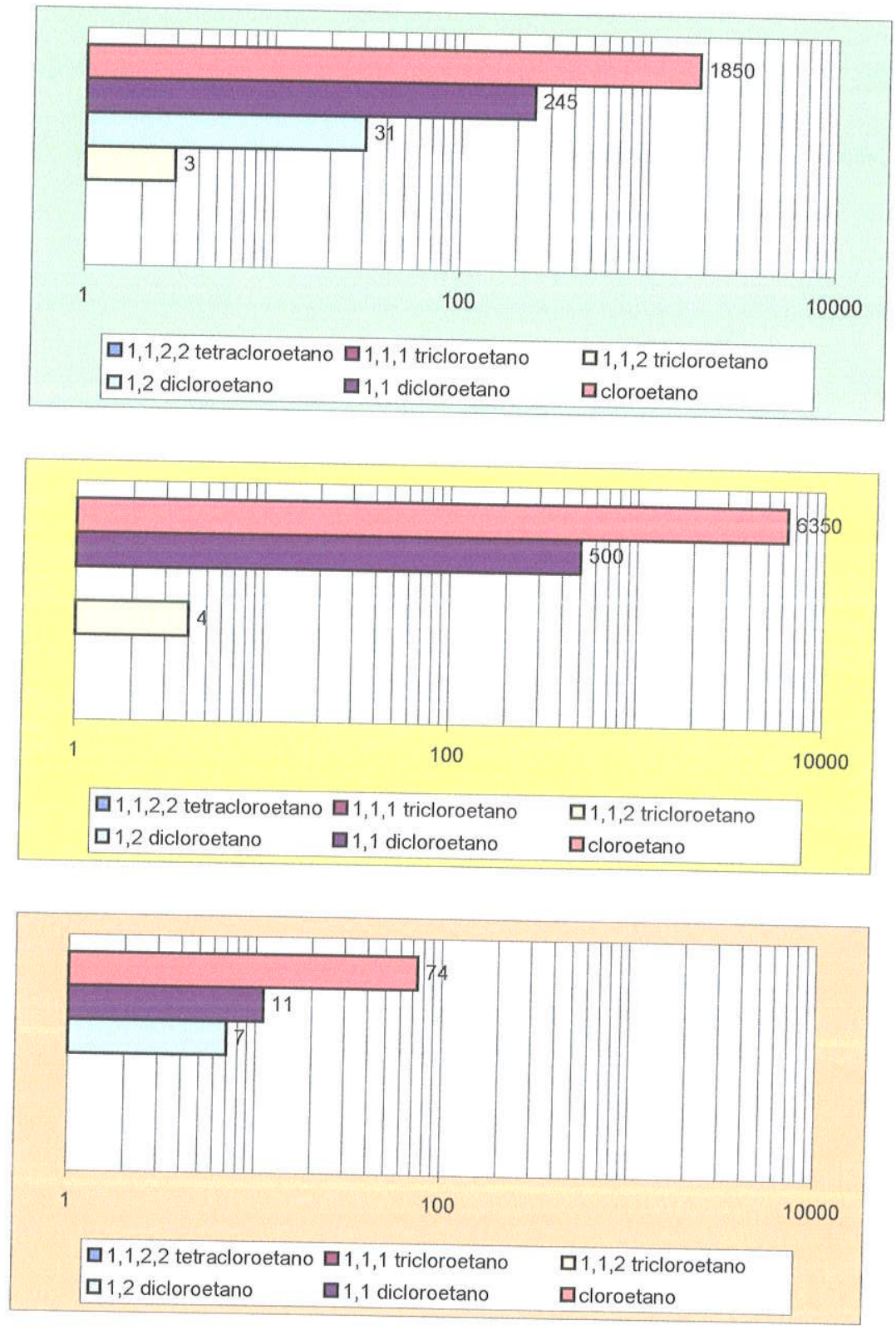
Dentre os compostos analisados na seqüência de etanos o composto 1,1,2 tricloroetano foi o de maior número de halogênios identificado.

Aparentemente a seqüência de degradação do 1,1,2 tricloroetano se deu preferencialmente na barreira reativa para o 1,1 dicloroetano, uma vez que as concentrações de 1,2 dicloroetano são pouco relacionadas à presença do primeiro composto. Entretanto, percebe-se claramente que a pluma de contaminação identificada a montante do sistema de remediação apresenta invariavelmente concentrações de 1,1 dicloroetano, o que dificulta a interpretação da seqüência de degradação.

Os dados apresentados na Tabela 2 indicam que o tempo de meia-vida para o 1,1,1 tricloroetano pode ser de alguns minutos (200 para o menor valor encontrado), desta forma, o seu isômero 1,1,2 tricloroetano pode apresentar degradação acelerada, razão pela qual concentrações elevadas deste composto, como as identificadas nas amostras entre os Meses 8 e 10, podem estar associadas às elevadas concentrações de cloroetano no poço do interior da barreira reativa.

O cloroetano, por sua vez, apresenta degradação parcial após a passagem pela barreira reativa, com taxa de redução variável ao longo dos eventos de monitoramento. Pode-se afirmar que a variação das concentrações de cloroetano no sentido de fluxo da água subterrânea (do PM SR01 M ao PM SR02 J) denota o processo de degradação imposto pela barreira reativa, uma vez que as concentrações deste composto invariavelmente são maiores nas amostras do poço PMSR01 B em comparação às amostras do PM SR01 M e menores quando comparadas às amostras do poço de jusante.

Apesar de inesperadas (a literatura não relata degradação abiótica destes compostos na presença de ferro zero-valente), reduções nas concentrações de 1,1-dicloroetano e 1,2-dicloroetano foram obtidas como padrão em todos os eventos de monitoramento, sendo reduzidas a valores inferiores aos limites de detecção dos métodos analíticos na maioria dos casos e determinadas em concentrações residuais (máxima de $9,0 \mu \mathrm{g} / \mathrm{L}$ ) nos Meses 4, 5, 10 e 12.

Mesmo considerando o tempo necessário para que a água subterrânea percorra o trajeto entre os poços de montante e jusante, o que levaria a supor 
que a concentração determinada no poço de montante poderia ser identificada no poço de jusante apenas no evento posterior, as concentrações residuais de 1,2 dicloroetano e 1,1 dicloroetano não podem ser associadas à elevadas concentrações destes compostos a montante, mesmo porque nos eventos em que as máximas concentrações de 1,2 dicloroetano (990 $\mu \mathrm{g} / \mathrm{L}$ no Mês 10) e 1,1 dicloroetano (4200 $\mu \mathrm{g} / \mathrm{L}$ no Mês 9) foram determinadas, as concentrações nos poços a jusante no mesmo evento e no evento posterior (o Mês 11 é desconsiderado neste caso por apresentar padrão anômalo de concentrações) atingiram valores máximos de $11 \mu \mathrm{g} / \mathrm{L}$ para 1,1 dicloroetano e $7 \mu \mathrm{g} / \mathrm{L}$ para 1,2 dicloroetano.

Apesar do processo de degradação dos compostos clorados constituídos apenas por ligações simples (etanos) não ter ocorrido em tempo de residência suficiente para completa dehalogeneização, tendo sido obtidas concentrações elevadas de cloroetano no poço de jusante em todos os eventos de monitoramento, os resultados indicam que o sistema de remediação contribuiu significativamente para redução da massa de contaminantes.

\subsection{Monitoramento da Seqüência de Degradação do Tetracloreto de Carbono}

A seqüência de apresentação segue o mesmo modelo adotado para os sub-itens anteriores.

Verde - Cor atribuída aos dados do PM SR01 M;

Amarela - Cor atribuída aos dados do PM SR01 B;

Laranja - Cor atribuída aos dados do PM SR02 J; 
Tabela 30. Resultados analíticos da sequência de Degradação do Tetracloreto de Carbono

Concentrações em $\mu \mathrm{g} / \mathrm{L}$

PM SR01 M; PM SR01 B; PM SR02 J

\begin{tabular}{|l|l|l|l|}
\cline { 2 - 4 } \multicolumn{1}{c|}{} & \multicolumn{3}{c|}{ Mês 1 } \\
\hline composto & PMSR01M & PMSR01B & PMSR02J \\
\hline tetracloreto de carbono & & & \\
\hline clorofórmio & & & \\
\hline cloreto de metileno & & & \\
\hline
\end{tabular}
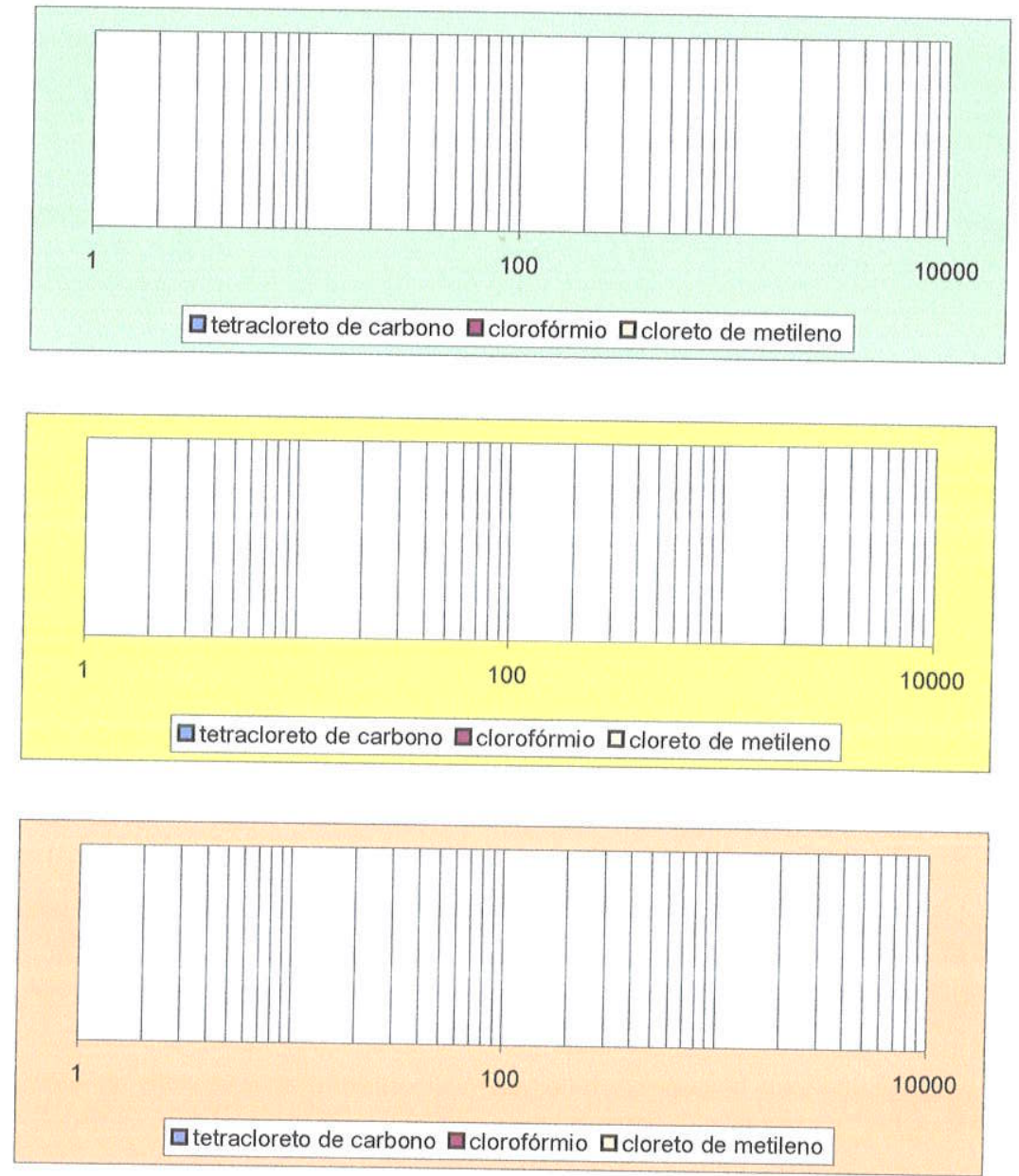
Tabela 31. Resultados analíticos da sequência de Degradação do Tetracloreto de Carbono

Concentrações em $\boldsymbol{\mu g} / \mathbf{L}$

PM SR01 M; PM SR01 B; PM SR02 J

\begin{tabular}{|l|c|c|c|}
\cline { 2 - 4 } \multicolumn{1}{c|}{} & \multicolumn{3}{c|}{ Mês 2 } \\
\hline composto & PMSR01M & PMSR01B & PMSR02J \\
\hline tetracloreto de carbono & & & \\
\hline clorofórmio & & & \\
\hline cloreto de metileno & 58 & & \\
\hline
\end{tabular}
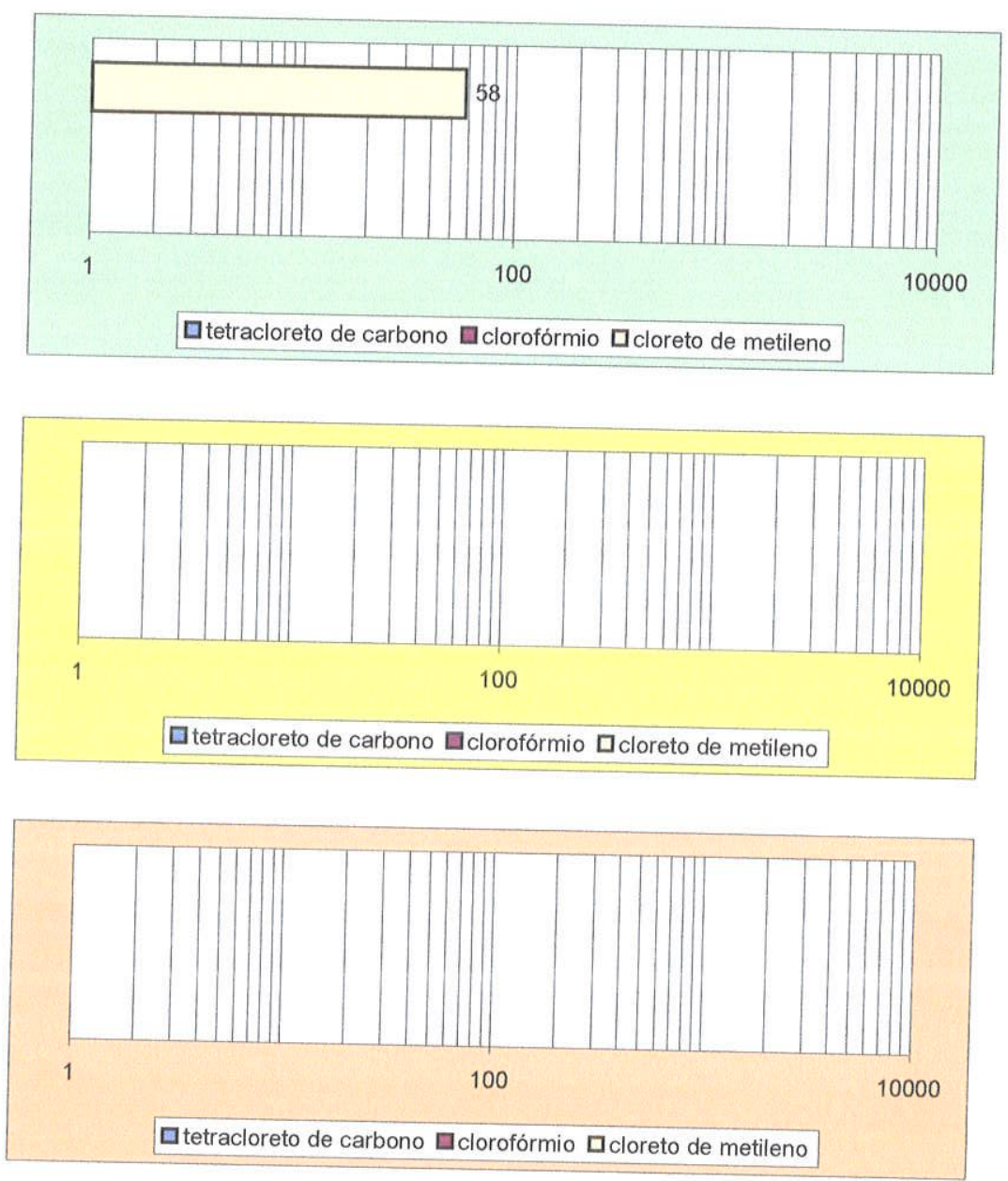
Tabela 32. Resultados analíticos da sequência de Degradação do Tetracloreto de Carbono

Concentrações em $\mu \mathrm{g} / \mathrm{L}$

PM SR01 M; PM SR01 B; PM SR02 J

\begin{tabular}{|l|c|c|c|}
\cline { 2 - 4 } \multicolumn{1}{c|}{} & \multicolumn{3}{c|}{ Mês 3 } \\
\hline composto & PMSR01M & PMSR01B & PMSR02J \\
\hline tetracloreto de carbono & & & \\
\hline clorofórmio & & & \\
\hline cloreto de metileno & 195 & 35 & \\
\hline
\end{tabular}
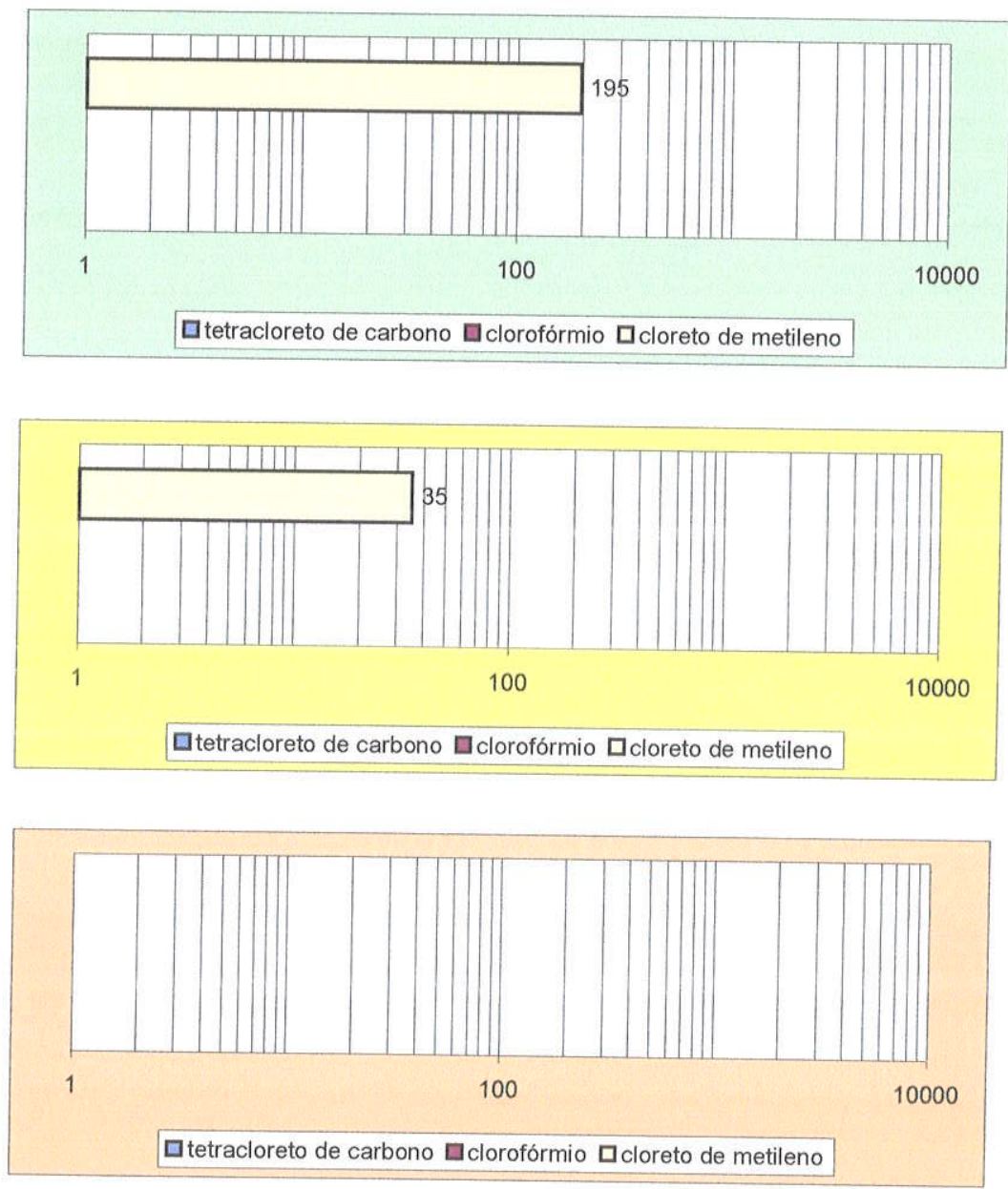
Tabela 33. Resultados analíticos da sequência de Degradação do Tetracloreto de Carbono

\section{Concentrações em $\mu \mathrm{g} / \mathrm{L}$}

PM SR01 M; PM SR01 B; PM SR02 J

\begin{tabular}{|l|c|c|c|}
\cline { 2 - 4 } \multicolumn{1}{c|}{} & \multicolumn{3}{c|}{ Mês 4 } \\
\hline composto & PMSR01M & PMSR01B & PMSR02J \\
\hline tetracloreto de carbono & & & \\
\hline clorofórmio & 11 & 10 & \\
\hline cloreto de mëtileno & 120 & 42 & \\
\hline
\end{tabular}
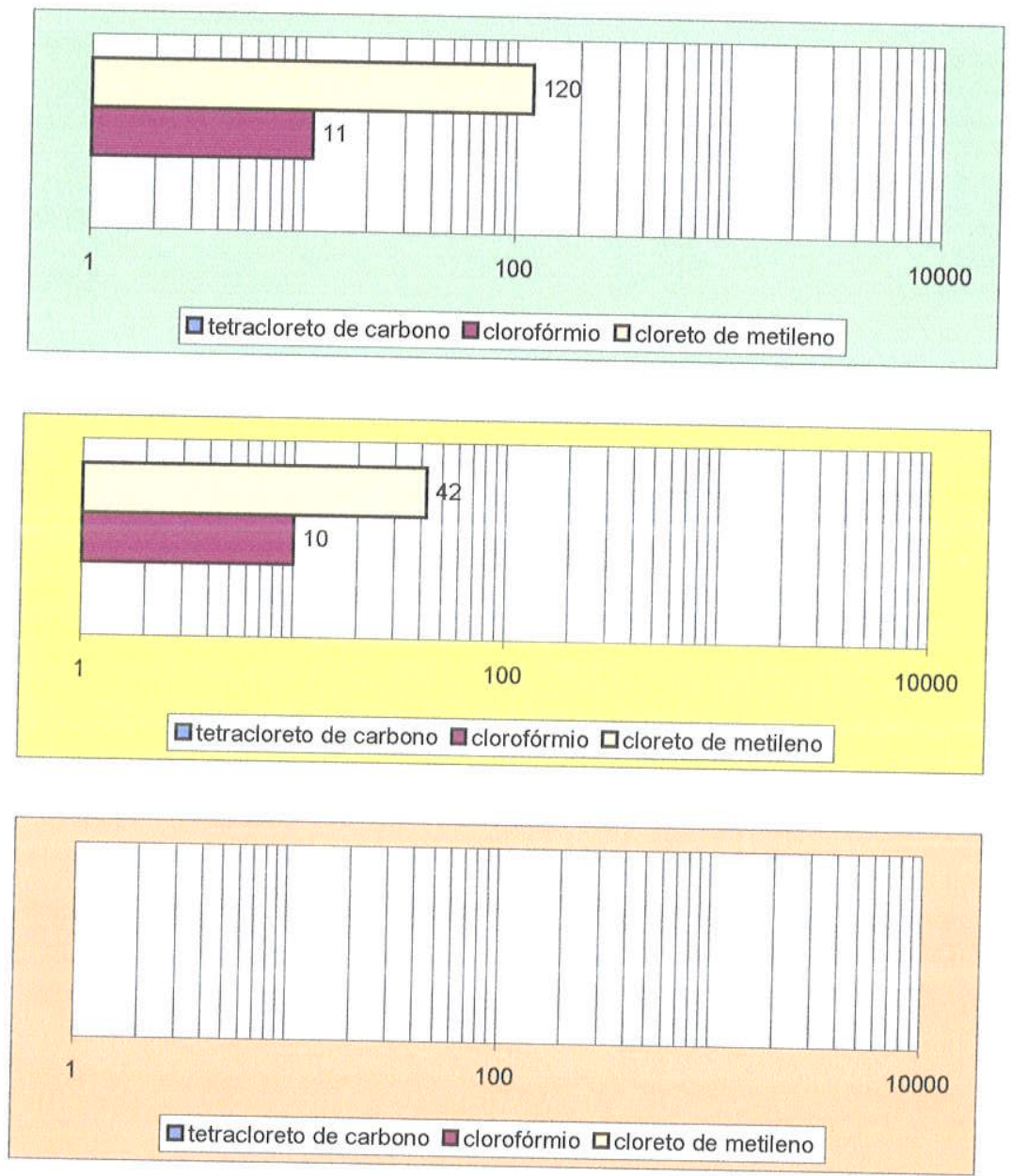
Tabela 34. Resultados analíticos da sequência de Degradação do Tetracloreto de Carbono

Concentrações em $\mu \mathrm{g} / \mathrm{L}$

PM SR01 M; PM SR01 B; PM SR02 J

\begin{tabular}{|l|c|c|c|}
\cline { 2 - 4 } \multicolumn{1}{c|}{} & \multicolumn{3}{c|}{ Mês 5 } \\
\hline composto & PMSR01M & PMSR01B & PMSR02J \\
\hline tetracloreto de carbono & & & \\
\hline clorofórmio & & 11 & \\
\hline cloreto de metileno & 32 & 40 & \\
\hline
\end{tabular}
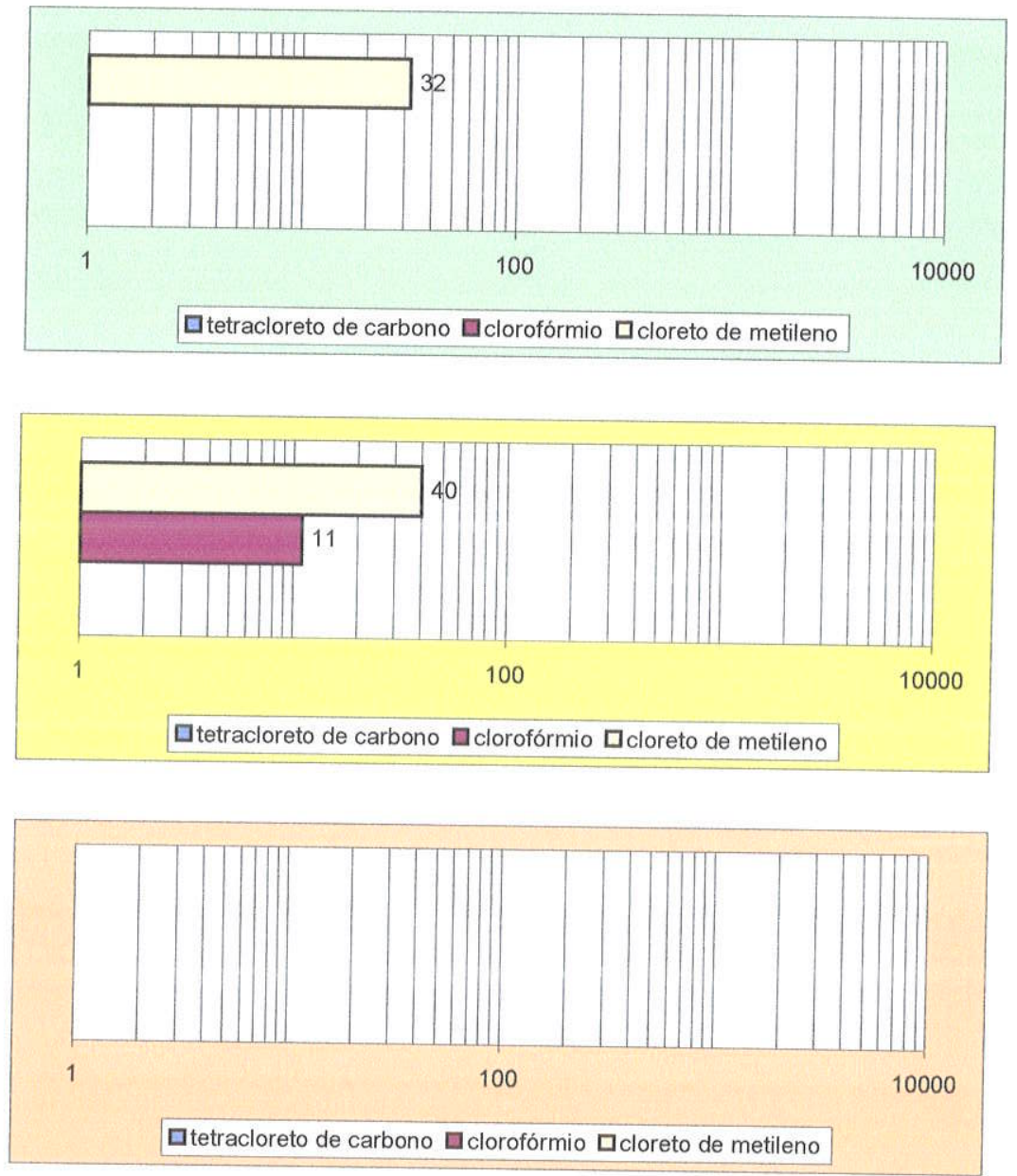
Tabela 35. Resultados analíticos da sequência de Degradação do Tetracloreto de Carbono

Concentrações em $\mu \mathrm{g} / \mathrm{L}$

PM SR01 M; PM SR01 B; PM SR02 J

\begin{tabular}{|l|c|c|c|}
\cline { 2 - 4 } \multicolumn{1}{c|}{} & \multicolumn{3}{c|}{ Mês 6 } \\
\hline composto & PMSR01M & PMSR01B & PMSR02J \\
\hline tetracloreto de carbono & & & \\
\hline clorofórmio & & 10 & \\
\hline cloreto de metileno & 96 & 44 & \\
\hline
\end{tabular}
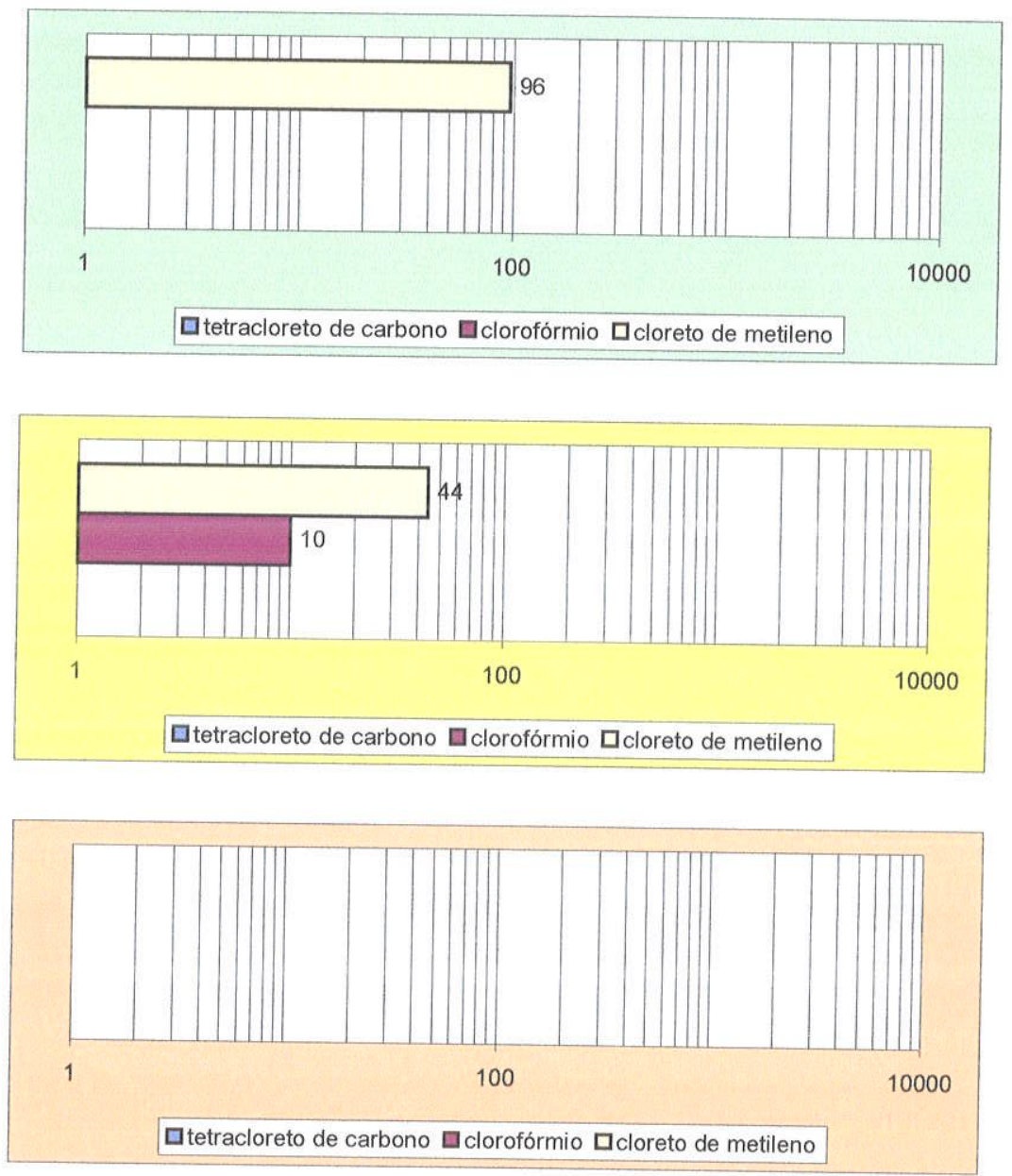
Tabela 36. Resultados analíticos da sequência de Degradação do Tetracloreto de Carbono

Concentrações em $\mu \mathrm{g} / \mathrm{L}$

PM SR01 M; PM SR01 B; PM SR02 J

\begin{tabular}{|l|c|c|c|}
\cline { 2 - 4 } \multicolumn{1}{c|}{} & \multicolumn{3}{c|}{ Mês 7 } \\
\hline composto & PMSR01M & PMSR01B & PMSR02J \\
\hline tetracloreto de carbono & & & \\
\hline clorofórmio & & & \\
\hline cloreto de metileno & & 32 & \\
\hline
\end{tabular}
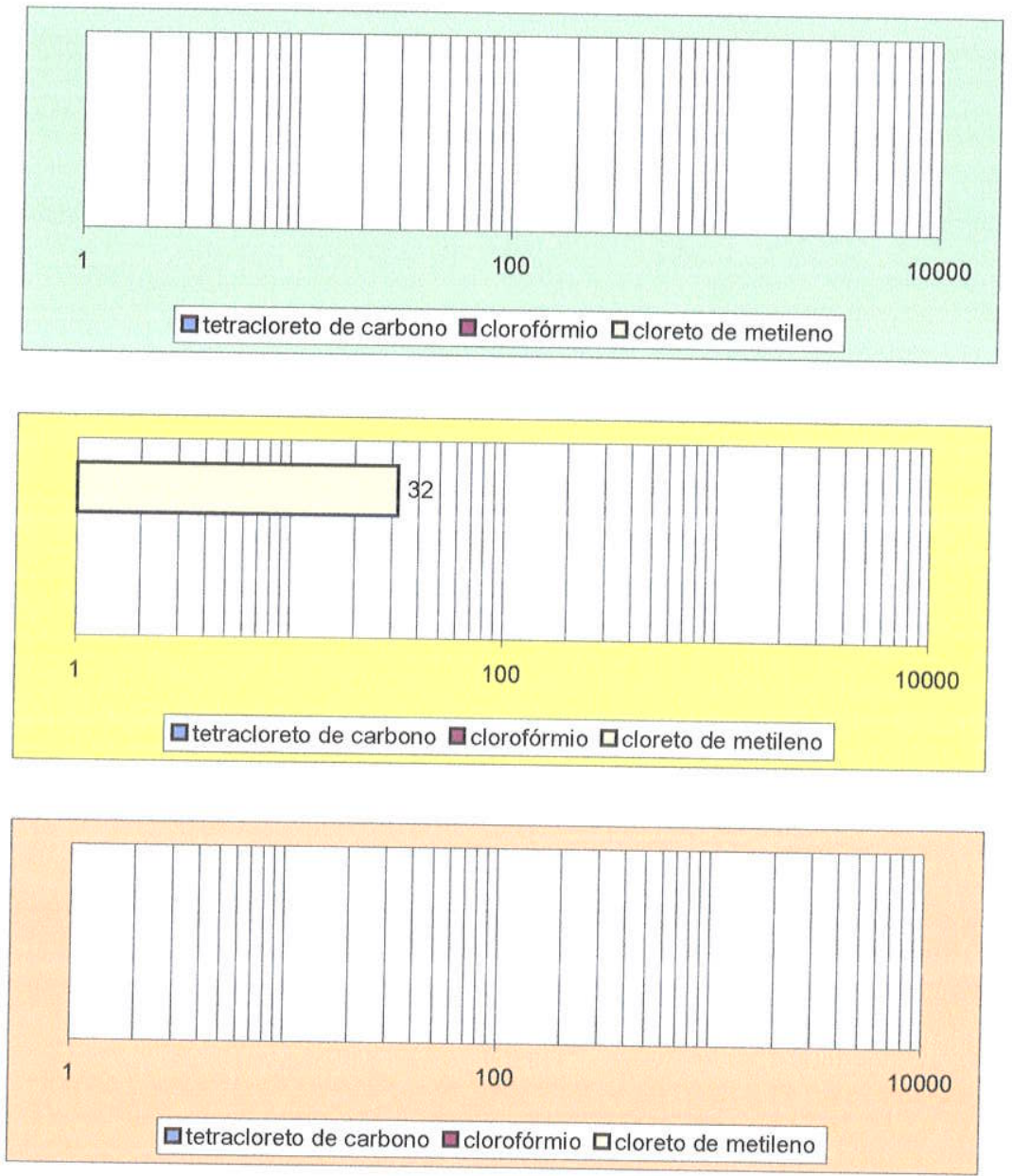
Tabela 37. Resultados analíticos da sequência de Degradação do Tetracloreto de Carbono

\section{Concentrações em $\mu \mathrm{g} / \mathrm{L}$}

PM SR01 M; PM SR01 B; PM SR02 J

\begin{tabular}{|l|c|c|c|}
\cline { 2 - 4 } \multicolumn{1}{c|}{} & \multicolumn{3}{c|}{ Mês 8 } \\
\hline composto & PMSR01M & PMSR01B & PMSR02J \\
\hline tetracloreto de carbono & & & \\
\hline clorofórmio & 187 & & \\
\hline cloreto de metileno & 577 & 468 & 1200 \\
\hline
\end{tabular}
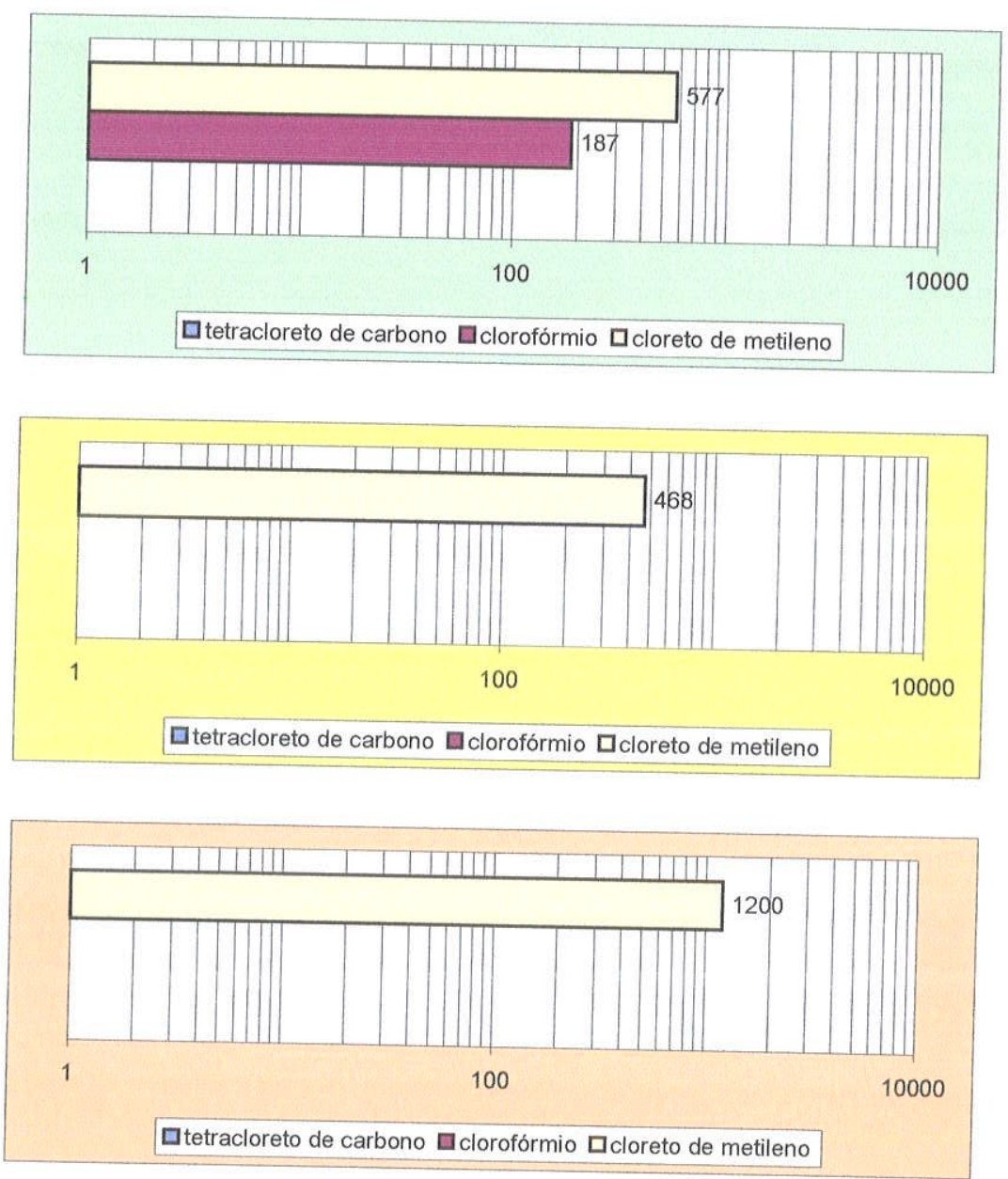
Tabela 38. Resultados analíticos da sequência de Degradação do Tetracloreto de Carbono

\section{Concentrações em $\mu \mathrm{g} / \mathrm{L}$}

PM SR01 M; PM SR01 B; PM SR02 J

\begin{tabular}{|l|c|c|c|}
\cline { 2 - 4 } \multicolumn{1}{c|}{} & \multicolumn{3}{c|}{ Mês 9 } \\
\hline composto & PMSR01M & PMSR01B & PMSR02J \\
\hline tetracloreto de carbono & & & \\
\hline clorofórmio & 101 & & \\
\hline
\end{tabular}
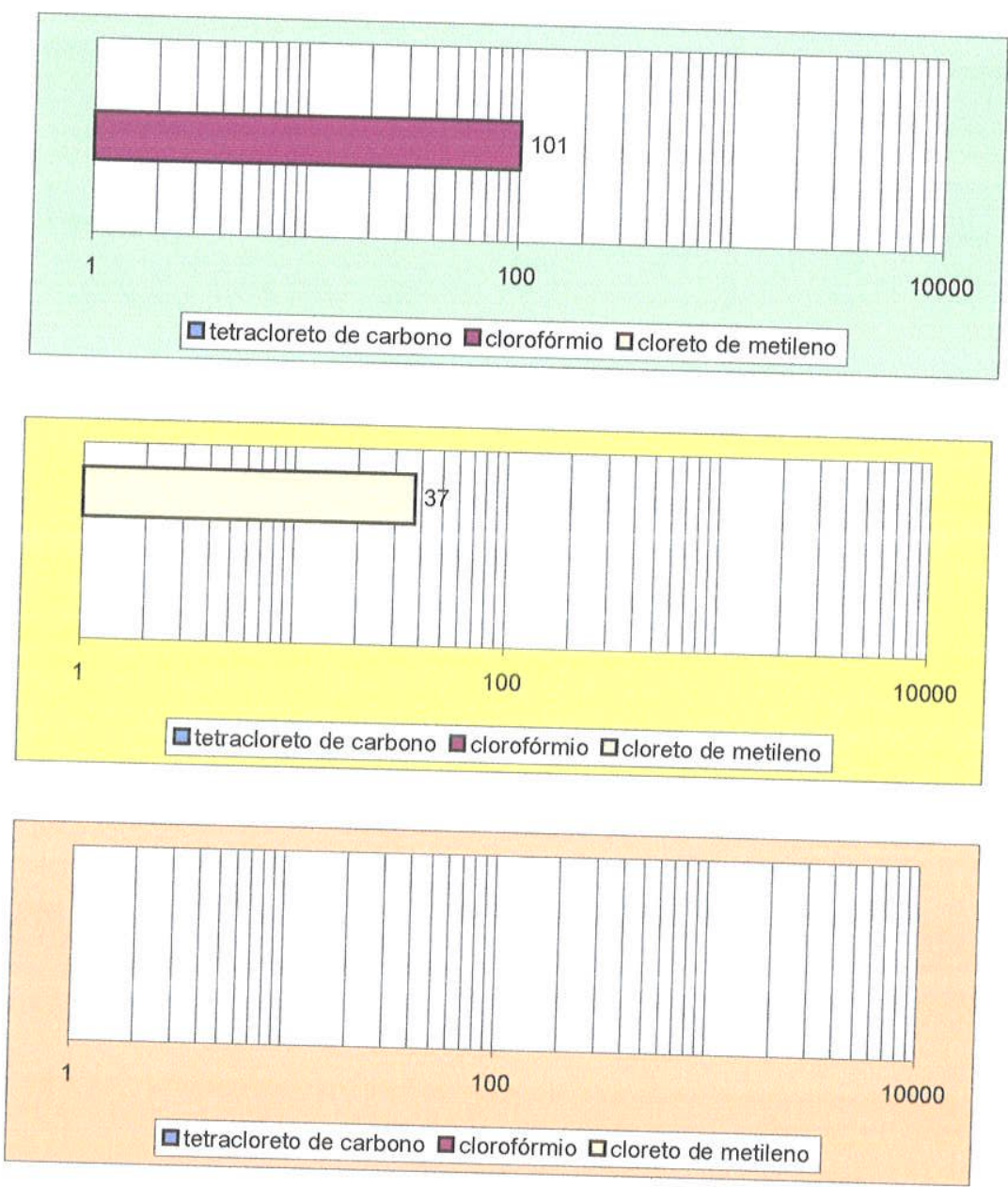
Tabela 39. Resultados analíticos da sequência de Degradação do Tetracloreto de Carbono

\section{Concentrações em $\mu \mathrm{g} / \mathrm{L}$}

PM SR01 M; PM SR01 B; PM SR02 J

\begin{tabular}{|l|c|c|c|}
\hline & \multicolumn{3}{|c|}{ Mês 10 } \\
\hline composto & PMSR01M & PMSR01B & PMSR02J \\
\hline tetracloreto de carbono & & & \\
\hline clorofórmio & 179 & 4 & \\
\hline cloreto de metileno & 154 & & 24 \\
\hline
\end{tabular}
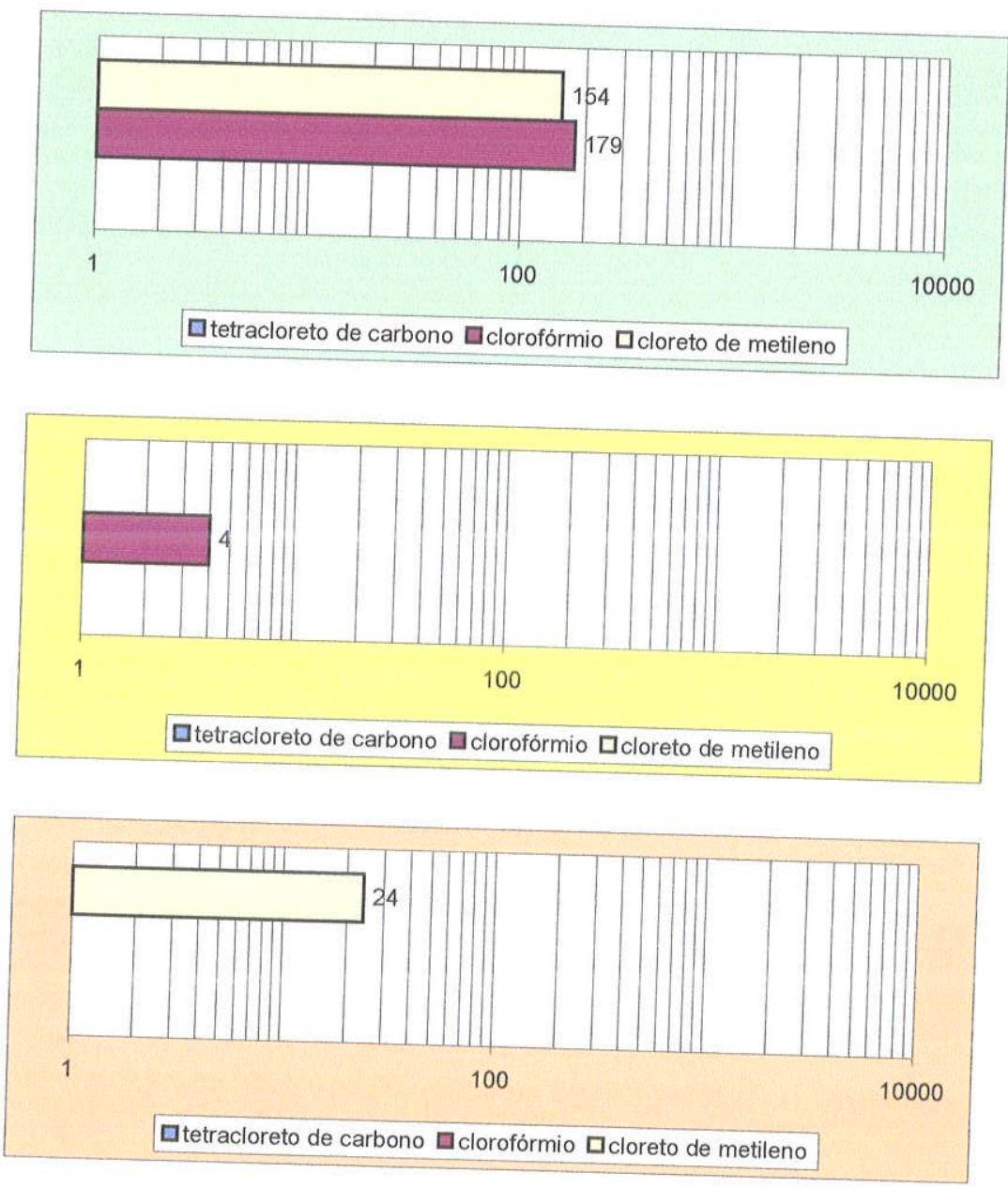
Tabela 40. Resultados analíticos da sequência de Degradação do Tetracloreto de Carbono

\section{Concentrações em $\mu \mathrm{g} / \mathrm{L}$}

PM SR01 M; PM SR01 B; PM SR02 J

\begin{tabular}{|l|c|c|c|}
\cline { 2 - 4 } \multicolumn{1}{c|}{} & \multicolumn{3}{c|}{ Mês 11 } \\
\hline composto & PMSR01M & PMSR01B & PMSR02J \\
\hline tetracloreto de carbono & & & \\
\hline clorofórmio & 95 & 4 & 335 \\
\hline cloreto de metileno & 42 & 38 & 18 \\
\hline
\end{tabular}
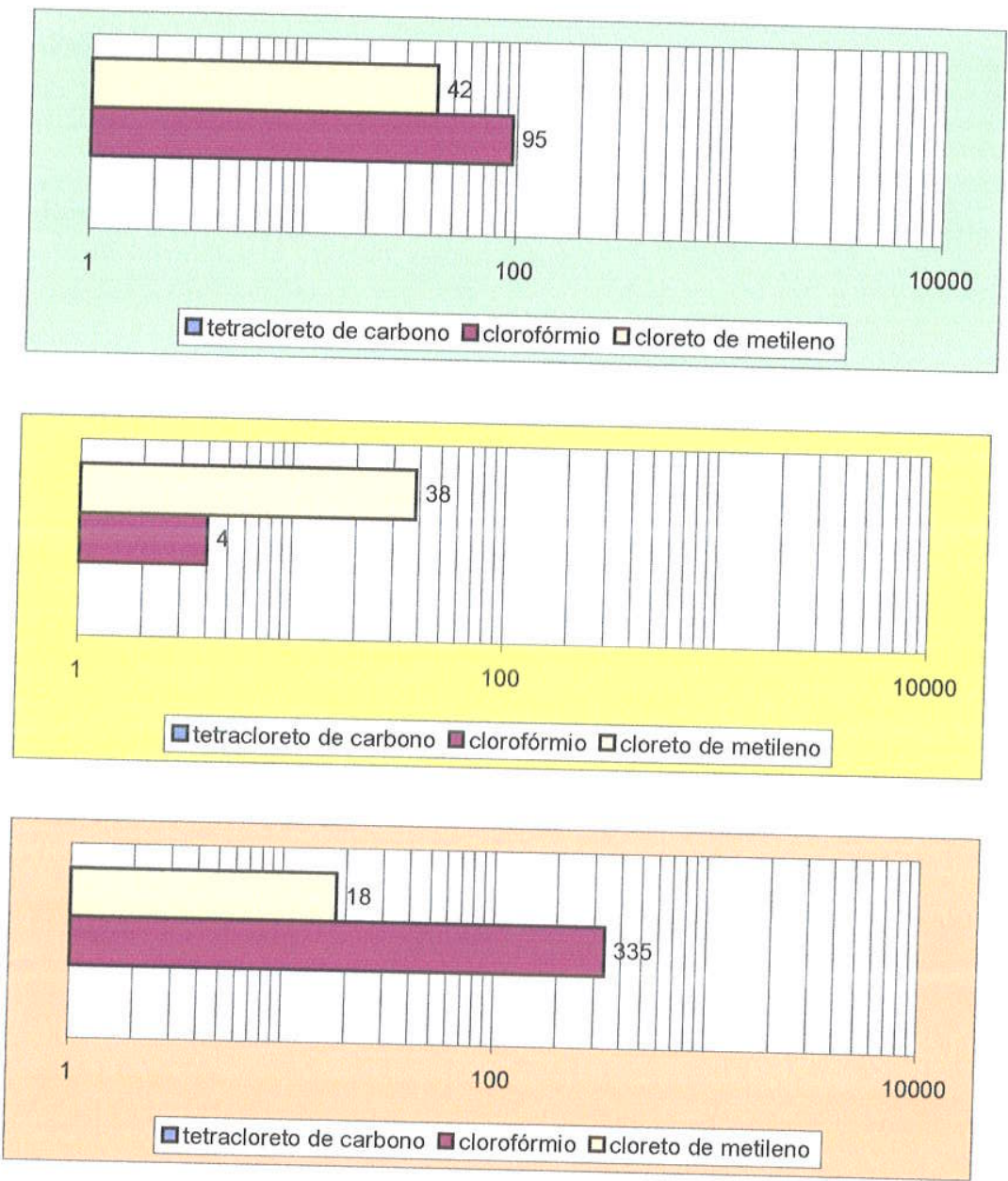
Tabela 41. Resultados analíticos da sequência de Degradação do Tetracloreto de Carbono

Concentrações em $\mu \mathrm{g} / \mathrm{L}$

PM SR01 M; PM SR01 B; PM SR02 J

\begin{tabular}{|l|c|c|c|}
\cline { 2 - 4 } \multicolumn{1}{c|}{} & \multicolumn{3}{c|}{ Mês 12 } \\
\hline composto & PMSR01M & PMSR01B & PMSR02J \\
\hline tetracloreto de carbono & & & \\
\hline clorofórmio & & & \\
\hline cloreto de metileno & 192 & 38 & \\
\hline
\end{tabular}
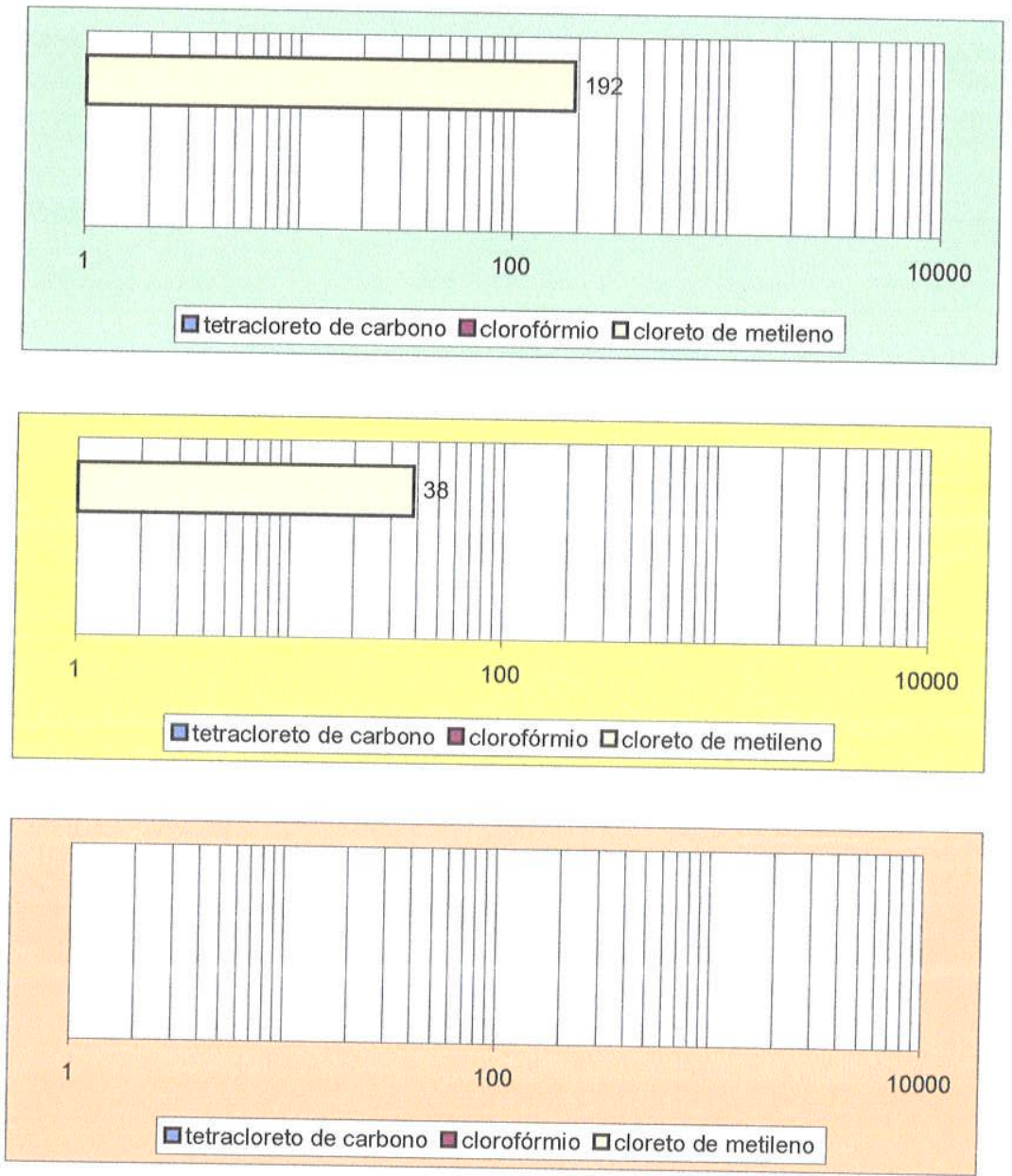
Não foram identificadas concentrações de tetracloreto de carbono acima dos limites de detecção, mas a seqüência de degradação redutiva pode ser inferida a partir do clorofórmio (Pankow; Cherry, 1996), que foi identificado em amostras coletadas no poço de montante e não foi identificado no poço de jusante, salvo no evento de monitoramento do Mês 11. O produto possivel desta degradação, cloreto de metileno, obedeceu ao mesmo padrão de identificação.

Em geral as concentrações de clorofórmio e de cloreto de metileno não apresentaram valores expressivos, o que permitiu a completa dehalogeneização após a passagem pela barreira reativa.

Os eventos dos Meses 8 e 10 apresentaram padrão distinto dos demais (o evento do Mês 11 é considerado anômalo) e indicaram a presença de cloreto de metileno no poço de jusante.

No primeiro evento citado observa-se porém, que a concentração de cloreto de metileno é superior a jusante à todas as concentrações deste composto identificadas nos eventos anteriores. Logo, a concentração de cloreto de metileno neste evento não pode ser relacionada à pluma de contaminação monitorada, a menos que seja produto de degradação de qualquer outro composto não analisado.

\subsection{Monitoramento de Parâmetros Inorgânicos}

Parâmetros inorgânicos foram monitorados nos poços, nem sempre na mesma data de coleta de amostras para determinação de compostos orgânicos, mas em datas próximas que permitem a correlação dos dados com os eventos originais.

A seqüência de Tabelas e Gráficos resultantes dos monitoramentos de parâmetros inorgânicos é apresentada a seguir. 
Tabela 42. Sequência de resultados analíticos para parâmetros inorgânicos

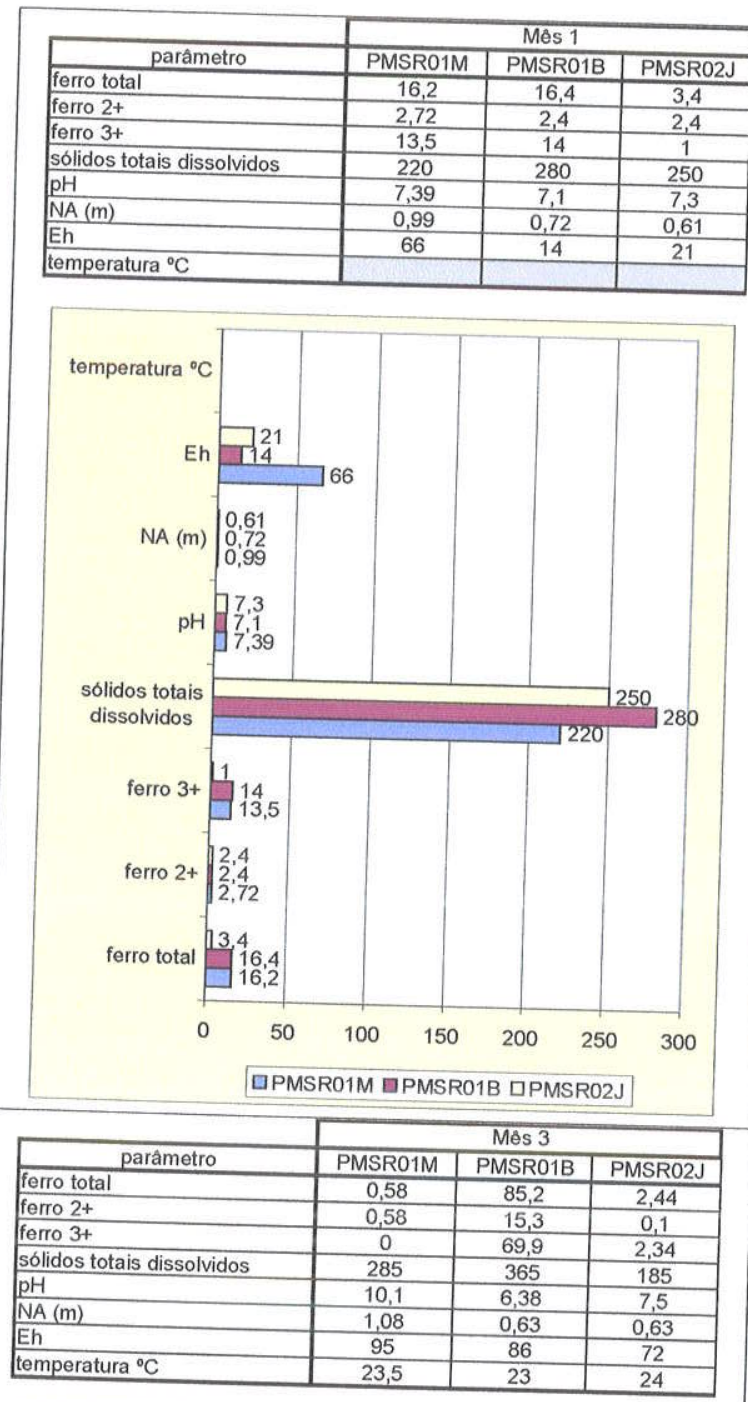

\begin{tabular}{|l|c|c|c|}
\cline { 2 - 4 } \multicolumn{1}{c|}{ parâmetro } & \multicolumn{3}{c|}{ Mês 2 } \\
\hline ferro total & PMSR01M & PMSR01B & PMSR02J \\
\hline ferro 2+ & 0,58 & 18,2 & 6,29 \\
\hline ferro 3+ & 0,28 & 18 & 5,96 \\
\hline sólidos totais dissolvidos & 0,3 & 0,2 & 0,33 \\
\hline pH & 245 & 180 & 230 \\
\hline $\mathrm{NA}(\mathrm{m})$ & 7,8 & 8,1 & 8,3 \\
\hline Eh & 0,81 & 0,6 & 0,6 \\
\hline temperatura ${ }^{\circ} \mathrm{C}$ & -19 & -30 & -43 \\
\hline
\end{tabular}
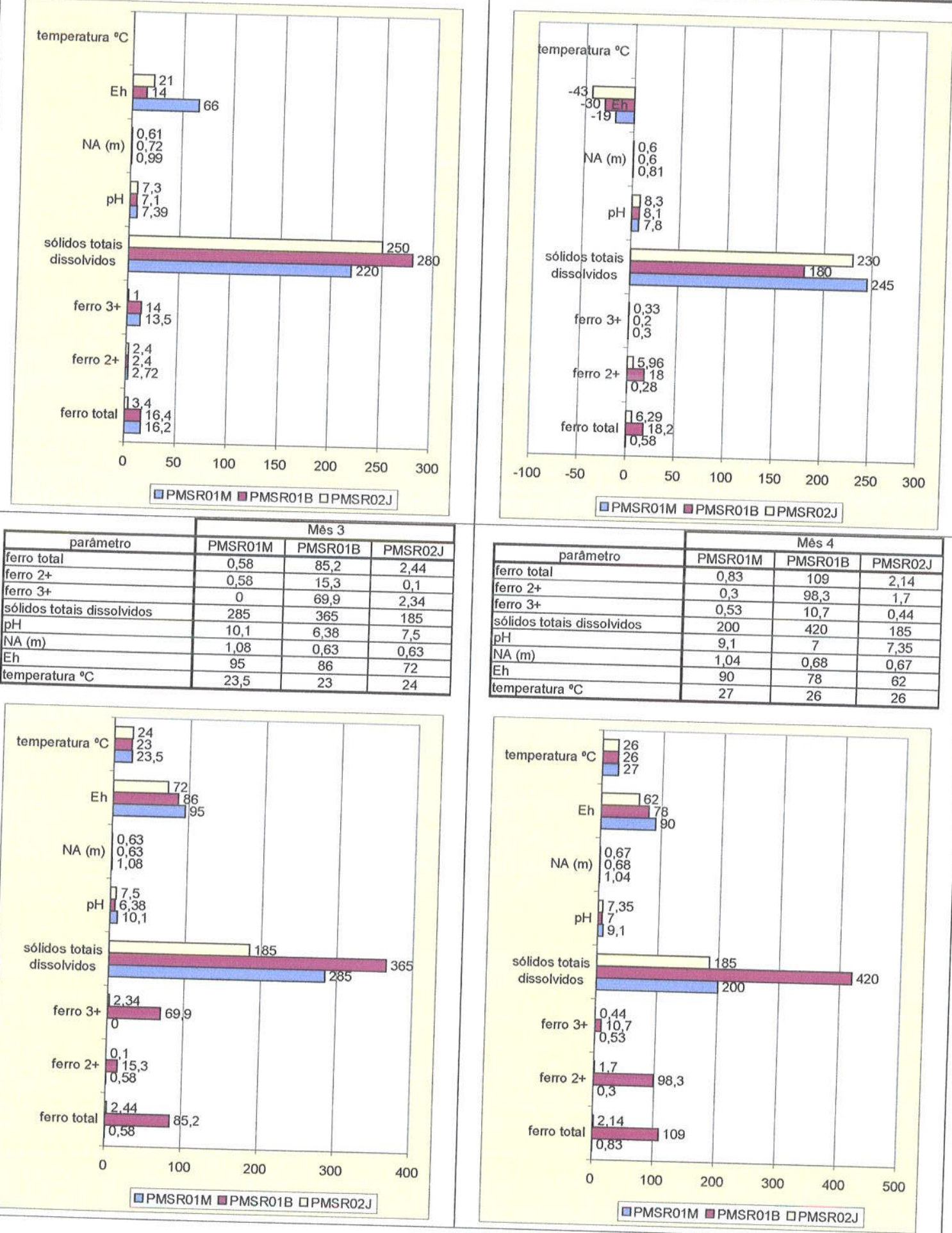
Tabela 42 cont. - Seqüência de resultados analíticos para parâmetros inorgânicos

\begin{tabular}{|l|c|c|c|}
\cline { 2 - 4 } \multicolumn{2}{|c|}{ parâmetro } & \multicolumn{3}{c|}{ Mès 5 } \\
\hline ferro total & PMSR01M & PMSR01B & PMSR02J \\
\hline ferro 2+ & 1,24 & 59,2 & 5,56 \\
\hline ferro 3+ & 0,67 & 5,96 & 4,75 \\
\hline sólidos totais dissolvidos & 0,57 & 53,2 & 0,81 \\
\hline $\mathrm{pH}$ & 220 & 435 & 145 \\
\hline $\mathrm{NA}(\mathrm{m})$ & 7,35 & 6,14 & 6,62 \\
\hline Eh & 0,8 & 0,4 & 0,4 \\
\hline temperatura ${ }^{\circ} \mathrm{C}$ & 45 & 0,58 & 0,63 \\
\hline
\end{tabular}

\begin{tabular}{|l|c|c|c|}
\cline { 2 - 4 } \multicolumn{1}{c|}{} & \multicolumn{3}{c|}{ Mếs 6 } \\
\hline parâmetro & PMSR01M & PMSR01B & PMSR02J \\
\hline ferro total & 0,9 & 100 & 3,75 \\
\hline ferro 2+ & 0,62 & 25 & 2,97 \\
\hline ferro 3+ & 0,28 & 75 & 0,78 \\
\hline sólidos totais dissolvidos & 255 & 435 & 175 \\
\hline pH & 7,23 & 6,5 & 6,94 \\
\hline NA $(m)$ & 0,5 & 0,5 & 0,5 \\
\hline Eh & 10,8 & 6,3 & 6,8 \\
\hline temperatura ${ }^{\circ} \mathrm{C}$ & 25 & 24 & 24 \\
\hline
\end{tabular}
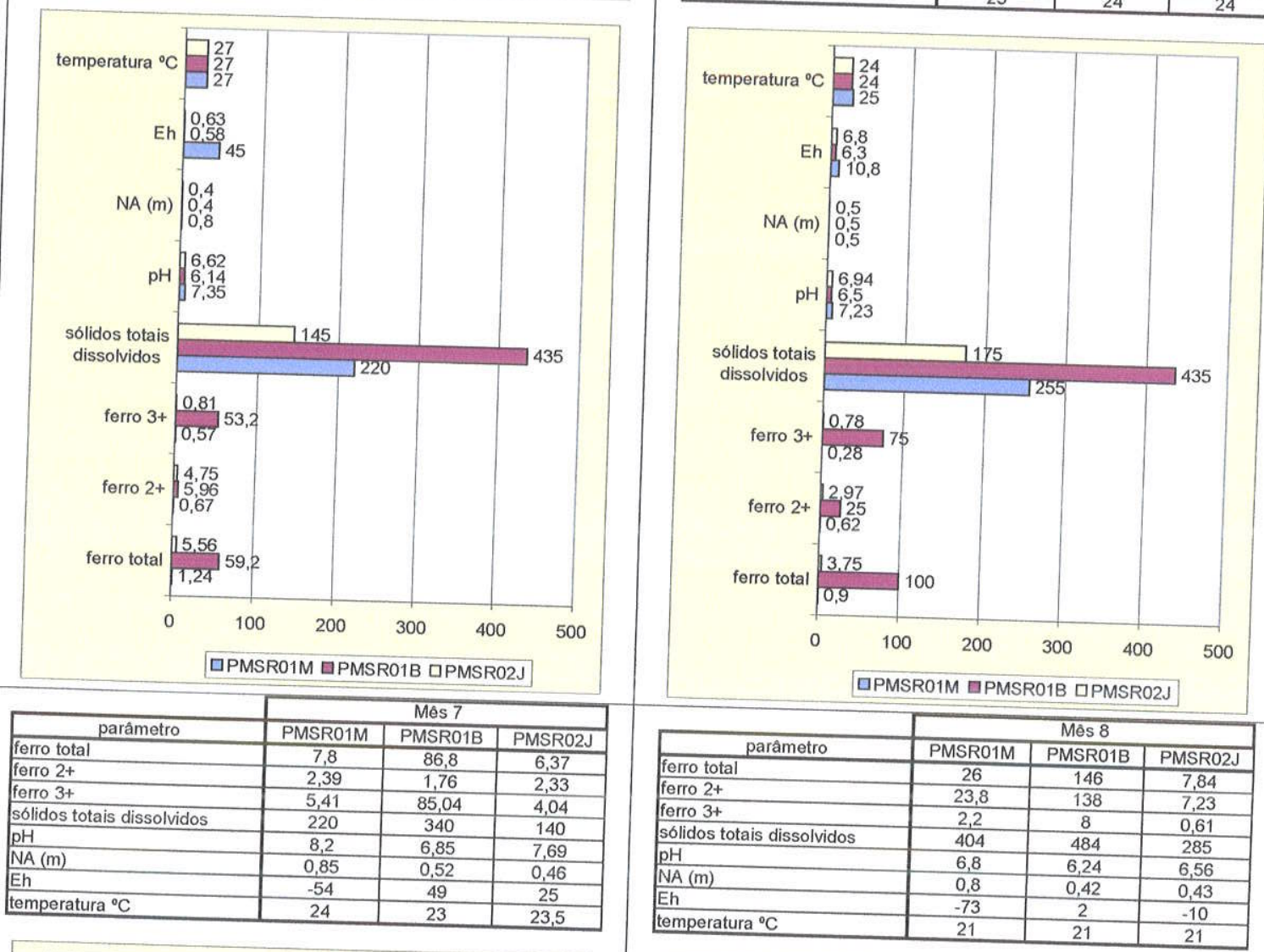

\begin{tabular}{|l|c|c|c|}
\cline { 2 - 4 } \multicolumn{1}{c|}{ parâmetro } & \multicolumn{3}{c|}{ Mês 7 } \\
\hline ferro total & PMSR01M & PMSR01B & PMSR02J \\
\hline ferro 2+ & 7,8 & 86,8 & 6,37 \\
\hline ferro 3+ & 2,39 & 1,76 & 2,33 \\
\hline Sólidos totais dissolvidos & 5,41 & 85,04 & 4,04 \\
\hline pH & 220 & 340 & 140 \\
\hline NA $(m)$ & 8,2 & 6,85 & 7,69 \\
\hline Eh & 0,85 & 0,52 & 0,46 \\
\hline temperatura ${ }^{\circ} \mathrm{C}$ & -54 & 49 & 25 \\
\hline
\end{tabular}
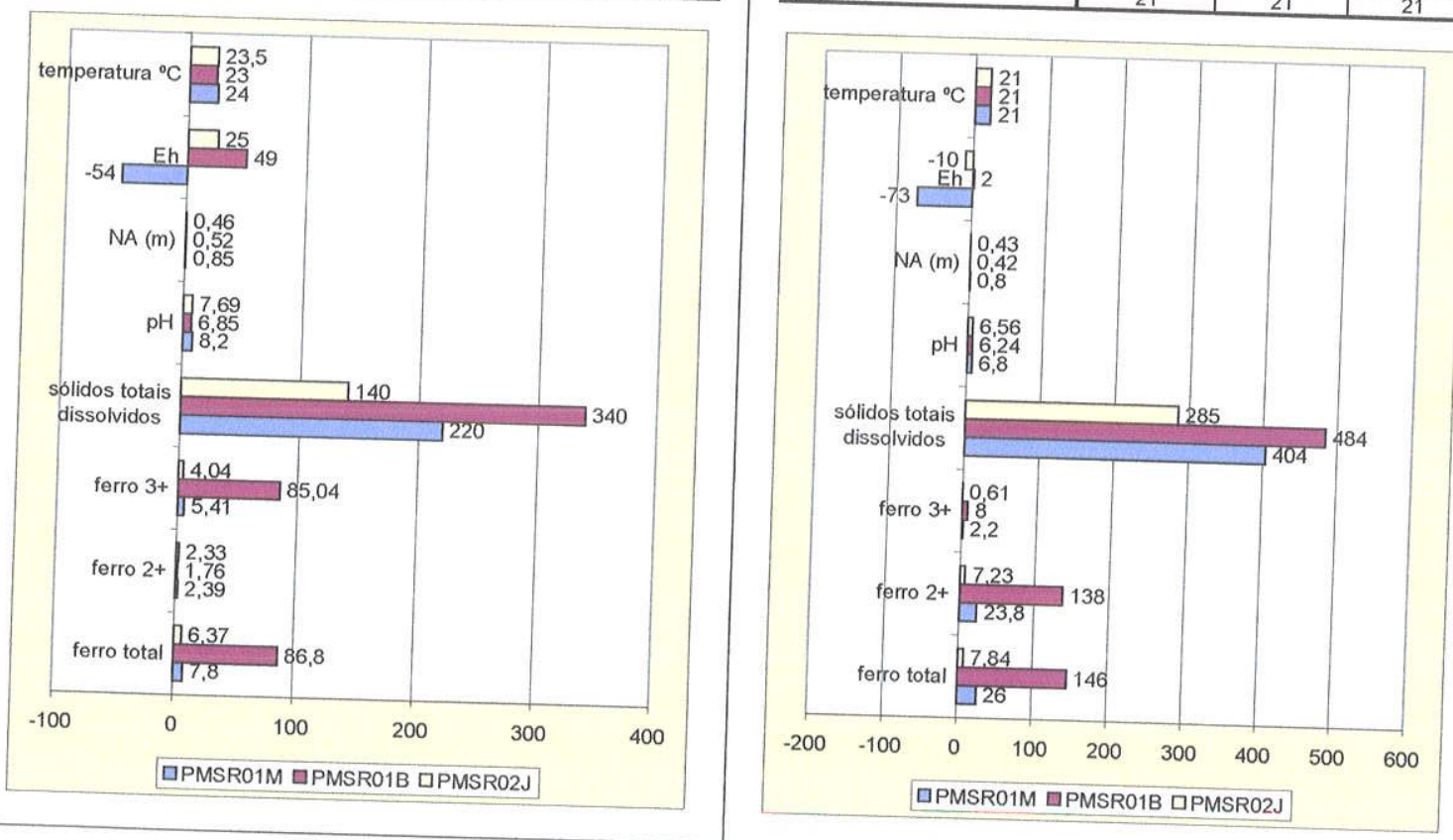
Tabela 42 cont. - Seqüência de resultados analíticos para parâmetros inorgânicos

\begin{tabular}{|l|c|c|c|}
\cline { 2 - 4 } \multicolumn{1}{c|}{ parâmetro } & \multicolumn{3}{c|}{ Mês 9 } \\
\hline ferro total & PMSR01M & PMSR01B & PMSR02J \\
\hline ferro 2+ & 72 & 126 & 13,5 \\
\hline ferro 3+ & 70,9 & 115 & 11,7 \\
\hline sólidos totais dissolvidos & 1,1 & 11 & 1,8 \\
\hline pH & 458 & 505 & 310 \\
\hline $\mathrm{NA}(\mathrm{m})$ & 6,5 & 6,2 & 6,6 \\
\hline Eh & 0,77 & 0,41 & 0,37 \\
\hline temperatura ${ }^{\circ} \mathrm{C}$ & -95 & -47 & -40 \\
\hline
\end{tabular}

\begin{tabular}{|l|c|c|c|}
\hline \multicolumn{1}{|c|}{ parâmetro } & \multicolumn{3}{c|}{ Mês 10 } \\
\hline ferro total & PMSR01M & PMSR01B & PMSR02J \\
\hline ferro 2+ & 70 & 152 & 15,6 \\
\hline ferro 3+ & 68,4 & 139 & 10 \\
\hline sólidos totais dissolvidos & 1,6 & 13 & 5,6 \\
\hline pH & 570 & 390 & 230 \\
\hline NA $(m)$ & 6,82 & 6,12 & 6,61 \\
\hline Eh & 1,3 & 0,89 & 0,88 \\
\hline temperatura ${ }^{\circ} \mathrm{C}$ & 31 & 72 & 11 \\
\hline
\end{tabular}
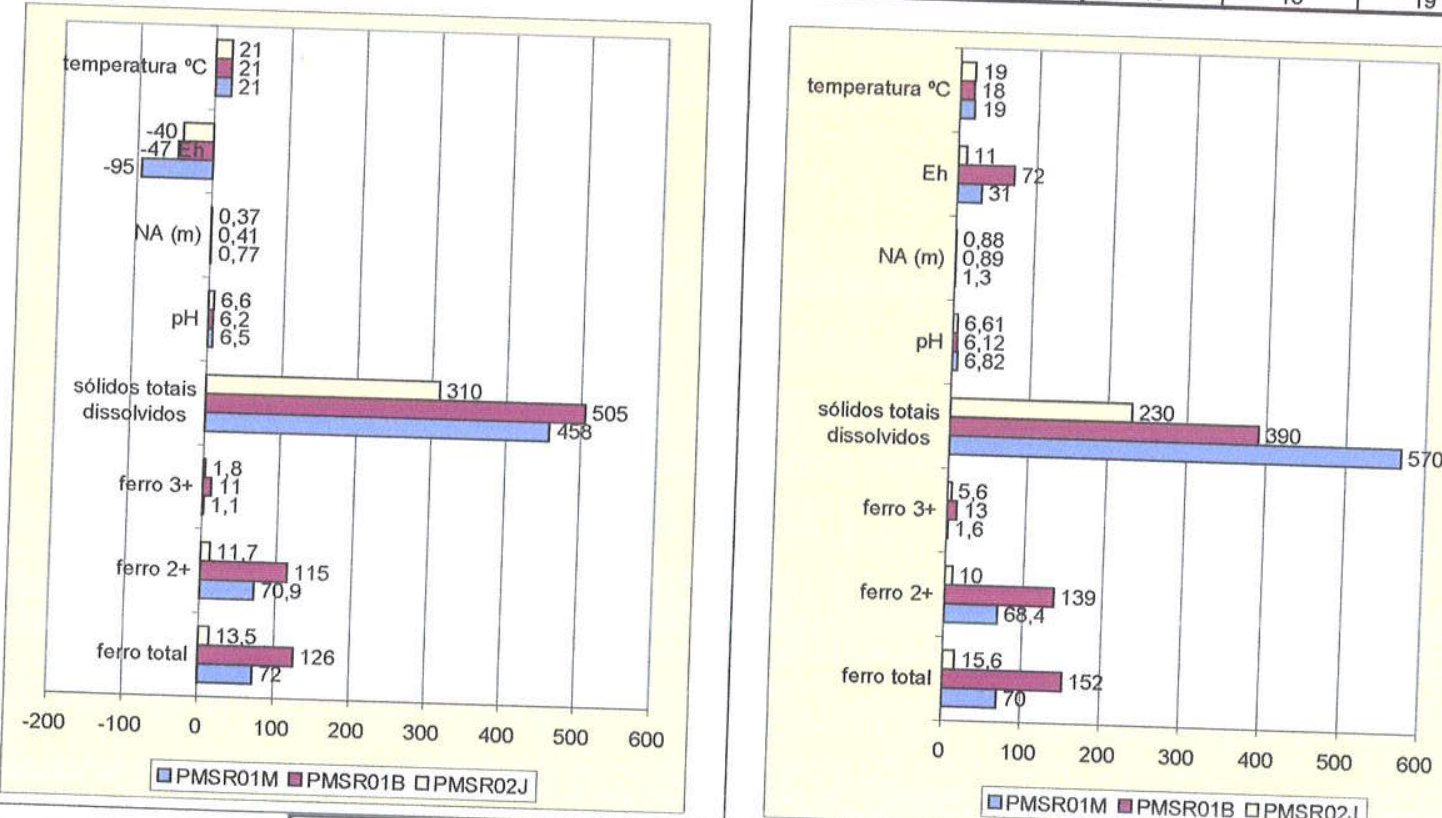

\begin{tabular}{|l|c|c|c|}
\cline { 2 - 4 } \multicolumn{1}{c|}{ parâmetro } & \multicolumn{3}{c|}{ Mês 11 } \\
\hline ferro total & PMSR01M & PMSR01B & PMSR02J \\
\hline ferro 2+ & 81,2 & 161 & 28,8 \\
\hline ferro 3+ & 77,9 & 154 & 23,4 \\
\hline sólidos totais dissolvidos & 3,3 & 7 & 5,4 \\
\hline pH & 520 & 575 & 240 \\
\hline $\mathrm{NA}(\mathrm{m})$ & 6,61 & 6,15 & 6,55 \\
\hline Eh & 1,41 & 0,94 & 1,3 \\
\hline temperatura ${ }^{\circ} \mathrm{C}$ & -25 & 40 & 15 \\
\hline
\end{tabular}

\begin{tabular}{|c|c|c|c|}
\hline \multicolumn{4}{|c|}{ 口PMSR01M EPMSR01B DPMSR02J } \\
\hline & \multicolumn{3}{|c|}{ Mês 12} \\
\hline parâmetro & PMSR01M & PMSR01B & PMSR02J \\
\hline ferro total & 32,8 & 126 & 7,18 \\
\hline ferro $2+$ & 31,2 & 121 & 6,89 \\
\hline ferro $3+$ & 1,6 & 5 & 0,29 \\
\hline sólidos totais dissolvidos & 420 & 568 & 265 \\
\hline 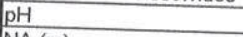 & 7 & 6,55 & 6,97 \\
\hline NA $(m)$ & 1,45 & 0,8 & 0,79 \\
\hline Eh & 134 & 158 & 257 \\
\hline temperatura ${ }^{\circ} \mathrm{C}$ & 21,5 & 21 & 21 \\
\hline
\end{tabular}
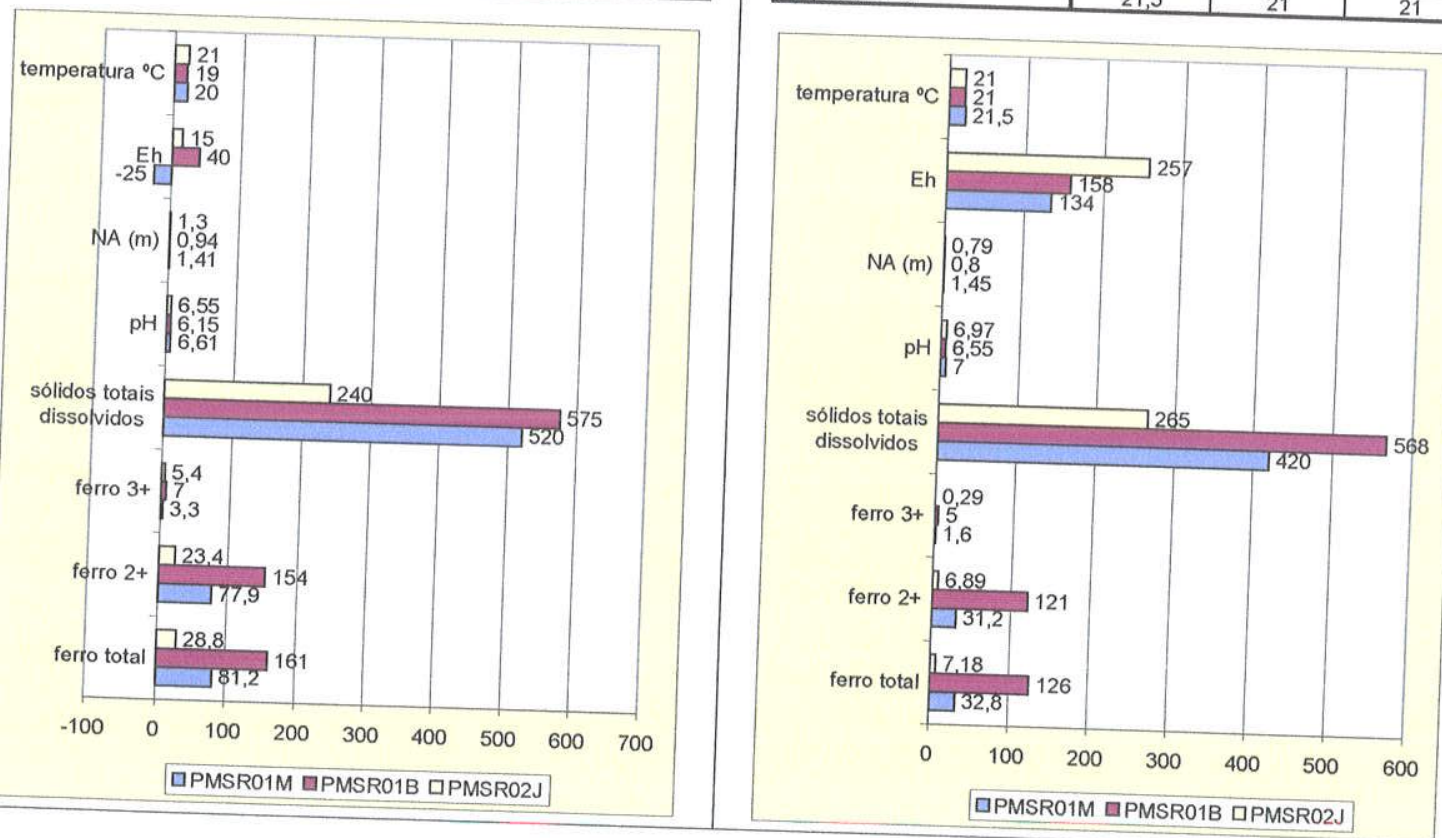
Os resultados apresentados anteriormente indicaram que a água subterrânea apresentou no período de monitoramento variação de $\mathrm{pH}$ entre o mínimo de 6,5 e o máximo de 10,1, em geral apresentando redução na passagem do PM SR01 M para o PM SR01 B e tornando a elevarmse no PM SR02 J.

As concentrações de ferro bivalente acompanham as variações de $\mathrm{pH} e$ se apresentam em maiores valores na medida em que o $\mathrm{pH}$ diminui.

Com exceção dos Meses 1 e 7 as concentrações de ferro bivalente aumentam na passagem do PM SR01 M para o PM SR01 B, indicando a oxidação do ferro metálico utilizado como material reativo no sistema de remediação.

O aumento das concentrações de $\mathrm{Fe}^{2+}$ no interior da barreira é acompanhado do aumento das concentrações de $\mathrm{Fe}^{3+}$, no entanto, as concentrações totais de ferro diminuem muito no PM SRO2 J. Este fator indica que o ferro está sendo consumido dentro da barreira reativa e a oxidação para a forma trivalente possivelmente está provocando a sua precipitação.

A precipitação do ferro trivalente não provocou alteração da eficiência da barreira até o último evento de monitoramento apresentado, uma vez que as concentraçôes de compostos organoclorados continuam apresentando redução após a passagem pelo sistema de remediação, no entanto, o acúmulo de ferro precipitado tende a reduzir a porosidade da barreira reativa, provocando:

- Aumento da velocidade de fluxo e conseqüente redução do tempo de residência dos contaminantes dentro da barreira reativa, o que diminui a eficiência do sistema de remediação; e/ou

- Redução da capacidade de escoamento da barreira reativa, provocando a passagem de água pelas laterais do material reativo. No caso de barreiras contínuas, a redução da porosidade e conseqüentemente da vazão, sem a possibilidade de fluxo pela lateral do sistema, pode provocar a passagem de água por sobre a barreira e, no caso onde o nível d'água encontra-se a pequena profundidade a partir da superfície do terreno (como no caso estudado), pode haver afloramento de água. 
Os meses caracterizados por maiores índices pluviométricos apresentam concentrações de $\mathrm{Fe}^{3+}$ geralmente mais elevadas que as concentrações de $\mathrm{Fe}^{2+}$, sugerindo que podem ter ocorrido reações de dehalogeneização a partir da presença de ferro bivalente derivado da corrosão do ferro metálico.

A tendência é revertida a partir do Mês 8 , onde se inicia o periodo com menores índices pluviométricos, indicando aumento das concentrações de $\mathrm{Fe}^{2+}$ em detrimento das de $\mathrm{Fe}^{3+}$, acompanhando a tendência de rebaixamento do nivel d'água freático. Neste período observa-se também redução generalizada dos valores de $\mathrm{pH}$, sugerindo reações de consumo de $\mathrm{H}_{2}$ e produção de $\mathrm{H}^{+}$.

O evento de monitoramento do Mês 11, que apresentou concentrações anômalas de compostos orgânicos, não indica correlação com concentrações de parâmetros inorgânicos que evidenciem a causa das anomalias. 


\section{EFICIÊNCIA DO SISTEMA DE REMEDIAÇÃO NA REMOÇÃO DE CONTAMINANTES}

Apesar da inexistência de uma estimativa do volume ou massa de contaminantes que constituem a fonte de contaminação em solo e águas subterrâneas, para avaliação do sistema de remediação podem-se efetuar algumas considerações.

Utilizando a relação de Darcy, considera-se a vazão de água subterrânea através da área da barreira reativa $(5,15 \mathrm{~m}$ de profundidade por $3,0 \mathrm{~m}$ de extensão), adotando-se os parâmetros hidrogeológicos apresentados, gradiente hidráulico de $5,22 \%$, porosidade efetiva de $12 \%$ (Fetter, 1988) e condutividade hidráulica variando entre $8,1 \times 10^{-4} \mathrm{~cm} / \mathrm{s}$ e $3,0 \times 10^{-6} \mathrm{~cm} / \mathrm{s}$. Como resultado, obtém-se a vazão $Q$ máxima aproximada de $0,2 \mathrm{~m}^{3} / \mathrm{h}$.

Desconsiderando o evento de monitoramento do Mês 11, que apresentou valores anômalos para todos os parâmetros analiticos considerados, apresentam-se os valores da Tabela 43.

Tabela 43. Concentrações totais de organoclorados nos poços monitorados

\begin{tabular}{|c|c|c|c|c|}
\hline Poço Monitorado & $\begin{array}{c}\text { Concentrações Totais } \\
\text { de Etanos }(\mu \mathrm{g} / \mathrm{L} .)\end{array}$ & $\begin{array}{c}\text { Concentrações } \\
\text { Totais de Etenos } \\
(\mu \mathrm{g} / \mathrm{L})\end{array}$ & $\begin{array}{c}\text { Concentraçöes } \\
\text { Totais de } \\
\text { Clorofórmio e } \\
\text { Cloreto de Metileno } \\
(\mu g / L)\end{array}$ & $\begin{array}{l}\text { Total } \\
(\mu g / L)\end{array}$ \\
\hline PM SRO $1 \mathrm{M}$ & 32.070 & $\{4.722$ & 1.902 & 48.694 \\
\hline PM SR01 B & 65.245 & 1.791 & 771 & 67.807 \\
\hline PM SR02 J & 10.702 & 0 & 1.224 & 11.926 \\
\hline
\end{tabular}

A soma das concentrações obtidas para o PM SR01 B $(67.807 \mu \mathrm{g} / \mathrm{L})$ é superior à soma dos totais obtidos para os poços de montante $(48.694 \mu \mathrm{g} / \mathrm{L}) \mathrm{e}$ jusante (11.926 $\mu \mathrm{g} / \mathrm{L})$.

Os dados apresentados limitam-se às três séries de degradação (etenos, etano e tetracloreto de carbono) e a um número limitado de compostos analisados. 
Sabe-se que a fonte de contaminação, suas características e as condições que a originaram não permitem avaliar a quantidade total de contaminantes que atingiram a água subterrânea, tão pouco a composição da mistura que compõe a pluma de contaminação, desta forma, inviabilizando o balanço de massa de contaminantes em remediação.

A pluma de contaminantes apresenta uma diversidade de compostos não avaliada neste trabalho e o aumento das concentrações dentro da barreira reativa indica que a degradação de compostos não analisados pode gerar subprodutos que se enquadram dentro da faixa de compostos analisados, principalmente na série dos etanos, cujas concentrações totais mais que duplicam dentro da zona reativa da barreira.

Os dados obtidos indicam que a concentração final total de contaminantes reduz -se a menos de $25 \%$ do observado no poço de montante (PM SR01 M), corroborando a eficiência já constatada e medida nos resultados dos monitoramentos apresentadas nos subitens 7.1, 7.2 e 7.3.

Sabendo que a vazão máxima calculada pode atingir $0,2 \mathrm{~m}^{3} / \mathrm{h}$, e adotando-se onze meses de trinta dias para o período monitorado, chega-se ao total de $7.920 \mathrm{~h}$ que perfazem o volume de $1.584 \mathrm{~m}^{3}$ de água subterrânea que atravessa o sistema de remediação instalado em escala piloto.

Adotando-se os valores da Tabela 43, que indica os valores das concentrações totais de organoclorados nos poços monitorados, podemse avaliar que no período analisado (excluindo-se o evento de monitoramento do Mês 11), para o volume calculado de $1.584 \mathrm{~m}^{3}$ de água, a massa total média de organoclorados monitorados atingiu cerca de $77 \mathrm{~kg}$ a montante, $107 \mathrm{~kg}$ no interior da barreira reativa e $19 \mathrm{~kg}$ no poço de jusante.

O potencial reativo da barreira instalada em escala piloto permaneceu inalterado, como refletido nos resultados analíticos do último evento de monitoramento. Este dado permite afirmar que a vida útil da barreira é superior, nas condições implantadas aos 29 meses ou 2 anos e 5 meses contados a partir de sua instalação. 
Estes números permitem reafirmar a eficiência do sistema, além de atestar o benefício de sua aplicação na redução dos custos de tratamentos para as concentrações não degradadas e na atenuação das concentrações para eventuais pontos receptores a jusante. 


\section{CONCLUSÕES SOBRE O SISTEMA DE REMEDIAÇÃO IN SITU}

A disponibilidade natural do ferro é uma possível alternativa para dehalogeneização de compostos organoclorados.

A geologia local, constituída por sequeência de rochas metamórficas compostas por sericita-xistos e filitos pertencentes ao Grupo Açungui, do Proterozóico Superior, é importante por apresentar rochas que contêm argilominerais em sua composição e pelo fato destes serem ricos em ferro.

Em água subterrânea, com exceção dos dados obtidos no monitoramento dos Meses 1 e 7, as concentrações de ferro bivalente aumentam na passagem do poço instalado a montante da Barreira Reativa (PM SR01 M) para o poço instalado no interior da Barreira Reativa (PM SR01 B), indicando a oxidação do ferro metálico utilizado como material reativo no sistema de remediação.

O aumento das concentrações de $\mathrm{Fe}^{2+*}$ no interior da barreira é acompanhado do aumento das concentrações de $\mathrm{Fe}^{3+}$, no entanto, as concentrações totais de ferro diminuem muito no PM SR02 J, instalado a jusante da barreira reativa, o que indica a precipitação do $\mathrm{Fe}^{3+*}$.

O acúmulo de ferro precipitado tende a reduzir a porosidade da barreira reativa, provocando:

- Para a mesma vazão de água definida no dimensionamento da Barreira, aumento da velocidade de fluxo e conseqüente redução do tempo de residência dos contaminantes dentro da barreira reativa, o que diminui a eficiência do sistema de remediação; e/ou

- Redução da capacidade de escoamento da barreira reativa, podendo provocar a passagem de água pelas laterais do material reativo. No caso de barreiras contínuas, a redução da porosidade e conseqüentemente da vazão, sem a possibilidade de fluxo pela lateral do sistema, pode provocar a passagem de água por sobre a barreira e, no caso onde o nível d'água encontra-se a pequena profundidade a partir da superfície do terreno (como no caso estudado), pode haver afloramento de água. 
Os resultados obtidos no monitoramento da barreira concluído após 29 meses contados a partir da data de sua instalação indicam que a proporção da mistura reativa adotada, de $81,93 \%$ em massa de areia para $18,07 \% \mathrm{em}$ massa de granalha, mostroumse eficiente para manutenção da capacidade reativa do sistema por, no mínimo, de 2 anos e 5 meses para as condições físico-químicas encontradas.

A forma com que foi originada a pluma de contaminação não permite que seja feito o balanço de massa dos contaminantes, tão pouco permite definir a composição da mistura que a compõe.

Mesmo na ausência de um balanço de massa definido, as análises para determinação de VOC evidenciam que a barreira reativa preenchida por ferro zero-valente não é suficiente para remediação de todos os compostos determinados na área avaliada exigindo a adoção de técnicas mistas de remediação.

Para solventes clorados de cadeias simples (etanos) a degradação obtida foi melhor que a esperada ao longo dos eventos de monitoramento, uma vez que a literatura consultada não prevê a degradação dos etanos analisados. Contudo o tempo de residência foi insuficiente para completa dehalogeneização, o que resultou em concentrações de cloroetano em amostra do poço de jusante.

Para os solventes clorados de cadeia dupla (etenos) obteve-se completa degradação dos compostos presentes na seqüência de dahalogeneização entre o tetracloroeteno e o cloreto de vinila, concluindo portanto que o sistema é totalmente aplicável para estes compostos.

No período analisado, excluindo-se o evento do Mês 11, calculamse em $1.584 \mathrm{~m}^{3}$ o volume de água subterrânea que passou pela barreira reativa.

Para o volume de água calculado, adotando-se a soma das concentrações dos organoclorados monitorados, a massa total atingiu cerca de $77 \mathrm{~kg}$ no poço de montante, $107 \mathrm{~kg}$ no interior da barreira reativa e $19 \mathrm{~kg}$ no poço de jusante, atestando a eficiência do sistema e o benefício de sua aplicação na redução dos custos de tratamentos para as concentrações não degradadas e na atenuação das concentrações para eventuais pontos 
receptores a jusante.

A soma das concentrações obtidas para o PM SR01 B é superior à soma dos totais obtidos para os poços de montante e jusante. A pluma de contaminantes apresenta uma diversidade de compostos não avaliada neste trabalho e o aumento das concentrações dentro da barreira reativa indica que a degradação destes compostos pode gerar sub-produtos que se enquadram dentro da faixa de compostos analisados, principalmente na série dos etanos, cujas concentrações totais mais que duplicam dentro da zona reativa da barreira.

O resultado final indica que a concentração final total de contaminantes reduz-se a menos de $25 \%$ do observado no poço de montante, corroborando a eficiência constatada e medida.

A massa de contaminantes apresentada não reflete toda a eficiência da Barreira Reativa, uma vez que compostos não monitorados certamente atravessaram o sistema de remediação e foram degradados, permitindo concluir que a massa total de contaminantes tratada no período foi superior à calculada. 


\section{RECOMENDAÇÔES SOBRE O SISTEMA DE REMEDIAÇÃO IN SITU}

Para obter eficiência em novos sistemas de remediação por Funnel and Gate que sigam a metodologia apresentada neste trabalho, recomenda-se que a hidrogeologia local e a extensão da pluma de contaminantes sejam muito bem definidas, de forma que a barreira possa ser corretamente dimensionada para captação de toda a frente de contaminação e que suas dimensões sejam suficientes para total dehalogeneização dos compostos de interesse.

Para a avaliação da eficiência do sistema de remediação, o monitoramento das concentrações de VOCs e de parâmetros inorgânicos é eficaz, mas recomenda-se analisar as seqüências completas de degradação dos compostos de interesse, incluindo sub-produtos não tóxicos como cloretos.

A avaliação da longevidade da barreira é um outro enfoque de pesquisa e deve englobar análises de outros parâmetros (Wilkin et al., 2003) que permitam definir efeitos geoquímicos e biológicos no processo de degradação e no material reativo.

A barreira reativa deve ser impermeabilizada nas suas laterais, de forma a evitar fluxo lateral e perda de contaminantes antes de sua total degradação.

Dependendo da extensão da barreira reativa, um poço de monitoramento localizado a montante, outro no seu interior, e um a jusante são suficientes para acompanhar a evolução do sistema. Os poços devem ser instalados em número suficiente para interceptação das plumas de contaminantes que atravessam a barreira em toda a sua extensão, assim sendo, barreiras extensas podem exigir a instalação de mais de um poço nas diferentes posições citadas.

Poços a montante e a jusante da barreira impermeável também são indicados para monitoramento de sua eficiência no impedimento de fluxo fora da zona reativa. 
A instalação de poços seqüenciais no interior da barreira reativa, no sentido preferencial de fluxo da água subterrânea, é aconselhável para acompanhamento do processo degradativo e eventual determinação das rotas de degradação predominantes.

Para a avaliação da eficiência da remediação de uma área contaminada deve-se levar em consideração não apenas a degradação na barreira reativa, mas também a degradação proporcionada pela disponibilidade de ferro no aqüífero estudado. Esta verificação pode ser feita através da análise dos compostos clorados de interesse, de seus sub-produtos, das concentrações de ferro e de parâmetros físico-químicos em poços de monitoramento instalados em seqüência (alinhados no sentido preferencial de fluxo da água subterrânea) dentro da pluma de contaminantes e posicionados antes e após a barreira reativa.

A Barreira Reativa foi dimensionada em escala piloto e não teve como objetivo interceptar toda a frente de contaminação, razão pela qual ensaios hidráulicos foram dispensados. Para sistemas definitivos de remediação, o padrão de fluxo da água subterrânea deve ser definido através da definição de suas variações sazonais, de sua relação com o ciclo hidrológico e através de modelagens matemáticas calibradas com dados reais de campo, permitindo avaliar os efeitos causados pela implantação de barreira que altere o fluxo em equilíbrio. 


\section{REFERÊNCIAS BIBLIOGRÁFICAS}

ABNT - Associação Brasileira de Normas Técnicas (1997)

NBR 13.895 - Construção de Poços de Monitoramento e Amostragem.

Barker, J.F.; Smyth, D.; Cherry, J.A. (1994) Controlled In Situ Groundwater Treatment. NATO/CCMS Pilot Study Meeting on the Evaluation of Demonstrated and Emerging Technologies for the Treatment ans Clean-Up of Contaminated Land and Groundwater. Oxford, U.K. September 19-22.

CETESB - Companhia de Tecnologia de Saneamento Ambiental (2001) Estabelecimento de Valores Orientadores para Solos e Água Subterrânea no Estado de São Paulo: Relatório Final. São Paulo, 246p.

CETESB - Companhia de Tecnologia de Saneamento Ambiental (2005) Áreas Contaminadas no Estado de São Paulo. Diretoria de Controle de Poluição Ambiental. Diretoria de Tecnologia, Engenharia e Qualidade Ambiental. Maio de 2005. Relação disponivel em http://www.cetesb.sp.gov.br/Solo/areas_contaminadas/relacao_.. areas.asp Fetter, C.W. (1988) Applied Hydrogeoloy. Merril Publishing Company. $2^{\text {nd }}$ edition. $591 \mathrm{p}$.

Gavaskar, A et al. (1997) Design Guidance for Application of Permeable Barriers to Remediate Dissolved Chlorinated Solvents. U.S. Air Force. February. 104p.

Gillham, R.W.; O'Hannesin, S.F. (1992) Metal-Catalysed Abiotic Degradation of Halogenated Organic Compounds. IAH Conference "Modern Trends in Hydrogeology, Hamilton, Ontario Canada, May 10-13.

Gusmão, A.D. (1999) Uso de Barreira Reativas na Remediação de Aqüíferos Contaminados. Tese de Doutoramento. Pontifícia Universidade Católica do Rio de Janeiro. Departamento de Engenharia Civil. 251 p. Setembro de 1999.

Harte et al (1991) Toxics A to Z, A Guide to Everyday Pollution Hazards. University of California Press, Oxford, England. $479 \mathrm{p}$. 
Kueper, B.H.; Feenstra, S., Rivett, M.O.; Cherry, J.A. (1992) A Series of Controlled Field Experiments to Study DNAPL Behavior: Implications for Site Remediation. HAZMAT International. Hazard Materials and Environmental Management Conference and Exhibition. Atlantic City, NJ. June 10-12.

Kueper, B.H.; Starr, R.C.; Reitsma, S.; Mah,M. (1993) A Field Experiment to Study the Behavior of Tetrachloroethylene Below the Water Table: Spatial Distribution of Residual and Pooled DNAPL. Ground Water, vol. 31, No. 5. September-October.

Mackay, D.M.; Cherry, J.A. (1989). Groundwater Contamination: Pump-andTreat Remediation (Second of a five parts). Environmental Science and Technology, vol 23, No. 6.

Ministério da Saúde (2004) Portaria 518 - Norma de Qualidade da Água para Consumo Humano. 25 de março de 2004.

Mccarty, P.L.; Semprini, L. (1992) Engineering and Hydrogeological Problems Associated with In Situ Treatment. In Situ Bioremediation Symposium. Niagara-on-the-Lake, Ontario, Canada, 20-24 september. P.261-272.

O'Hannesin, S.F. and Gillham, R.W. (1992) A Permeable Reaction Wall For In Situ Degradation of Halogenated Organic Compounds. $45^{\text {th }}$ Canadian

Geotechnical Society Conference, Toronto, Ontario, Oct 25-28.

Orth, W.S. and Gillham, R.W. (1993) Mass Balance of Degradation of Trichloroethylene in The Presence of Iron Fillings. Joint CSCE-ASCE National Conference on Environmental Engineering, Montreal, July 12-14.

Pankow, J.F. and Cherry, J.A. (1996) Dense Chlorinated Solvents and Other DNAPLs in Groundwater. Waterloo Press.

Pereira, W.S. e Freire, R.S. (2005) Ferro Zero: Uma Nova Abordagem para o Tratamento de Águas Contaminadas com Compostos Orgânicos Poluentes. Química Nova, Vol. 28, No. 1, 130-136.

Powell \& Associates Science Services (1998) Contaminant Remediation Using Permeable Reactive Barriers. Web Site. 
Rivett, M.O; Feenstra, S.; Cherry, J.A. (1992) Pump-and-Treat Remediation of a Chlorinated Solvent Plume: A Field Study. Subsurface Restoration Conference, $3^{\text {nd }}$ International Conference on Ground Water Quality Research. Dallas, Texas. June 21-24.

Salles, F.A.F (1999) Avaliação de Área Contaminada por Compostos Orgânicos às Margens da Represa de Guarapiranga, no Município de São PauloSP". Dissertação de Mestrado. Instituto de Geociências da Universidade de São Paulo. Junho de 1999. 99p.

Smith, D.J.A.; Cherry, J.A.; Jowett, R.J. (1994) Funnel-And-Gate for In Situ Groundwater Plume Containment. Superfund XV, Washington D.C, November 28 - December 1.

Starr, R.C. and Cherry, J.A. (1992) Applications of Low Permeability Cutoff Walls for Groundwater Pollution Control. 45 ${ }^{\text {th }}$. Canadian Geotechnical Conference. Toronto, Canada. October 26-28.

Starr, R.C. and Cherry, J.A. (1994a) In Situ Remediation of Contaminated Ground Water: The Funnel-and-Gate System. Ground Water, V.32, No.3.

Starr, R.C. and Cherry, J.A. (1994b) In Situ Barriers for Groundwater Pollution Control. Prevention and Treatment of Soil and Groundwater Contamination in the Petroleum Refining and distribution Industry, Montreal, Quebec, October 16-17

Stucki, J.W.; Lee, K; Zhang, L. and Larson, R.A. (2002) Effects of Iron Oxidation State on the Surface and Structural Properties of Smectite. Pure and Apllied Chemistry. V. 74. No. 11. p. 2145-2158.

Vieira, S.R.S.S; Coutinho, J.M.V.; Alves, F.R. (1990) Geologia e Evolução Geológica da Região de Embu-Guaçu - Parelheiros, SP. Revista Brasileira de Geociências, V.20 n 1-4, p.277-281.

Vieira, S.R.S.S; Coutinho, J.M.V.; Alves, F.R. (1992) Considerações sobre o Metamorfismo das Rochas de Embu-Guaçu - Parelheiros, SP.. Revista Brasileira de Geociências, V.22 (1), p.82-92. Março de 1992.

Vogel, T.M. and McCarty, P.L. (1987) Abiotic and Biotic Transformations of 1,1,1 - Trichloroethane Under Methanogenic Conditions. Environ and Science Technology, v 21, p.1208-1213. 
Wilkin, R.T; Puls, R.W.; Sewell, G.W (2003) Long-Term Performance of Permeable Reactive Barriers Using Zero-Valent Iron: Geochemical and Microbiological Effects. Groundwater Journal v. 41, nº4, july-august 2003. p.493-p.503. 